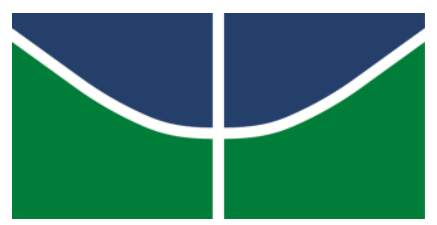

Universidade de Brasília

Instituto de Psicologia

Departamento de Psicologia Clínica

Programa de Pós-Graduação em Psicologia Clínica e Cultura

\title{
AVALIAÇÃo DE RESULTADOS E PROCESSO DE UMA INTERVENÇÃO PARA PREVENÇÃO DO VAZIO EXISTENCIAL ENTRE ADOLESCENTES
}

José Marcelo Oliveira da Luz

Brasília, 2015. 


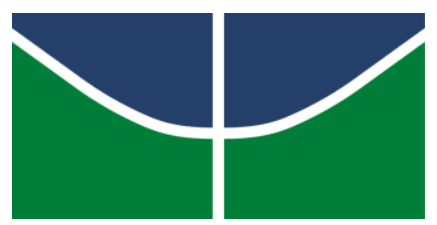

Universidade de Brasília

Instituto de Psicologia

Departamento de Psicologia Clínica

Programa de Pós-Graduação em Psicologia Clínica e Cultura

AVALIAÇÃO DE RESULTADO E PROCESSO DE UMA

INTERVENÇÃO PARA PREVENÇÃO DO VAZIO EXISTENCIAL

ENTRE ADOLESCENTES

José Marcelo Oliveira da Luz

Dissertação apresentada ao Instituto de Psicologia da Universidade de Brasília como requisito parcial para obtenção do Grau de Mestre em Psicologia Clínica e Cultura.

Orientadora: Prof. Dra. Sheila Giardini Murta

Coorientador: Prof. Dr. Thiago Antonio Avellar de quino

Brasília, 2015. 
Trabalho apresentado ao Instituto de Psicologia da Universidade de Brasília, sob a orientação da Professora Doutora Sheila Giardini Murta e coorientação do Professor Doutor Thiago Antonio Avellar de Aquino.

\section{Banca Examinadora}

Prof $^{a}$. Dra ${ }^{a}$. Sheila Giardini Murta

Universidade de Brasília - UnB

Prof $^{a}$. Dr ${ }^{\mathrm{a}}$. Márcia Helena da Silva Melo Bertolla

Universidade de São Paulo - USP

Prof $^{\mathrm{a}}$. Dr ${ }^{\mathrm{a}}$. Silvia Renata Magalhães Lordello Borba Santos

Universidade de Brasília - UnB

Prof. Dr. Ileno Izídio da Costa

Universidade de Brasília - UnB 
À minha mãe, Terezinha de Jesus (in memoriam), pelo eterno exemplo de cuidado. À minha família, pelo amor incondicional. 


\section{Agradecimentos}

Aos meus mestres Prof. ${ }^{a}$ Dr. ${ }^{a}$ Sheila Giardini Murta e Prof. Dr. Thiago Antonio Avellar de Aquino, pelo acolhimento e cuidado. Obrigado por acreditarem em mim e por fazerem parte desse meu crescimento pessoal e profissional. Essa parceria, além de bons frutos, me mostrou modelos de pessoa e pesquisador. Quando eu crescer quero ser como vocês!

Aos companheiros/as do GEPPS Vida: Samia, por ter me apresentado indiretamente ao meu objeto de pesquisa; Cristineide, Jordana, Janaína e Karine, pelas contribuições no aprimoramento do projeto; Leonardo, por rabiscar integralmente de vermelho meus primeiros escritos; Arthur, pela contribuição na versão apresentada ao Comitê de Ética e nas negociações de local para a coleta de dados; Ana e Tânia, por ajudarem nas revisões finais dos artigos juntamente com Larissa, que além de revisora foi um suporte em momentos invernosos. A todos, por me acompanharem neste início da vida de pesquisador.

Aos velhos amigos, que se mostraram compreensivos diante de compromissos desmarcados, passeios não realizados, conversas adiadas, aniversários esquecidos e que também torceram para que tudo transcorresse bem. Tenham certeza que esse esforço foi também por vocês, afinal levo todos no coração. Obrigado, Berg, Jonair, Edina, Anderson, Geraldo, Ceila, Flávio, Emerson, Joamara, Mariela e Guilherme.

A Janice, Marcelo e Marcos, que me fizeram encontrar forças em momentos em que eu parecia não mais ter. Assim como os outros amigos, vocês são presentes de Deus pra mim.

Aos colegas da UnB, pelo apoio, incentivo e compreensão em muitos momentos, em especial a Laene, Jane, Angela, Joyce, Pietro, Mirele, Rodrigo, Dr. Nilton e Dra. Lia.

À Adriana Mascarenhas, que apareceu aos 45 minutos do segundo tempo, mas deixou sua marca neste trabalho.

Aos professores do PPG Psicologia Clínica e Cultura-UnB, em especial à Prof.a. Teresa Cristina, pelo carinho e cuidado.

Ao grupo de adolescentes, que confiou a mim parte de seu tempo e de suas vidas e à Andreia Crispim que viabilizou o encontro com esses adolescentes.

Às professoras Dra . Márcia Melo - USP, Dra . Silvia Lordello - UnB e ao professor Ileno Costa - UnB, pela disponibilidade em ler e contribuir para o aprimoramento desta dissertação.

À toda a Família Luz, em especial minha irmã, Maria Giovane, que acompanhou de perto todos os desafios dessa jornada.

A Deus, pelo dom da vida, por ter me dado essa família e esses amigos. 


\section{INDICE}

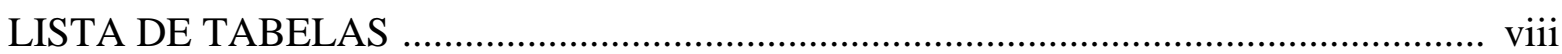

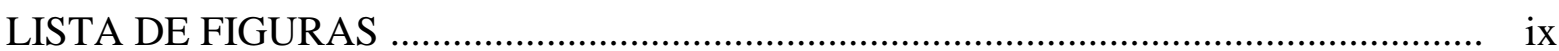

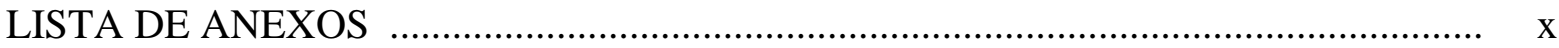

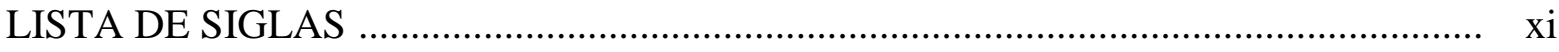

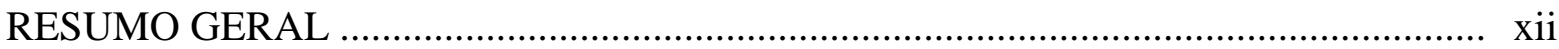

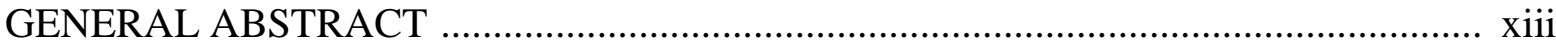

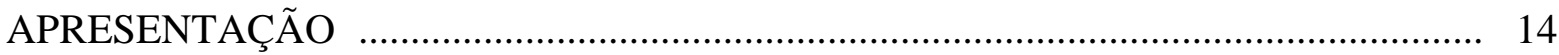

Manuscrito 1 - Programas de Promoção de Saúde Mental para Adolescentes em Grupo . 18

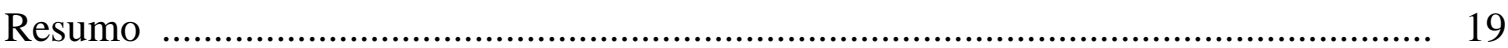

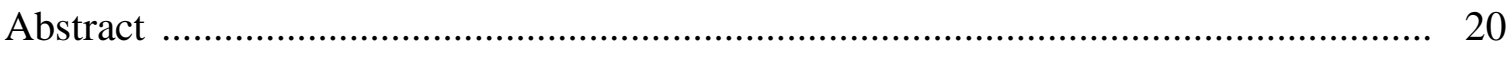

Programas de Promoção de Saúde Mental para Adolescentes em Grupo ................... 21

Prevenção e Promoção de Saúde ............................................................................ 23

Saúde Mental, Promoção de Saúde Mental e Psicologia Positiva ............................... 26

Intervenções em Grupo para Promoção de Saúde Mental para Adolescentes e Jovens . 28

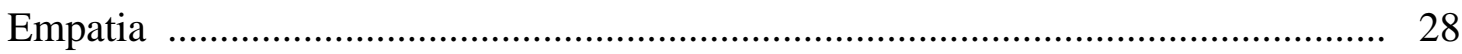

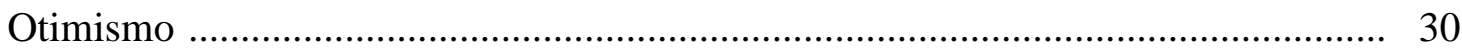

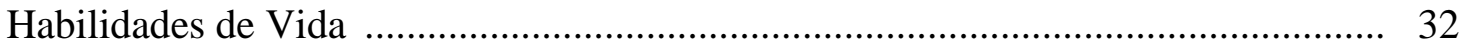

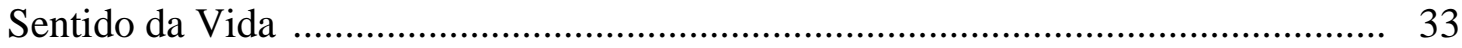

Intervenções para Promoção de Saúde Mental para Adolescentes ................................ 35

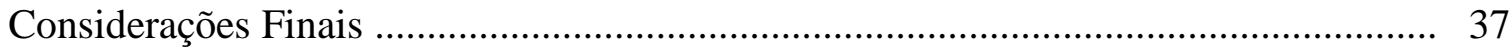

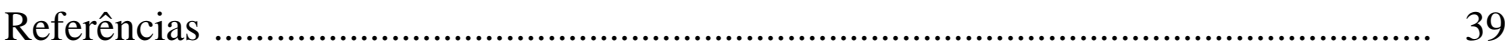

Manuscrito 2 - Prevenção em Saúde Mental à Luz da Logoterapia e Análise Existencial . 44

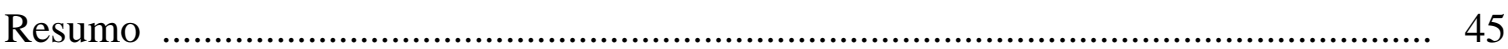

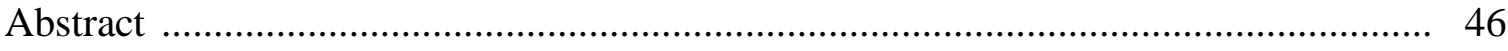

Prevenção em Saúde Mental à Luz da Logoterapia e Análise Existencial .................... 47

Sentido da vida e Saúde Mental ............................................................................. 48

Sentido da vida, Logoterapia e Prevenção em Saúde Mental ...................................... 50

Práticas Preventivas Baseadas na Logoterapia .......................................................... 56

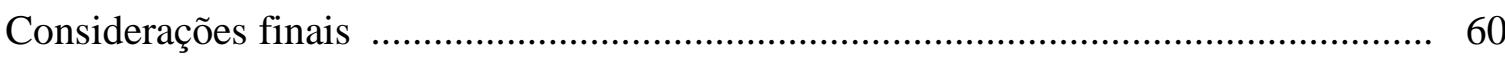

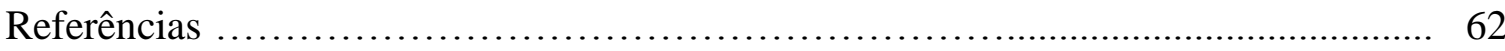

Manuscrito 3 - Avaliação de resultados e processo de uma intervenção para prevenção do vazio existencial entre adolescentes 


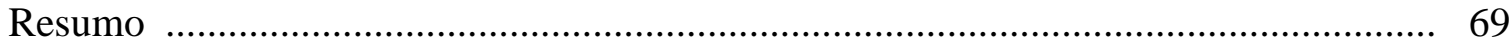

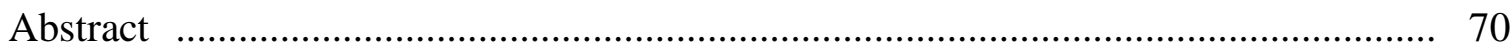

Avaliação de resultados e processo de uma intervenção para prevenção do vazio existencial entre adolescentes ............................................................................. 71

Bem-estar subjetivo e sentido da vida ................................................................... 72

Prevenção ao vazio existencial ........................................................................... 79

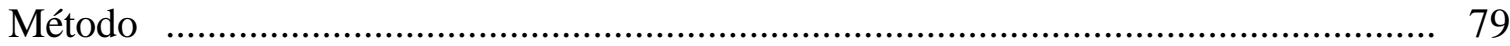

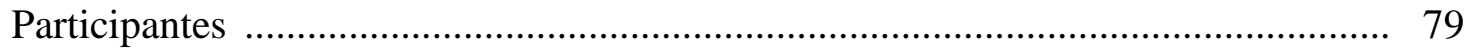

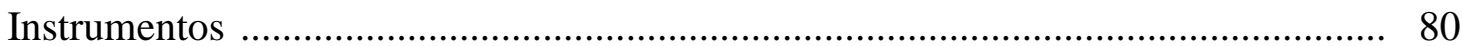

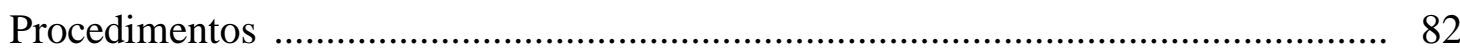

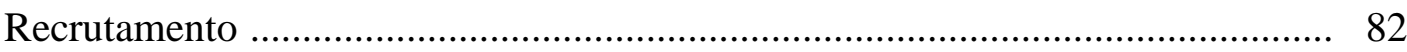

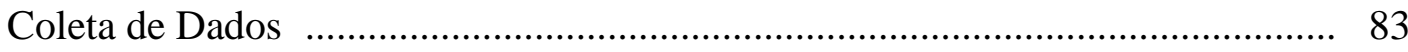

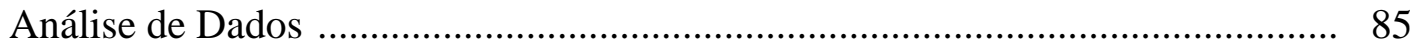

Considerações éticas .................................................................................. 85

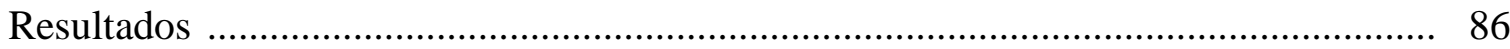

Caracterização sociodemográfica .................................................................... 86

Avaliação de Resultados ............................................................................... 87

Avaliação de Processo .................................................................................... 90

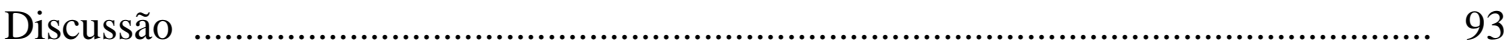

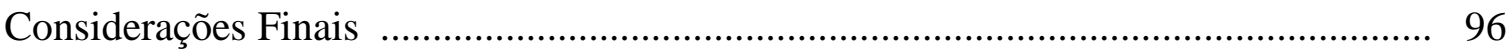

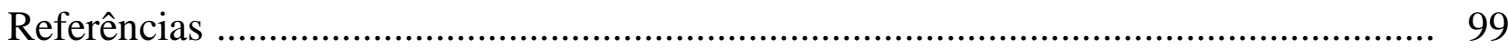

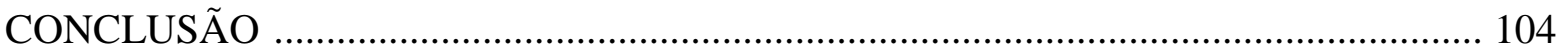

ANEXOS

Anexo A 


\section{LISTA DE TABELAS}

\section{Artigo 1}

Tabela 1. Estudos de intervenção para promoção da empatia

Tabela 2. Estudos de intervenção para promoção do otimismo

Tabela 3. Estudos de intervenção para promoção de habilidades de vida

Tabela 4. Estudos de intervenção para promoção do sentido da vida

\section{Artigo 3}

Tabela 1. Roteiro da Intervenção para Prevenção do Vazio Existencial

Tabela 2. Caracterização da amostra quanto aos dados sociodemográficos, conforme a condição dos grupos.

Tabela 3. Comparação entre os grupos experimental e controle no pré e pós-teste, a partir das variáveis presença de sentido e busca de sentido.

Tabela 4. Comparação entre os grupos experimental e controle no pré e pós-teste, a partir das variáveis afetos positivos e afetos negativos.

Tabela 5.Relatos dos participantes que indicam planos futuros. 


\section{LISTA DE FIGURAS}

\section{Artigo 1}

Figura 1. Modelo integrativo entre promoção, prevenção e tratamento de Weisz, Sandler, Durlak e Anton, 2005

Figura 2. Modelo integrado de implementação de programas de Berkel, Mauricio, Schoenfelder e Sandler, 2011

Figura 3. Habilidades do facilitador promotoras de fatores terapêuticos do grupo

\section{Artigo 2}

Figura 1. Modelo de prevenção em Logoterapia.

\section{Artigo 3}

Figura1. Nuvem de palavras com a frequência nos discursos dos adolescentes.

Figura 2. Frequência de emoções na avaliação de satisfação dos participantes em relação à intervenção.

Figura 3. Distribuição das emoções coletadas na avaliação de satisfação do participante a cada sessão. 


\section{LISTA DE ANEXOS}

\section{Artigo 3}

Anexo A. Questionário de Avaliação Sociodemográfica

Anexo B. Questionário de Sentido de Vida - QSV

Anexo C. Escala de Afetos Positivos e Negativos - EAPN

Anexo D. Diário de Emoções

Anexo E. Árvore da Minha Vida

Anexo F. Parecer Consubstanciado do Comitê de Ética em Pesquisa

Anexo G. Termo de Assentimento

Anexo H. Termo de Consentimento Livre e Esclarecido 


\section{LISTA DE SIGLAS}

ABEP - Associação Brasileira de Empresas de Pesquisas

AIDS - Síndrome da Imunodeficiência Adquirida

APA - American Psychological Association

BEP - Bem-estar Psicológico

BES - Bem-estar Subjetivo

CAPS - Centro de Atenção Psicossocial

CEP - Comitê de Ética em Pesquisa

CRAS - Centros de Referência em Assistência Social

DST - Doença Sexualmente Transmissível

EAPN - Escala de Afetos Positivos e Negativos

EAPN - Escala de Afetos Positivos e Negativos.

GC - Grupo Controle

GE - Grupo Experimental

HIV - Vírus da Imunodeficiência Humana

IBGE - Instituto Brasileiro de Geografia e Estatística

OMS - Organização Mundial de Saúde

PeNSE - Pesquisa Nacional de Saúde do Escolar

QSV - Questionário de Sentido da Vida

QSV - Questionário de Sentido da Vida

SNJ - Secretaria Nacional de Juventude

SNJ - Secretaria Nacional de Juventude

TGS - Treinamento para Gerenciamento de Stress

TGSs - Treinamento para Gerenciamento de Stress com Abordagem de Sentido

WHO - World Health Organization 


\section{RESUMO GERAL}

$\mathrm{Na}$ adolescência, quando o indivíduo se depara com os primeiros questionamentos existenciais, a sensação de falta de sentido da vida pode potencializar desfechos negativos em saúde mental. Assim, intervenções promotoras de sentido da vida para adolescentes tornamse relevantes. Este estudo almejou replicar uma intervenção baseada em logoterapia para prevenção do vazio existencial entre adolescentes e avaliar o seu processo de implementação e resultados. Utilizou-se um delineamento quase-experimental, com medidas quantitativas e qualitativas, com 47 adolescentes residentes no Distrito Federal, de ambos os sexos, com idades entre 15 e 17 anos, distribuídos em duas condições: experimental - GE (N=22) e controle - GC $(\mathrm{N}=25)$. Ambos os grupos foram submetidos às avaliações de pré-teste e pósteste, quando foram utilizados a Ficha Sociodemográfica, o Questionário de Sentido da Vida e a Escala de Afetos Positivos e Negativos. Outros instrumentos utilizados no decorrer da intervenção foram: Diário de Emoções, Árvore da Minha Vida, Carta a um Amigo e Diário de Campo. Ao GE foi oferecida uma intervenção grupal, centrada na leitura de poemas, fábulas e parábolas e reflexões baseadas em uma relação dialógica. O GC não recebeu nenhum tipo de intervenção. A intervenção consistiu em seis encontros semanais de 150 minutos cada. Análise temática e teste $t$ foram utilizados para a análise dos dados. Os resultados da avaliação de processo revelaram que os adolescentes se engajaram na intervenção e a perceberam como relevante e satisfatória. Verificou-se um aumento significativo na percepção de sentido de vida e diminuição de afetos negativos para o GE quando comparado ao GC. Conclui-se que a intervenção foi benéfica para os participantes. Sugere-se que estudos futuros façam uso de delineamentos experimentais com avaliações de seguimento e considerem a qualidade da implementação em novas replicações.

Palavras-chave: sentido da vida, promoção da saúde, programa de intervenção, prevenção, saúde mental. 


\section{GENERAL ABSTRACT}

In adolescence, when the individual is faced with the first existential questions, the sense of meaninglessness of life may potentiate negative outcomes in mental health. Thus, interventions promoting meaning of life for teenagers become relevant. This study craved replicate an intervention based on logotherapy for prevention of existential emptiness among adolescents and evaluate their implementation process and results. Was used a quasiexperimental design with quantitative and qualitative measures, with 47 adolescents living in the Distrito Federal, of both sexes, aged between 15 and 17 years, distributed in two groups: experimental - GE $(\mathrm{N}=22)$ and control - GC $(\mathrm{N}=25)$. Both groups were subjected to pretest and post-test when we used the Sociodemographic Form, the Meaning in Life Questionnaire and the Scale of Positive and Negative Affect. Other instruments used during the intervention were: Emotions Diary, Tree of My Life, Letter to a Friend and Field Diary. The GE was offered a group intervention, focused on reading poems, fables and parables and reflections based on a dialogic relationship. The CG did not receive any intervention. The intervention consisted of six weekly meetings of 150 minutes each. Thematic analysis and $\mathrm{T}$ test were used for data analysis. The process of evaluation results showed that adolescents engaged in the intervention and perceived as relevant and satisfactory. There was a significant increase in the perception of meaning of life and decreased negative affects to GE when compared to GC. It concludes that the intervention was beneficial for participants. It is suggested that future studies make use of experimental designs with follow-up evaluations and consider the quality of implementation in new replications.

Keywords: meaning in life, health promotion, intervention program, prevention, mental health. 


\section{APRESENTAÇÃO}

O trabalho com jovens e adolescentes sempre esteve presente em minha trajetória. Desde cedo estive envolvido, de alguma forma, em coletivos de adolescentes e jovens vivenciando o processo de formação dentro da pastoral da juventude. Inicialmente como militante e depois como assessor, pautávamos nossas atividades na defesa dos jovens como sujeitos de direitos. Um dos espaços onde foi possível desenvolver esse trabalho foi a Casa da Juventude, em Goiânia-GO, onde por anos participei de suas atividades e depois colaborei no desenvolvimento e execução de novas ações, que tinham entre seus objetivos acolher as diversas juventudes e promover a autonomia juvenil. Já percorria o caminho da prevenção sem me dar conta disso.

Após a graduação, na Pontifícia Universidade Católica de Goiás, continuei os trabalhos na Casa da Juventude até vir para Brasília, onde fui trabalhar com adolescentes, em contexto escolar e em seguida, na Universidade de Brasília, onde inicialmente integrei uma equipe de atenção à saúde mental, com trabalhos voltados a servidores e estudantes. Essas duas experiências me levaram a pensar na possibilidade de desenvolver ações que se antecipassem ao sofrimento das pessoas. Especificamente a experiência na UnB foi me apresentando este desafio cotidianamente, pois se tratava de um programa de prevenção do suicídio, voltado para a comunidade acadêmica, onde a falta de sentido para continuar vivendo era a queixa mais frequente. Nesse contexto surgiu a ideia de investir em estudos de prevenção, mas especificamente em intervenções que pudessem prevenir alguns desfechos negativos em saúde mental. A decisão firme de iniciar esse novo projeto veio após cursar uma disciplina como aluno especial, com a professora Dra. Sheila Murta, onde conheci a intervenção desenvolvida pelo professor Dr. Thiago Aquino e colaboradores, cujo objetivo primário era promover o sentido da vida e foi desenvolvida em um grupo de adolescentes, a partir de uma reflexão dialógica com base na leitura de fábulas, poesias e textos da literatura 
geral. Este estudo, portanto, se propõe a replicar e ampliar a avaliação da intervenção proposta pelo professor Dr. Thiago Aquino.

O início desta caminhada como pesquisador me exigiu uma boa dose de autonomia, uma vez que minha orientadora estava realizando estudos de pós-doutorado fora do país. Mas foi um início tranquilo com sua assistência à distância, do meu coorientador, professor Dr. Thiago Aquino e o apoio do Grupo de Estudos em Prevenção e Promoção da Saúde no Ciclo da Vida - GEPPS Vida. Porém, a execução do programa foi um desafio à parte. Primeiramente ele havia sido formatado para estudantes universitários em seu primeiro ano acadêmico, por conta da grande procura destes jovens pelos serviços de atenção em saúde mental disponíveis na universidade. Foi levantada a dificuldade de se achar um grupo que tivesse disponibilidade para uma intervenção com duração de 15 encontros. Daí veio a primeira adequação ao projeto: mudar o público alvo e buscar parcerias em escolas para que a coleta de dados fosse adiante. Na primeira escola contatada não foi possível devido ao calendário de atividades apertado. Na segunda escola, houve uma abertura para que a coleta integrasse a grade horária. Mas como não houve uma consulta prévia junto aos estudantes, a intervenção ficou inviabilizada pela não adesão dos adolescentes. E assim prosseguimos nossa caminhada na busca de um local para implementarmos a coleta. Depois de algumas negociações e novas adequações quanto ao formato, conseguimos, finalmente, iniciar a coleta de dados. Aos poucos, essa caminhada foi mostrando na prática alguns elementos que víamos na teoria sobre processo de implementação de programas. Este processo mostrou o tamanho do desafio que é trabalhar com prevenção e quão gratificante é, quando se percebe que as pessoas podem se beneficiar de intervenções com esse foco, animando-nos a aceitar novos desafios.

Esta dissertação está construída em três manuscritos. O Estudo 1 é um estudo teórico conceitual, onde se propõe uma reflexão sobre saúde mental, implementação de programas de 
promoção de saúde mental em grupo para adolescentes e as dimensões relevantes para sua eficácia e efetividade. São apresentados os conceitos básicos de prevenção, promoção da saúde e a compreensão de saúde mental compartilhada pela Psicologia Positiva, que coloca o sentido da vida como um dos de seus elementos constituintes. A partir da constatação da necessidade de estratégias que busquem prevenir seus desfechos negativos na adolescência, são descritos programas de promoção de saúde mental, em grupos, para essa população. As intervenções apresentadas foram sistematicamente avaliadas e sugerem evidências de eficácia para diversas condições como: promoção da empatia, otimismo, sentido da vida e habilidades de vida. Esses programas estão baseados em abordagens psicológicas diversas, mostrandonos um cardápio diverso de teorias que sustenta tais ações. Por fim, discute-se ainda a importância do processo de implementação de um programa preventivo e os impactos desse processo no alcance de resultados positivos.

O Estudo 2 aborda a compreensão do sentido de vida como construto psicológico, sua evolução conceitual e suas implicações na promoção da saúde mental. Apresenta a Logoterapia - escola terapêutica criada por Viktor Frankl - que tem como principal fundamento o sentido da existência humana e que coloca a busca por esse sentido como um importante fator de proteção para a pessoa. Descreve programas com foco na prevenção em saúde mental, amparados pelo arcabouço teórico da logoterapia, sugerindo, em função dos resultados alcançados, a adequabilidade dessa teoria no desenvolvimento de intervenções preventivas em saúde mental.

O Estudo 3 é um estudo empírico, com delineamento quase-experimental, que avalia o processo de implementação e os resultados alcançados em uma intervenção para prevenção do vazio existencial entre adolescentes. Esse estudo destaca alguns dados sobre a saúde mental de adolescentes brasileiros, apontando para a necessidade de investimento em políticas preventivas para essa população. Retomam-se alguns conceitos para se estabelecer 
uma relação entre sentido da vida e saúde mental e possíveis desfechos para uma vida percebida sem sentido. Apresenta-se então a proposta desenvolvida por Aquino et al. (2011) como estratégia preventiva do vazio existencial entre adolescentes, objeto de avaliação desse estudo.

Por último, a conclusão da dissertação integra esses estudos, mostrando os resultados do estudo empírico e as contribuições dos manuscritos para o desenvolvimento da prevenção como ciência. Ao mesmo tempo, aponta as limitações deste estudo, com sugestões de aprimoramento para estudos futuros. 


\section{Manuscrito 1}

Programas de Promoção de Saúde Mental para Adolescentes em Grupo ${ }^{1}$

\footnotetext{
1 Publicado como capítulo de livro em: Luz, J. M. O., Murta, S. G., \& Aquino, T. A. A. (2015). Programas de promoção de saúde mental para adolescentes em grupo. In C. B. Neufeld (Ed). Intervenções cognitivocomportamentais em grupo para crianças e adolescentes (pp. 52-71). Porto Alegre: Artmed.
} 


\section{Resumo}

O presente estudo tem por objetivo propor uma reflexão sobre programas de promoção de saúde mental, implementados em grupo para adolescentes, apresentando dimensões relevantes para sua eficácia e efetividade. Busca-se aqui discutir os conceitos de prevenção, promoção da saúde e saúde mental, além de apresentar evidências de eficácia de programas de promoção de empatia, otimismo, sentido da vida e habilidades de vida, conduzidos com adolescentes em grupo. Os estudos selecionados estão baseados na Psicologia Positiva em interlocução com a Terapia Cognitivo Comportamental e a Logoterapia. Discute-se também o processo de implementação de programas de promoção da saúde em grupo, bem como cuidados que podem maximizar a qualidade da implementação.

Palavras-chave: saúde mental, adolescência, promoção da saúde, grupoterapias. 


\begin{abstract}
This study aims to propose a reflection on mental health promotion programs implemented in group for teens, showing relevant dimensions to their efficiency and effectiveness. Search here to discuss the concepts of prevention, health promotion and mental health, and present evidence of efficacy of empathy promotion programs, optimism, sense of life and life skills, conducted with adolescents in group. The selected studies are based on Positive Psychology in dialogue with Cognitive Behavioral Therapy and Logotherapy. It also discusses the process of implementation of health promotion programs in group and care that can maximize the quality of implementation.
\end{abstract}

Keywords: mental health, adolescence, health promotion, group therapies. 


\section{Programas de Promoção de Saúde Mental para Adolescentes em Grupo}

A palavra "adolescência" etimologicamente tem sua origem do verbo latino "adolescere", que significa "crescer". Historicamente, o adolescer pode ser compreendido como uma fase intermediária entre a infância e a idade adulta, que se constitui por meio de diversos significados culturais, tendo em vista que se trata de um fenômeno psicossocial, na maioria das vezes coincidente com as transformações biológicas impostas pela puberdade (Fierro, 1995; Outeiral, 1994). Também pode ser considerada como um período de vulnerabilidade na medida em que o adolescente envolto neste processo de mudanças biopsicossociais não consegue fazer uso adequado dos recursos que possui para se proteger dos riscos presentes em seu ambiente social, levando-o a uma condição desfavorável (Outeiral, 1994; Pessalacia, Menezes, \& Massuia, 2010).

Segundo estatísticas oficiais, no Brasil há cerca de 51,3 milhões de jovens e adolescentes. Destes, aproximadamente 10,3 milhões têm entre 15 e 17 anos (Secretaria Nacional de Juventude, 2014a). A saúde está entre os problemas que mais preocupam essa população, bem como a oferta de serviços que levem em consideração as especificidades de quem vivencia essa etapa do ciclo de vida. Entre os adolescentes e jovens, há um contraste entre a expectativa de ter "boa saúde" e os riscos comuns a este público, carente de políticas de prevenção (Secretaria Nacional de Juventude, 2014b). Aspectos ligados à saúde se destacam entre os assuntos que mais despertam a atenção de adolescentes e jovens: drogas, vitimização por violência, direitos sexuais e reprodutivos (Secretaria Nacional de Juventude, 2014a), prevenção de DST's, programas de redução de danos e ações de promoção de saúde (Secretaria Nacional de Juventude, 2014b).

A Pesquisa Nacional da Saúde do Escolar - PeNSE 2012 (Instituto Brasileiro de Geografia e Estatística, 2013) reforça esses dados e aponta para aspectos ligados à saúde mental que também precisam da atenção de profissionais de saúde e governantes. A PeNSE 
2012 revelou que 16,5\% dos adolescentes experimentaram um sentimento de solidão e 3,5\% relataram não possuir nenhum amigo. Isto sugere um empobrecimento da rede social do adolescente, aumentando o risco de adoção de comportamentos prejudiciais à saúde. No que diz respeito à experimentação precoce de substâncias, foi relatado o uso de tabaco $(19,6 \%)$, álcool $(70,5 \%)$ e drogas ilícitas (7,3\%). O uso regular foi de 5,1\%, 26,1 \% e 2,5\% respectivamente. No que diz respeito a transtorno mental menor (TMM), foi encontrada uma prevalência de $29,4 \%$, em uma amostra de 1.923 adolescentes entre 10 e 19 anos, do $8^{\circ}$ ano do ensino fundamental ao $3^{\circ}$ anodo ensino médio (Avanci, Assis, Oliveira, Ferreira, \& Pesce, 2007).

Esse cenário mostra a necessidade de investimentos em ações de promoção e prevenção em saúde, buscando potencializar os fatores de proteção, minimizar os fatores de risco à saúde de adolescentes e jovens e promover seu bem-estar. Desta forma, este estudo objetiva discutir programas de promoção de saúde mental implementados em grupo para esta população e dimensões metodológicas relevantes para sua eficácia e efetividade. O texto está organizado em quatro seções. Na primeira parte são discutidos os conceitos de prevenção e promoção de saúde. Na segunda parte são abordados os conceitos de saúde mental e promoção de saúde mental à luz da Psicologia Positiva. Na terceira parte, são apresentadas evidências de eficácia de programas de promoção de empatia, otimismo, sentido da vida e habilidades de vida conduzidos com adolescentes em grupo. Estes estudos foram selecionados como fins ilustrativos de intervenções em grupo para promoção de saúde mental para adolescentes e jovens baseados em abordagens diversas como a Psicologia Positiva, a Logoterapia e a Terapia Cognitivo Comportamental. Na última parte é discutido o processo de implementação de programas de promoção de saúde em grupo, com ênfase em cuidados para maximizar a qualidade da implementação, principal preditora de eficácia e efetividade desses programas. 


\section{Prevenção e Promoção de Saúde}

Como construção social, o conceito de prevenção guarda múltiplos significados (Dalton, Elias, \& Wandersman, 2007). Neste texto, será adotado o conceito de prevenção aplicado ao campo da saúde mental segundo o qual prevenção refere-se a ações implementadas antes do surgimento de um transtorno mental já diagnosticado. A prevenção a transtornos mentais pode se dar em três níveis: prevenção universal, prevenção seletiva e prevenção indicada. A prevenção universal consiste em intervenções direcionadas ao público em geral, incluindo desde indivíduos saudáveis e não expostos a riscos até os expostos a riscos e com manifestações iniciais do problema que se almeja prevenir. A prevenção seletiva, por sua vez, refere-se a ações focadas em subgrupos da população expostos a fatores de risco para algum transtorno. Por fim, a prevenção indicada é voltada para pessoas com sinais ou sintomas de um dado transtorno ou desordem, sem contudo atender aos critérios para diagnóstico de um transtorno (Muñoz, Mrazek, \& Haggerty, 1996).

Compreensões mais atualizadas tratam da indissociabilidade entre os conceitos de promoção e prevenção (Weisz, Sandler, Durlak, \& Anton, 2005; Czeresnia, 2003) e as situam em um continuum de cuidados em saúde mental, desde a promoção de saúde até o tratamento (ver Figura 1). Prevenção e promoção de saúde guardam semelhanças significativas entre si, dado que ambas podem utilizar-se das mesmas estratégias para o planejamento de suas ações por meio do incremento de fatores de proteção à saúde, sejam eles sociais, comunitários, familiares ou individuais. A principal diferença reside nas metas de cada uma: as ações preventivas são orientadas para evitar o surgimento de doenças/transtornos específicos, reduzindo sua incidência e prevalência, enquanto as ações de promoção enfatizam o fortalecimento individual e coletivo para lidar com os condicionantes da saúde para promoção de bem-estar. 
Em conformidade com a Carta de Ottawa, a "promoção de saúde é o processo de capacitação da comunidade para atuar na melhoria de sua qualidade de vida e saúde, incluindo uma maior participação no controle deste processo" (Organização Mundial de Saúde, 1986, p. 1). O alcance do desenvolvimento integral da saúde passa pela capacidade de identificar e atuar ativamente em seus determinantes, considerando os aspectos pessoais, sociais e ambientais. Dessa forma, promover saúde implica em uma garantia de acesso a vários direitos como, por exemplo, educação, esporte, lazer, cultura, habitação e geração de renda. A promoção de saúde surge então como um instrumento de justiça social (Kenny \& Hage, 2009). Desta forma, intervenções voltadas para a promoção de saúde de adolescentes e jovens podem ser desenvolvidas em diferentes contextos, incluindo, por exemplo, escolas, universidades, centros comunitários, unidades básicas de saúde, Centros de Referência em Assistência Social, organizações de trabalho e centros culturais. Tais intervenções englobam ações dirigidas ao próprio adolescente e jovem, mas também a outros significativos e fontes de influência, como os pares, parceiros amorosos, professores, pais, profissionais de saúde, líderes comunitários, gestores de políticas públicas e mídia (ver Figura 1). Podem também ser desenvolvidas em diversos formatos, desde oficinas pontuais de curta duração a intervenções de média ou longa duração, campanhas educativas e orientações por meio de ferramentas computadorizadas. 


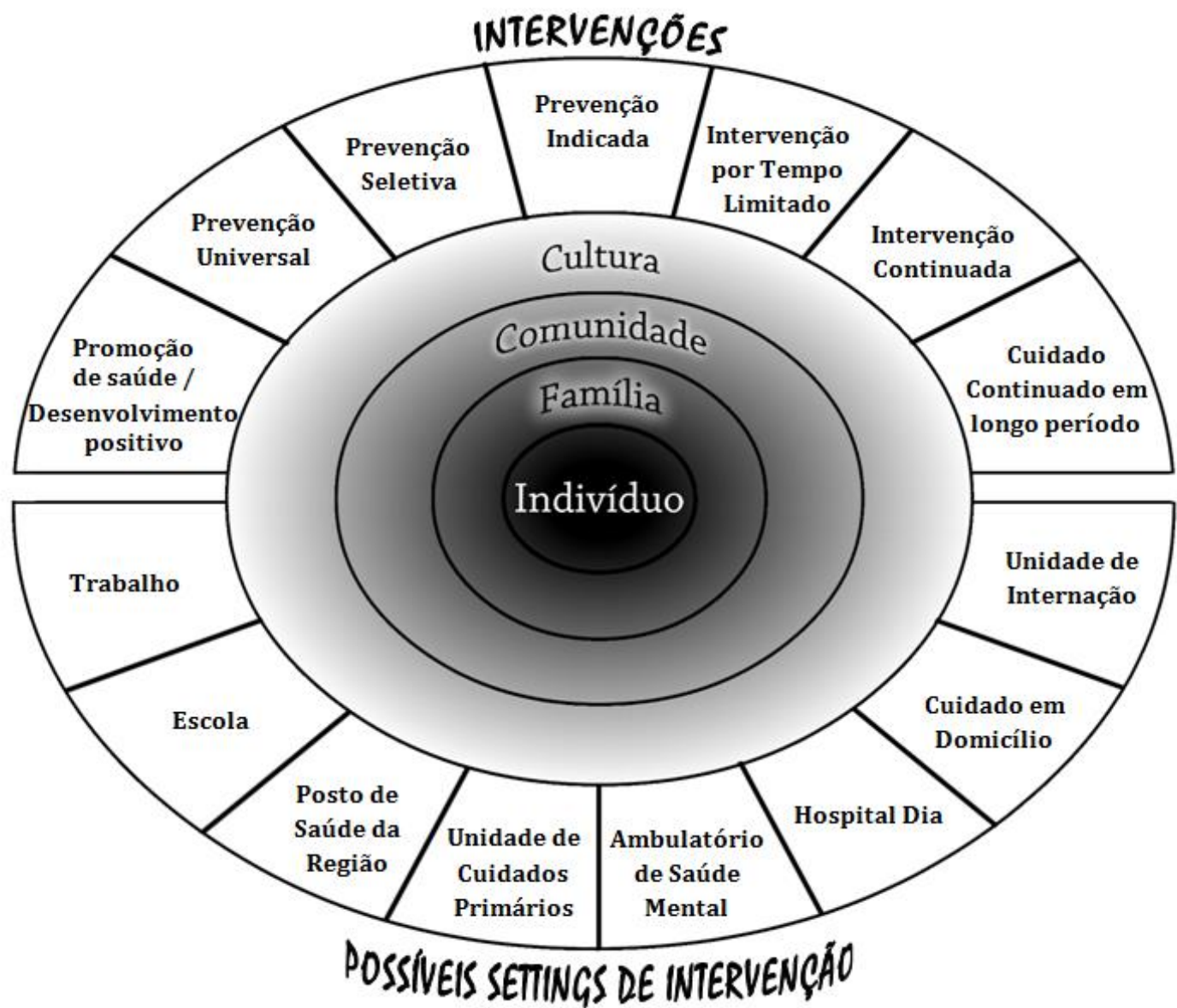

Figura 1. Modelo integrativo entre promoção, prevenção e tratamento de Weisz, Sandler, Durlak e Anton, 2005 (Fonte: Murta \& Barletta, no prelo).

Segundo Aguiar, Bock e Ozella (2001) a promoção de saúde deve ser compreendida em um contexto amplo, levando em conta os aspectos socioculturais, proporcionando condições adequadas de vida e de relações saudáveis. Para esses autores, "promover saúde, significa trabalhar para ampliar a consciência que o indivíduo possui sobre a realidade que o cerca, instrumentando-o para agir, no sentido de transformar e resolver as dificuldades que essa realidade lhe apresenta" (p. 172). Promover a saúde de adolescentes e jovens supõe, portanto, encorajar a responsabilidade de indivíduos, famílias, organizações ou comunidades sobre a saúde, por meio da partilha de informações, habilidades e instrumentos que facilitem a adoção de comportamentos, atitudes, práticas e políticas favorecedoras de saúde. 


\section{Saúde Mental, Promoção de Saúde Mental e Psicologia Positiva}

O conceito de saúde mental tem sido alvo de revisões e a ele tem sido agregadas características positivas, respaldadas em estudos sobre bem-estar (Keyes, 2007), autonomia, esperança, felicidade (Seligman \& Csikszentmihalyi, 2000) e sentido da vida (Frankl, 2008). Tais características positivas associadas à saúde mental incluem, conforme proposto por Keyes (2007), as emoções positivas (ex.: entusiasmo, calma, esperança e interesse pela vida), a qualidade de vida percebida (ex.: satisfação com os vários domínios da vida), o funcionamento psicológico positivo (ex.: atribuição de sentido à vida, autoaceitação, busca de crescimento pessoal, autonomia e relações interpessoais gratificantes) e o funcionamento social positivo (ex.: reconhecimento e valorização das diferenças humanas, senso de pertencimento a grupos e comunidades, autoatribuição de responsabilidade social e crença no potencial de crescimento das pessoas, grupos e comunidades). Nesta perspectiva, ter saúde mental não é sinônimo de não ter um transtorno mental, mas gozar de um funcionamento social e psicológico positivo e viver uma vida percebida como tendo qualidade.

Coerentemente com esta visão, a Organização Mundial de Saúde preconiza que a saúde mental (a) é mais que ausência de doença mental, (2) é parte integrante da saúde e (3) relaciona-se com a saúde física e o comportamento (World Health Organization, 2005). Promover saúde mental deve levar em consideração a saúde como um valor em si mesmo e um direito humano básico, necessário ao desenvolvimento social e econômico. Isto implica na criação de condições individuais sociais e ambientais de forma a impactar sobre os determinantes da saúde mental (Organização Mundial de Saúde, 1997). A promoção de saúde mental vai muito além da prevenção de transtornos mentais. Busca desenvolver iniciativas que envolvam os indivíduos no processo de busca de uma saúde mental positiva (World Health Organization, 2004). 
Neste aspecto, a Psicologia Positiva tem dado uma contribuição significativa para o desenvolvimento de ações de promoção de bem-estar. Estudos em Psicologia Positiva vem fomentando um interesse crescente por intervenções que promovam forças e potencialidades do indivíduo. Para Seligman e Csikszentmihalyi (2000), a psicologia não precisa restringir sua atenção a ações para reparação do que está errado. Uma de suas missões é fortalecer o que está bom, promovendo o desenvolvimento de aspectos virtuosos no ser humano. Dessa forma, ela atenderia ao que se entende por promoção de saúde, em seu sentido mais amplo.

Na história da ciência psicológica, podemos observar trabalhos como os de Abraham Maslow, Carl Rogers e Viktor Frankl como precursores da abordagem aos aspectos salutogênicos da natureza humana. Martin Seligman, enquanto presidente da American Psychological Association (APA), foi responsável pelo início do movimento denominado Psicologia Positiva. Segundo ele, era necessário investir em estudos com rigor metodológico que focassem em aspectos positivos da experiência humana como, por exemplo, felicidade, esperança, criatividade, gratidão, espiritualidade e otimismo. A aplicação deste conhecimento para potencializar forças e virtudes no ser humano constitui uma importante derivação deste movimento (Seligman, 2011).

No Brasil, as pesquisas com este foco vêm ganhando espaço. Embora não se saiba precisar quando começou, construtos estudados pela Psicologia Positiva tem sido objeto de estudos nacionais desde 1996. Estudos de adaptação e validação de instrumentos tem sido desenvolvidos em núcleos como o Laboratório de Mensuração da Universidade Federal do Rio Grande do Sul (Pacico \& Bastianello, 2014), ampliando o conhecimento em avaliação e facilitando a investigação de efeitos de intervenções. Contudo, estudos nacionais de avaliação de intervenções baseadas em construtos da Psicologia Positiva parecem ser ainda em pequeno número. De forma geral, a Psicologia Positiva está interessada na promoção de saúde mental na medida em que focaliza os seus esforços para a diminuição do sofrimento e para o 
aumento do bem-estar subjetivo (Seligman, Steen, Park, \& Peterson, 2005), assim como de virtudes e competências que podem atuar como fatores de proteção para a saúde mental. Há, portanto, um amplo campo de investigação e prática profissional a ser explorado.

\section{Intervenções em Grupo para Promoção de Saúde Mental para Adolescentes e Jovens}

As intervenções de promoção de saúde mental voltadas para o indivíduo embasadas em Psicologia Positiva focam o desenvolvimento de emoções positivas, como a gratidão; a qualidade de vida percebida, como a satisfação com a vida e o bem-estar subjetivo; e o funcionamento psicológico positivo, como autoestima e autoeficácia. Para o público adolescente, as intervenções mais comumente descritas na literatura são oferecidas em formato grupal e abordam a promoção da empatia, otimismo, habilidades de vida e sentido da vida, como descrito a seguir.

\section{Empatia}

A empatia tem sido objeto de estudo em vários campos da psicologia. Ela desempenha um papel importante na promoção do ajuste psicológico e social de adolescentes e jovens e pode ser entendida como uma resposta emocional, derivada de uma percepção, compreensão e aceitação do estado ou condição do outro. A atitude empática em relação ao outro diz respeito à capacidade de experienciar e expressar tanto emoções positivas quanto negativas (Cecconello \& Koller, 2000).

Um programa visando o desenvolvimento da empatia como prevenção à agressão entre pares adolescentes foi executado por Castillo, Salguero, Fernández-Berrocal e Balluerka (2013). Participaram do estudo 590 adolescentes (46\% meninos e 54\% meninas) de oito escolas públicas localizadas em três cidades espanholas com idade entre 11 e 17. Desta amostra, 361 estudantes compuseram o grupo experimental e 229 estudantes o grupo controle. Tratou-se de um estudo quase-experimental, com pré-teste e pós-teste. Ao grupo experimental, 
foi oferecido o programa ITEMO, que consiste em um treinamento foi desenvolvido em 12 sessões de 1 hora de duração cada, em um período de dois anos acadêmicos. O objetivo principal do treinamento foi realçar as capacidades de (1) percepção clara, avaliação e expressão de emoções; (2) consciência dos sentimentos e capacidade de gerar emoções para facilitar o pensamento; (3) compreensão de emoções, inclusive a capacidade de nomeá-las de forma adequada; e (4) a regulação de emoções para fomentar o crescimento emocional e intelectual. $\mathrm{Na}$ avaliação foram utilizados questionários sobre agressividade e empatia. Os resultados mostraram que houve um aumento na promoção de respostas empáticas, resultando numa diminuição da agressão entre adolescentes. Na Tabela 1, a seguir, estão descritos exemplos adicionais de programas de promoção da empatia.

Tabela 1

Estudos de intervenção para promoção da empatia

\begin{tabular}{|c|c|c|}
\hline \multirow{5}{*}{$\begin{array}{l}\text { Treinamento de } \\
\text { Empatia como } \\
\text { Programa de } \\
\text { Prevenção do } \\
\text { Bullyng } \\
\text { (Şahin, 2012) }\end{array}$} & $\begin{array}{c}\mathrm{N}^{\mathbf{0}} \text { de } \\
\text { Participantes }\end{array}$ & $\begin{array}{l}38 \text { estudantes ( } 19 \text { - grupos experimentais e } 19 \text { - grupos controle, } \\
\text { distribuídos de forma aleatória) }\end{array}$ \\
\hline & $\begin{array}{l}\text { Condição } \\
\text { Promovida }\end{array}$ & Empatia para prevenção de bullying \\
\hline & Formato & 11 sessões semanais de 75 minutos cada. \\
\hline & $\begin{array}{l}\text { Conteúdo do } \\
\text { Programa }\end{array}$ & $\begin{array}{l}\text { Conhecendo empatia e habilidades empáticas; ensinando consciência } \\
\text { da sensibilidade emocional; diferenciação perceptiva; obtenção de um } \\
\text { ponto de vista interno; atmosfera compreensiva e fluxo de informação } \\
\text { compreensiva; desenvolvimento da capacidade de escuta } \\
\text { compreensiva; desenvolvimento da capacidade de resposta } \\
\text { compreensiva; encerramento do grupo. }\end{array}$ \\
\hline & Resultados & $\begin{array}{l}\text { Diminuição do comportamento de bullying nos grupos experimentais. } \\
\text { Pós-teste aplicado } 60 \text { dias apontou para a manutenção dos resultados. }\end{array}$ \\
\hline \multirow{5}{*}{$\begin{array}{l}\text { Programa de } \\
\text { Treinamento da } \\
\text { Empatia } \\
\text { (Falcone, 1999) }\end{array}$} & $\begin{array}{c}\mathrm{N}^{\circ} \text { de } \\
\text { Participantes }\end{array}$ & $\begin{array}{l}17 \text { estudantes universitários (10 grupo experimental e } 7 \text { grupo } \\
\text { controle) }\end{array}$ \\
\hline & $\begin{array}{l}\text { Condição } \\
\text { Promovida }\end{array}$ & Empatia \\
\hline & Formato & $\begin{array}{l}11 \text { encontros de } 120 \text { minutos cada, duas vezes por semana, com follow } \\
\text { up de } 1 \text { mês. }\end{array}$ \\
\hline & $\begin{array}{l}\text { Conteúdo do } \\
\text { Programa }\end{array}$ & $\begin{array}{l}\text { Desenvolvimento das capacidades de identificar sinais emocionais } \\
\text { não-verbais no comportamento do outro; identificar fatores que } \\
\text { dificultam a escuta e compreensão do outro; expressar entendimento da } \\
\text { perspectiva e sentimentos da outra pessoa e demonstrar compreensão e } \\
\text { aceitação através de comunicação não-verbal. }\end{array}$ \\
\hline & Resultados & $\begin{array}{l}\text { O treinamento mostrou-se eficaz em melhorar significativamente o } \\
\text { desempenho do grupo experimental na comunicação empática verba, e } \\
\text { no aspecto de aproximação. Os resultados se mantiveram após o follow } \\
\text { up, confirmado por parte de parentes e amigos. }\end{array}$ \\
\hline
\end{tabular}




\begin{tabular}{|c|c|c|}
\hline \multirow{5}{*}{$\begin{array}{c}\text { Intervenção } \\
\text { Psicológica em } \\
\text { Fatores de } \\
\text { Desenvolvimento } \\
\text { Emocional } \\
\text { (Garaigordobil, } \\
\text { 2004) }\end{array}$} & $\begin{array}{c}\mathrm{N}^{\circ} \text { de } \\
\text { Participantes }\end{array}$ & 174 adolescentes ( 125 no grupo experimental e 49 como controle) \\
\hline & $\begin{array}{l}\text { Condição } \\
\text { Promovida }\end{array}$ & Empatia \\
\hline & Formato & 1 sessão semanal de 2 horas, durante todo o ano acadêmico. \\
\hline & $\begin{array}{c}\text { Conteúdo do } \\
\text { Programa }\end{array}$ & $\begin{array}{l}\text { Autoconhecimento e autoconceito; comunicação positiva entre pares; } \\
\text { compreensão da expressão de sentimentos; desenvolvimento de } \\
\text { relações cooperativas; percepções estereotipadas; discriminação e } \\
\text { solução de conflitos socioemocionais. }\end{array}$ \\
\hline & Resultados & $\begin{array}{l}\text { No grupo experimental ocorreram mudanças significativas no } \\
\text { autoconceito, autoestima e comportamento empático, em comparação } \\
\text { com o grupo controle. }\end{array}$ \\
\hline
\end{tabular}

\section{Otimismo}

O otimismo pode ser definido tipicamente como uma tendência ou disposição para esperar o melhor. Vai além de uma mera expectativa de que algo aconteça. Os constructos esperança e otimismo tem recebido uma atenção maior de pesquisadores devido à emergência e influência da psicologia positiva e o estudo sistematizado das emoções positivas (Seligman \& Csikszentmihalyi, 2000). São considerados importantes indicadores tanto de saúde física quanto mental, impactando à vezes até mesmo no sistema imunológico (Scheier \& Carver, 1992).

Remor, Gómez e Carrobles (2010) implementaram um programa com o objetivo de potencializar forças e recursos psicológicos. Os autores trabalharam com três amostras distintas A - 22 estudantes espanhóis saudáveis, B - 14 estudantes com esclerose múltipla, C - 24 estudantes salvadorenhos saudáveis. Para as amostras A e B foi utilizado um delineamento quase experimental de grupo único, com pré-teste, pós teste e folllow up de 3 meses. Para a amostra $\mathrm{C}$ foi utilizado um delineamento quase experimental com pré-teste, pós teste e grupo controle. À exceção do grupo controle, todos foram submetidos a um programa para potencialização de forças e recursos psicológicos, constituído de 10 sessões semanais com duração de 90 minutos cada uma. O conteúdo da intervenção contemplou informações sobre o que são os recursos psicológicos, sua importância e relação entre o seu uso, saúde e bem estar subjetivo; estilos de comunicação assertivo, não assertivo e agressivo; 
desenvolvimento de estratégias para resolução de problemas; identificação dos pontos chaves para o desenvolvimento do entusiasmo e vitalidade; importância da capacidade de perdoar; diferenças entre pensamentos positivos e negativos e suas influências sobre a saúde e bem estar subjetivo; comunicação empática e a importância de reconhecer progressos pessoais e a capacidade para alcançá-los. Na avaliação foram utilizados escala e questionários para medir estado de ânimo, recursos psicológicos existentes, estresse, satisfação com a vida, otimismo, saúde mental geral e queixas subjetivas de saúde. De modo geral, os resultados mostraram que a intervenção foi eficaz para potencializar os recursos psicológicos, com destaque para o aumento do otimismo, da capacidade de resolução de problemas e do autocontrole. A Tabela 2 traz alguns exemplos de programas de promoção de saúde, com foco no desenvolvimento do otimismo.

Tabela 2

Estudos de intervenção para promoção do otimismo

\begin{tabular}{|c|c|c|}
\hline \multirow{5}{*}{$\begin{array}{l}\text { Programa de escrita } \\
\text { expressiva para } \\
\quad \text { adolescentes } \\
\text { (Soliday, Garofalo, } \\
\text { \& Rogers, 2004) }\end{array}$} & $\begin{array}{c}\mathrm{N}^{\circ} \text { de } \\
\text { Participantes }\end{array}$ & $\begin{array}{l}106 \text { adolescentes ( } 49 \text { na condição experimental e } 57 \text { na condição } \\
\text { controle). }\end{array}$ \\
\hline & $\begin{array}{l}\text { Condição } \\
\text { Promovida }\end{array}$ & Otimismo, disposição positiva \\
\hline & Formato & $\begin{array}{l}1 \text { encontro para preenchimento de questionários, } 1 \text { encontro para } \\
\text { orientar o exercício de escrita expressiva ( } 3 \text { dias consecutivos de } 20 \\
\text { minutos cada), follow ups de } 2 \text { e } 6 \text { semanas. }\end{array}$ \\
\hline & $\begin{array}{c}\text { Conteúdo do } \\
\text { Programa }\end{array}$ & $\begin{array}{l}\text { Condição experimental: exercício de escrita expressiva }{ }^{2} \text { sobre algum } \\
\text { problema emocional ou estressante que que tenha afetado a vida do } \\
\text { adolescente. } \\
\text { Condição controle: escrita neutra }\end{array}$ \\
\hline & Resultados & $\begin{array}{l}\text { Houve um aumento nos índices de otimismo e uma diminuição de } \\
\text { afetos negativos e sofrimento psicológico entre os adolescentes que } \\
\text { praticaram a escrita expressiva. }\end{array}$ \\
\hline \multirow{5}{*}{$\begin{array}{c}\text { Programa } \\
\text { psicoeducacional } \\
\text { em desamparo } \\
\text { aprendido e crenças } \\
\text { irracionais (Ulusoy } \\
\text { \& Duy, 2013) }\end{array}$} & $\begin{array}{c}\mathrm{N}^{\circ} \text { de } \\
\text { Participantes }\end{array}$ & $\begin{array}{l}27 \text { adolescentes ( } 9 \text { no grupo experimental, } 9 \text { no grupo placebo e } 9 \text { no } \\
\text { grupo controle }\end{array}$ \\
\hline & $\begin{array}{l}\text { Condição } \\
\text { Promovida }\end{array}$ & Otimismo \\
\hline & Formato & 10 sessões de 40 minutos cada. \\
\hline & $\begin{array}{l}\text { Conteúdo do } \\
\text { Programa }\end{array}$ & $\begin{array}{l}\text { Para o grupo experimental foi oferecida didática estruturada com } \\
\text { estratégias cognitivo-comportamental orientadas para superação do } \\
\text { desamparo aprendido. } \\
\text { Para o grupo placebo, informações sobre os desenvolvimentos na } \\
\text { adolescência. Ao grupo controle nada foi oferecido }\end{array}$ \\
\hline & Resultados & O programa foi eficaz para redução de crenças irracionais \\
\hline
\end{tabular}

\footnotetext{
2 Técnica que consiste em escrever sobre pensamentos e sentimentos em relação a acontecimentos significativos na vida da pessoa (Pennebaker, 1997)
} 


\section{Habilidades de Vida}

Habilidades de vida podem ser entendidas como a potencialidade de comportar-se de forma positiva e adaptativa, permitindo aos indivíduos lidar de forma produtiva com as demandas e os desafios da vida cotidiana. Compreendem as habilidades de autoconhecimento, relacionamento interpessoal, empatia, lidar com os sentimentos, lidar com o estresse, comunicação eficaz, pensamento crítico, pensamento criativo, tomada de decisão e resolução de problemas (World Health Organization, 1997).

Murta et al. (2013) conduziram uma intervenção com o objetivo de promover habilidades de vida e direitos sexuais e reprodutivos em adolescentes. Utilizaram um delineamento quase-experimental, com avaliação de pré e pós-teste, e follow up de 5 meses com uma população de 60 estudantes do primeiro ano do ensino médio. Os participantes foram divididos em dois grupos: experimental $(\mathrm{N}=27)$ e controle $(\mathrm{N}=33)$. Ao grupo na condição experimental foi oferecida uma intervenção de 7 encontros semanais, com duração de 80 minutos. Fizeram parte do conteúdo as temáticas (1) tomada de decisão em contextos de interação afetivo-sexual; (2) reconhecimento de relações de namoro abusivas e saudáveis; (3) comunicação assertiva e enfrentamento à violência no namoro; (4) anticoncepção, papéis de gênero, direitos sexuais e reprodutivos;(5) manejo de emoções e empoderamento. Na avaliação foram utilizados questionários de interesse e de avaliação de impacto, formulário para avaliação de dose recebida e uma técnica de sentenças incompletas para avaliação de crenças sexistas e homofóbicas e intenção de enfrentamento à violência no namoro. Os resultados apontaram que houve um decréscimo acentuado em respostas sexistas hostis, aumento em respostas sexistas benévolas e diminuição de respostas homofóbicas explícitas no grupo experimental, contrapondo-se ao observado no grupo controle. Outros programas de promoção de habilidades de vida são apresentados na Tabela 3. 
Tabela 3

Estudos de intervenção para promoção de habilidades de vida

\begin{tabular}{|c|c|c|}
\hline \multirow{5}{*}{$\begin{array}{l}\text { Programa de } \\
\text { Habilidades de } \\
\text { Vida } \\
\text { (Murta et al., 2009) }\end{array}$} & $\begin{array}{c}\mathrm{N}^{\circ} \text { de } \\
\text { Participantes }\end{array}$ & 18 adolescentes \\
\hline & $\begin{array}{l}\text { Condição } \\
\text { Promovida }\end{array}$ & Habilidades de Vida \\
\hline & Formato & $\begin{array}{l}16 \text { sessões semanais com } 90 \text { minutos de duração cada, ao longo de } 5 \\
\text { meses com follow up de } 1 \text { ano. }\end{array}$ \\
\hline & $\begin{array}{l}\text { Conteúdo do } \\
\text { Programa }\end{array}$ & $\begin{array}{l}\text { Autoconceito, autoeficácia, riscos para o crescimento pessoal e riscos } \\
\text { vazios; relação crenças, emoções e comportamento; comunicação } \\
\text { assertiva; empatia; resolução de problemas; enfrentamento ao estresse; } \\
\text { tomada de decisão; pensamento crítico e riscos à saúde associados ao } \\
\text { gênero; locus de controle interno e saúde; rede de apoio social e } \\
\text { prevenção de recaída. }\end{array}$ \\
\hline & Resultados & $\begin{array}{l}\text { Os resultados apontaram para a ocorrência de metas intermediárias } \\
\text { como autorevelação de problemas e mudanças positivas em seus } \\
\text { desempenhos, identificação das causas de seus comportamentos, apoio } \\
\text { social e manifestação de sentimentos, que foram propostas pelo } \\
\text { programa, aumentando o repertório de habilidades dos adolescentes. O } \\
\text { follow up confirmou a manutenção de algumas habilidades, } \\
\text { confirmado pelos pais dos adolescentes. }\end{array}$ \\
\hline \multirow{5}{*}{$\begin{array}{l}\text { Uma Equipe contra } \\
\text { a Aids (Givaudan, } \\
\text { Van de Vijver, } \\
\text { Poortinga, Leenen, } \\
\text { \& Pick, 2007) }\end{array}$} & $\begin{array}{c}\mathrm{N}^{\circ} \text { de } \\
\text { Participantes }\end{array}$ & $\begin{array}{l}2064 \text { adolescentes (1107 no grupo experimental e } 957 \text { no grupo } \\
\text { controle) }\end{array}$ \\
\hline & $\begin{array}{l}\text { Condição } \\
\text { Promovida }\end{array}$ & Habilidades de Vida para prevenção ao HIV \\
\hline & Formato & 15 sessões semanais com duração de 2 horas cada. \\
\hline & $\begin{array}{l}\text { Conteúdo do } \\
\text { Programa }\end{array}$ & $\begin{array}{l}\text { Sexualidade; normas e valores; informações sobre HIV/Aids; sexo, } \\
\text { seguro; orientação sexual; habilidades de vida e educação sexual. }\end{array}$ \\
\hline & Resultados & $\begin{array}{l}\text { O grupo experimental apresentou melhoras significativas em todas as } \\
\text { variáveis, pós-intervenção. Além do aumento no conhecimento sobre } \\
\text { HIV/Aids, houve melhora na atitude em relação ao uso do } \\
\text { preservativo. }\end{array}$ \\
\hline
\end{tabular}

\section{Sentido da Vida}

Frankl (2008) compreende que a motivação primária do ser humano é a busca de sentido e que este poderá adoecer psiquicamente quando não encontra uma razão para viver. Dessa forma, o sentido na vida é concebido como principal fator de sobrevivência e realização humana, capacitando-o a superar e enfrentar situações estressantes. A busca pelo sentido na vida pode ser entendida, então, como a mola propulsora do existir humano e o principal fator de proteção à saúde (Frankl, 2003; Lukas, 1990). Segundo Aquino, Silva, Figueiredo, Dourado e Farias (2011), em geral, na adolescência é comum surgirem sentimentos de desesperança por falta de perspectivas para o futuro, como se a vida estivesse sem sentido. Desta forma, a discussão sobre o sentido da vida, pode constituir um fator de 
proteção, prevenindo o vazio existencial e promovendo competências na busca de novos valores e significados.

Aquino et al. (2011) realizaram uma intervenção para uma população não clínica, composta por 33 adolescentes de uma escola da rede pública de ensino de Campina Grande PB, com idade entre 14 e 18 anos. O objetivo da proposta era aumentar a sensação de sentido da vida. O delineamento do estudo foi quase-experimental, com aplicação de pré-teste e pósteste e, para o grupo experimental, foi oferecida uma intervenção composta de 15 encontros semanais de 45 minutos cada. Por meio de parábolas e fábulas e baseado em uma relação dialógica, foram trabalhados os temas (1) a dimensão do espírito humano; (2) vontade de sentido; (3) liberdade e responsabilidade; (4) autotranscendência; (5) conformismo e totalitarismo; (6) descobrindo nosso valor como ser humano; (7) encontrar sentido em situações-limite; (8) dizer sim à vida apesar de tudo; (9) o suprassentido; (10) a descoberta de sentido e (11) projeto de vida. Na avaliação foi utilizada uma escala que mede o construto sentido da vida em suas graduações: níveis de vazio existencial e realização do sentido da vida. Os resultados mostraram que houve um aumento significativo da sensação de sentido na vida bem como uma diminuição nos níveis de desespero e de vazio existencial, entre os participantes do grupo experimental. Exemplos de programas focados na promoção do sentido da vida estão expostos na Tabela 4 .

Tabela 4

Estudos de intervenção para promoção do sentido da vida

\begin{tabular}{|c|c|c|}
\hline \multirow{5}{*}{$\begin{array}{l}\text { Treinamento em } \\
\text { Logoterapia } \\
\text { (Kang et al., } \\
\text { 2009). }\end{array}$} & $\begin{array}{c}\mathrm{N}^{\mathbf{0}} \text { de } \\
\text { Participantes }\end{array}$ & $\begin{array}{l}29 \text { adolescentes com diagnóstico de câncer (17 no grupo } \\
\text { experimental e } 12 \text { no grupo controle) }\end{array}$ \\
\hline & $\begin{array}{l}\text { Condição } \\
\text { Promovida }\end{array}$ & Sentido da vida \\
\hline & Formato & 5 sessões diárias de 30 minutos, durante 1 semana \\
\hline & $\begin{array}{l}\text { Conteúdo do } \\
\text { Programa }\end{array}$ & $\begin{array}{l}\text { As três naturezas da mente humana; valores criativos; valores } \\
\text { experienciais, valores atitudinais e tornando-me o mestre da } \\
\text { minha vida. }\end{array}$ \\
\hline & Resultados & $\begin{array}{l}\text { O programa de educação de logoterapia mostrou-se eficaz na } \\
\text { assistência aos adolescentes com câncer, na busca de } \\
\text { significação para suas vidas. O estudo apontou um satisfação dos } \\
\text { pacientes com o aumento no bem estar psicológico e baixa } \\
\text { sensação de desamparo. }\end{array}$ \\
\hline
\end{tabular}




\begin{tabular}{c|c|l}
\hline \multirow{4}{*}{$\begin{array}{c}\text { Treinamento de } \\
\text { Conceitos em }\end{array}$} & $\begin{array}{c}\mathrm{N}^{\mathbf{o}} \text { de } \\
\text { Participantes }\end{array}$ & $\begin{array}{l}\text { 30 adolescentes (15 no grupo experimental e 15 no grupo } \\
\text { controle) }\end{array}$ \\
\cline { 2 - 3 } $\begin{array}{c}\text { Condição } \\
\text { Promovida }\end{array}$ & Sentido da Vida \\
\cline { 2 - 3 } $\begin{array}{c}\text { (Haditabar, Far, } \\
\text { \& Amani, 2013) }\end{array}$ & $\begin{array}{c}\text { Conteúdo do } \\
\text { Programa }\end{array}$ & $\begin{array}{l}\text { Técnica específicas da logoterapia; intenção paradoxal, } \mathrm{n}^{\circ} 13 ; \\
\text { derreflexão } \mathrm{n}^{\circ} \text {. 14; correção de atitudes; conscientização de } \\
\text { valores e as técnicas de convocação. }\end{array}$ \\
\cline { 2 - 3 } & Resultados & $\begin{array}{l}\text { Houve um aumento nos escores de qualidade de vida dos } \\
\text { participantes do grupo experimental, no pós-teste. }\end{array}$ \\
\hline
\end{tabular}

\section{A Implementação de Intervenções para Promoção de Saúde Mental para Adolescentes}

O alcance de resultados positivos em programas preventivos ou de promoção de saúde mental está diretamente associado ao sucesso de sua implementação. A Figura 2 apresenta algumas dimensões apontadas por Berkel, Mauricio, Schoenfelder e Sandler (2011) que caracterizam um processo de implementação adequado. Estas dimensões tanto dizem respeito ao comportamento do facilitador (fidelidade, qualidade e adaptação) quanto ao comportamento do participante (responsividade).

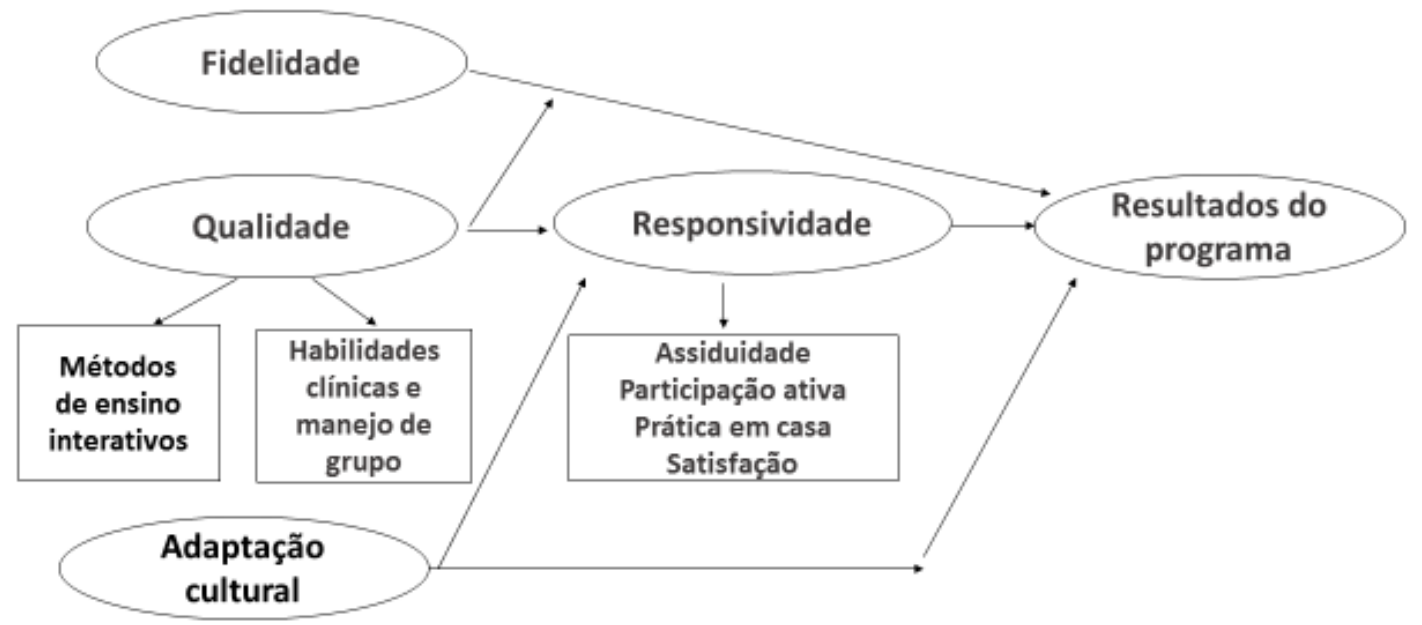

Figura 2. Modelo integrado de implementação de programas de Berkel, Mauricio, Schoenfelder e Sandler, 2011 (Fonte: Berkel et al., 2011).

No processo de implementação, a fidelidade diz respeito à oferta de um programa de modo coerente com o previsto no programa original, em termos de seus componentes centrais expressos em seus objetivos, conteúdo e procedimentos. A adaptação refere-se a modificar 
elementos de um programa para adequá-lo às especificidades da população para quem a intervenção será oferecida (Berkel et al., 2011), atentando para aspectos contextuais como nível socioeconômico, níveis de escolarização, recursos e oportunidades disponíveis na comunidade. A qualidade na implementação de um programa para adolescentes e jovens requer a qualificação dos profissionais responsáveis pela condução dos trabalhos no que se refere à sua capacitação teórica, habilidades clínicas e de manejo de grupo. Estas habilidades incluem habilidades para fomentar o potencial de ajuda entre os membros do grupo e habilidades sociais, tais como habilidades para fazer perguntas abertas, ouvir com empatia, fazer autorrevelações pertinentes e expressar sentimentos, sobretudo em ocasiões em que os membros do grupo relatam experiências dolorosas e problemáticas ou gratificantes e de crescimento. Uma síntese destas habilidades pode ser vista na Figura 3. A atuação profissional qualificada potencializa a adesão dos adolescentes à intervenção, como níveis mais elevados de participação, assiduidade, prática de tarefas de casa e satisfação (Berkel et al., 2011). Ademais, promove uma relação de confiança entre adolescentes e facilitador e maximiza a eficácia destas intervenções (Sale, Bellamy, Springer, \& Wang, 2008). 


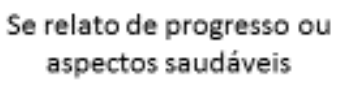

Se relato de problema ou sofrimento

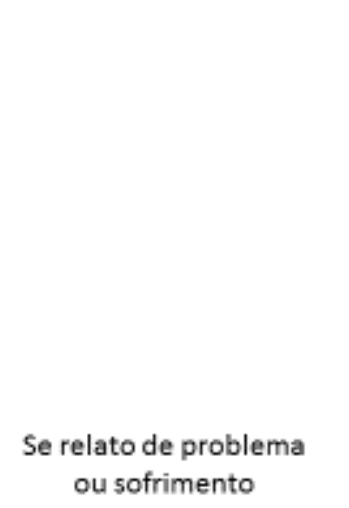

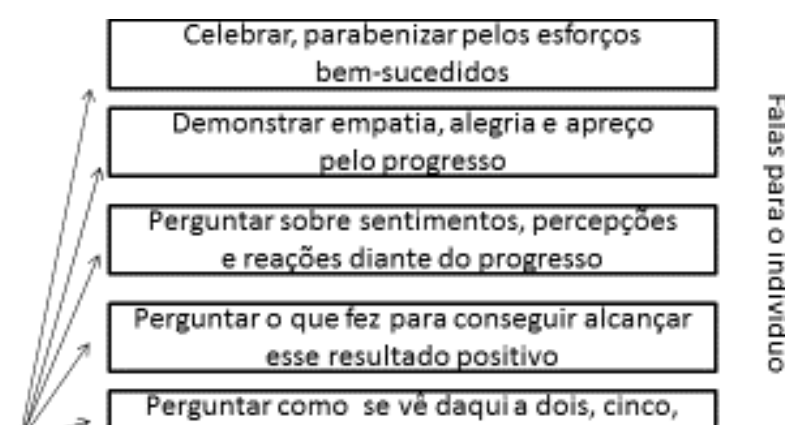

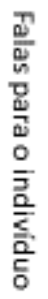

Convidaro grupo a refletir sobre o percurso feito pelo colega para chegar a tal resultado

Perguntar ao grupo como o progresso do colega os inspira a cuidar de si mesmos

Convidar o grupo a refletir sobre as tarefas que podem se dar a partir dessa experiência

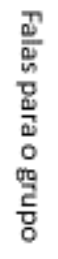

$\downarrow$ Solicitar aos participantes relembrar e resumir outros progressos do grupo
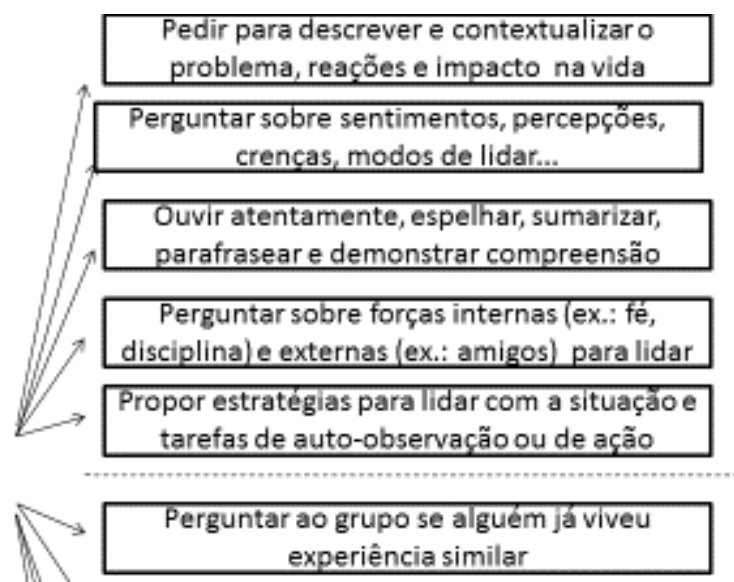

$\checkmark$ Perguntar ao grupo o que deseja dizer à pessoa que relata sofrimento ou problema

Convidaro grupo a expressar seus sentimentos frente à experiência do colega

Perguntar ao grupo que forças usaram para lidar com problemas similares no passado colega os ajudam enxergar as próprias lutas

Figura 3. Habilidades do facilitador promotoras de fatores terapêuticos do grupo (Fonte: Murta, Borges \& Costa-Júnior, 2014).

\section{Considerações Finais}

A adolescência e a juventude vivenciam inúmeros problemas de saúde que podem ser alvo de iniciativas preventivas ou promotoras de saúde, desde ações dirigidas ao indivíduo e 
seu entorno social até a comunidade e as políticas públicas. Intervenções dirigidas ao indivíduo em grupo embasadas na Psicologia Positiva consistem em uma das modalidades de ações promotoras de saúde. Evidências de eficácia de intervenções para promoção de empatia, otimismo, habilidades de vida e sentido da vida, como as relatadas neste texto, indicam ser esta uma rota promissora nos cuidados à saúde mental desta população. A aplicabilidade de programas assim embasados no contexto nacional é vasta, seja no âmbito educacional, comunitário, clínico ou em saúde. Contudo, como esta é uma área de produção ainda relativamente nova no Brasil, evidências de eficácia e efetividade devem ser acumuladas em estudos posteriores, assim como identificadas as eventuais limitações, indicações e contraindicações desta modalidade de intervenção na adolescência.

A eficácia destas intervenções, tal como de outros programas preventivos ou de promoção de saúde para adolescentes, está associada à qualidade de sua implementação. Quando transpostos de um contexto para outro, os programas devem ser adaptados à nova cultura e, ao mesmo tempo, devem ser conduzidos de modo a se preservar seus componentes centrais. A fidelidade da implementação e a sensibilidade cultural, associadas às habilidades clínicas e de manejo de grupo do facilitador, estão entre os principais determinantes da adesão dos adolescentes e jovens aos grupos de intervenção. Recomenda-se o investimento na qualidade da implementação para que seja potencializada a eficácia e a efetividade de intervenções voltadas para a adolescência e a juventude. 


\section{Referências}

Aguiar, W. M. J.; Bock, A. M. B., \& Ozella (2001). Orientação profissional com adolescentes: um exemplo de prática na abordagem sócio-histórica. In A. M. B. Bock \& M. da G. Marchina (Eds.), Psicologia sócio-histórica: Uma perspectiva crítica em Psicologia (pp. 161-178). São Paulo: Cortez.

Aquino, T. A. A., Silva, J. P., Figueiredo, A. T. B., Dourado, E. T. S., \& Farias, E. C. S. (2011). Avaliação de uma proposta de prevenção ao vazio existencial com adolescentes. Psicologia: Ciência e Profissão, 31, 146-159.

Avanci, J. Q., Assis, S. G., Oliveira, R. V. C, Ferreira, R, M., \& Pesce, R. P (2007). Fatores Associados aos Problemas de Saúde Mental em Adolescentes. Psicologia: Teoria e Pesquisa, 23(3), 287-294.

Berkel, C., Mauricio, A.M., Schoenfelder, E., \& Sandler, I. N. (2011). Putting the pieces together: An integrated model of program implementation. Prevention Science, 12, 23-33.

Castillo, R.; Salguero, J. M.; Fernández-Berrocal, P., \& Balluerka, N. (2013). Effects of an emotional intelligence intervention on aggression and empathy among adolescentes. Journal of Adolescence 36, 883-892

Cecconello, A. M. \& Koller, S. H. (2000). Competência social e empatia: um estudo sobre resiliência com crianças em situação de pobreza. Estudos de Psicologia. 5(1), 71-93.

Czeresnia, D. (2003). O conceito de saúde e a diferença entre prevenção e promoção. In D. Czeresnia \& C. M. Freitas (Eds.), Promoção da saúde: conceitos, reflexões e tendências (pp.39-53). Rio de Janeiro: Fiocruz.

Dalton, J. H., Elias, M. J., \& Wandersman, A. (2007). Community Psychology: linking individuals and communities. Thomsom Wadsworth: Belmont, California.

Falcone, E. (1999). Avaliação de um programa de treinamento da empatia com universitários. Revista Brasileira de Terapia Comportamental e Cognitiva, 1, 23-32. 
Fierro, A (1995). Desenvolvimento da personalidade na adolescência. In: C. Coll, J. Palaccios \& A. Marchesi (Eds.), Desenvolvimento psicológico e educação: psicologia evolutiva (pp. 288-305). Porto Alegre: Artmed.

Frankl, V. E. (2003). Psicoterapia e sentido da vida: Fundamentos da logoterapia e análise existencial. São Paulo: Quadrante.

Frankl, V. E. (2008) Em busca de sentido. Petrópolis: Vozes.

Garaigordobil, M. (2004). Effects of a psychological intervention on factors of emotional development during adolescence. European Journal of Psychological Assessment, 20(1), 66-80.

Givaudan, M., Van de Vijver, F. J. R., Poortinga, Y. H., Leenen, I., \& Pick, S. (2007) Effects of a School-Based Life Skills and HIV-Prevention Program for Adolescents in Mexican High Schools. Journal of Applied Social Psychology, 37 (6), 1141-1162.

Haditabar, H., Far, N. S., \& Amani, Z. (2013). Effectiveness of logotherapy concepts training in increasing the quality of life among students. International Journal of Psychology and Behavioral Research, 2(4), 223-230.

Instituto Brasileiro de Geografia e Estatística (2013). Pesquisa Nacional da Saúde do Escolar 2012. Rio de Janeiro, Brasil

Johnstone, J., Rooney, R. M., Hassan, S., \& Kane, R. T. (2014). Prevention of depression and anxiety symptoms in adolescents: 42 and 54 months follow-up of the Aussie Optimism Program-Positive Thinking Skills. Frontiers in Psychology, 5, 1-10.

Kang, K., Im, J., Kim, H., Kim, S., Song, M., \& Sim, S. (2009) The effect of logotherapy on the suffering, finding meaning, and spiritual well-being of adolescents with terminal cancer. Journal of Korean Academy of Nursing, 15(2), 136-144.

Kenny, M. E. \& Hage, S. M. (2009). The next frontier: prevention as an instrument of social justice. Journal of Primary Prevention, 30, 1-10. 
Keyes, C. L. M. (2007). Promoting and protecting mental health as flourishing. American Psychologist, 62, 95-108.

Lukas, E. (1990) Mentalização e saúde. Petrópolis: Vozes

Muñoz, R. E., Mrazek, P. J., \& Haggerty, R. J. (1996). Institute of medicine report on prevention of mental disorders. American Psychologist, 51, 1116-1122.

Murta, S. G. \& Barletta, J. B. (no prelo). Promoção de saúde mental e prevenção aos transtornos mentais em terapia cognitivo-comportamental. In Rangé, B., Falcone, E. \& Neufeld, B. (Eds.), PROCOGNITIVA, Programa de Atualização em Terapia CognitivoComportamental. Porto Alegre: Artmed.

Murta, S. G., Borges, F. A., Ribeiro, D. C., Rocha, E. P., Menezes, J. C. L., \& Prado, M. M. (2009). Prevenção primária em saúde na adolescência: avaliação de um programa de habilidades de vida. Estudos de Psicologia, 14(3), 181-189.

Murta, S. G., Borges, L. M., \& Costa-Junior, A. (2014). Manejo de grupos de educação para aposentadoria. In S. G. Murta, C. Leandro França e J. Seidl (Eds.), Programas de educação para aposentadoria: como planejar, implementar e avaliar (pp. 68-83). Novo Hamburgo: Sinopsys.

Murta, S. G., Santos, B. R. P., Nobre, L. A., Araújo, I. F., Miranda, A. A. V., Rodrigues, I. O., \& Franco, C. T. P. (2013). Prevenção à violência no namoro e promoção de habilidades de vida em adolescentes. Psicologia USP. 24(2), 263-288.

Organização Mundial de Saúde (1986). $1^{a}$ Conferência Internacional sobre Promoção de saúde. Ottawa, Canadá.

Organização Mundial de Saúde (1997). $4^{a}$ Conferência Internacional sobre Promoção de saúde. Jacarta, Indonésia.

Outeiral, J. O. (1994). Adolescer: estudos sobre adolescência. Porto Alegre: Artes Médicas. 
Pacico, J. C. \& Bastianello, M. R. (2014). As origens da Psicologia Positiva e os primeiros estudos brasileiros. In C. S. Hutz (Ed.), Avaliação em Psicologia Positiva (pp. 13-22). Porto Alegre: Artmed.

Pennebaker, J. (1997). Writing about emotional experiences as a therapeutic process. American Psychological Society, 8(3), 162-166

Pessalacia, J. D. R., Menezes, E. S., \& Massuia, D. (2010). A vulnerabilidade do adolescente numa perspectiva das políticas de saúde pública. Revista Bioethikos, 4, 423-430.

Remor, E.; Gómez, M. A., \& Carobles, J. A. (2010). Eficacia de un programa manualizado de intervención en grupo para la potenciación de las fortalezas y recursos psicológicos. Anales de Psicologia, 26(1), 49-57.

Şahin, M. (2012). An investigation into the efficiency of empathy training program on preventing bullying in primary schools. Children and Youth Services Review, 34, 13251330.

Sale, E., Bellamy, N., Springer, F., \& Wang, M. Q. (2008) Quality of Provider-Participant Relationships and Enhancement of Adolescent Social Skills. Journal of Primary Prevent, 29, 263-278.

Scheier, M. F. \& Carver, C. S. (1992). Effects of optimism on psychological and physical well-being: Theoretical overview and empirical update. Cognitive Therapy and Research, 16, 201-228

Secretaria Nacional de Juventude (2014a). Agenda juventude Brasil. Brasília, Brasil.

Secretaria Nacional de Juventude (2014b). Estação juventude: conceitos fundamentais. Brasília, Brasil.

Seligman, M. E. P. \& Csikszentmihalyi, M. (2000). Positive psychology: an introduction. American Psychologist. 55, 5-14. 
Seligman, M. E. P., Steen, T., Park, N., \& Peterson, G. (2005). Positive psychology progress: Empirical validation of interventions. American Psyhologist, 60, 410-421.

Seligman, M. P. (2011). Florescer. Rio de Jeniro: Objetiva.

Soliday, E., Garofalo, J. P., \& Rogers, D. (2004) Expressive writing intervention for adolescents somatic symptoms and mood. Journal of Clinical Child and Adolescent Psychology, 4(33), 792-801

Ulusoy, Y. \& Duy, B. (2013). Effectiveness of a psycho-education program on learned helplessness and irrational beliefs. Educational Sciences: Theory \& Practice, 13(3), $1440-1446$

Weisz, J. R., Sandler, I. N., Durlak, J. A., \& Anton, B. S. (2005). Promoting and protecting youth mental health through evidence-based prevention and treatment. American Psychologist, 60, 628-648.

World Health Organization (1997). Life skills education for children and adolescents in schools. Geneve, Switzerland.

World Health Organization (2004). Prevention of mental disorders - effective interventions and policy options. Paris, France.

World Health Organization (2005). Promoting mental health: concepts, emerging evidence, practice. Geneve, Switzerland. 
Manuscrito 2

Prevenção em Saúde Mental à Luz da Logoterapia e Análise Existencial 


\section{Resumo}

A proposta desse estudo é descrever o construto sentido da vida, sua relação com a saúde mental e o desenvolvimento de ações de prevenção e promoção de saúde, a partir de um modelo de prevenção baseada na logoterapia e análise existencial. Apresenta ainda a logoterapia - escola terapêutica criada por Viktor Frankl - como uma abordagem que vem sendo utilizada para fundamentar intervenções preventivas para públicos e condições diversas. Para tanto, recorre aos conceitos fundamentais da logoterapia - liberdade de vontade, vontade de sentido e sentido da vida - e aos resultados exitosos de estudos que sugerem a aplicabilidade desta nos trabalhos de prevenção em saúde mental.

Palavras-chave: sentido da vida, logoterapia, saúde mental, prevenção 


\begin{abstract}
Abastract
The purpose of this study is to describe the construct meaning of life, its relation to mental health and the development of prevention and health promotion actions, from a prevention model based on logotherapy and existential analysis. It also presents the speech therapy therapy school created by Viktor Frankl - as an approach that has been used to support preventive interventions for public and various conditions. The article draws on fundamental concepts of logotherapy - freedom of will, will to meaning and sense of life - and the successful results of studies suggesting the applicability of the work of prevention in mental health.
\end{abstract}

Keywords: meaning in life, logotherapy, mental health, prevention 


\section{Prevenção em Saúde Mental à Luz da Logoterapia e Análise Existencial}

Diversos estudos vêm apontando a eficácia de programas de prevenção no âmbito da saúde mental. De acordo com Matos e Spence (2008), tais estudos revelam uma mudança de paradigma, deslocando o foco das intervenções no indivíduo adoecido para uma intervenção voltada para a participação desse indivíduo na promoção, recuperação e manutenção de sua saúde mental, através do desenvolvimento de competências que maximizem seus fatores protetivos. Em estudo sobre o estado da arte da pesquisa em prevenção em saúde mental no Brasil, Abreu (2012) encontrou programas avaliados de forma sistematizada, com foco na prevenção de comportamento antissocial, rejeição por pares, de violência e de abuso de álcool e outras drogas. Murta et al (2012) descrevem a avaliação de um programa preventivo para adolescentes, professores e familiares, focado em direitos sexuais e reprodutivos, resiliência e habilidades sociais assertivas. Em estudos internacionais foram encontradas intervenções para diversas condições como: ansiedade (Fisak Junior, Richard \& Mann, 2011), depressão (Gillham, Hamilton, Freres, Patton, \& Gallop, 2006), uso e abuso de álcool e outras drogas (Hawkins, Catalano \& Arthur, 2002) e transtornos alimentares (Stice, Rohde, Gau \& Shaw, 2012). Também foram identificados estudos com foco na promoção da igualdade de gênero (Verma et al, 2006), otimismo (Ulusoy \& Duy, 2013, Soliday, Garofalo, \& Rogers, 2004) e sentido da vida (Kang et al., 2009, Haditabar, Far, \& Amani, 2013).

O sentido da vida faz parte dos questionamentos existenciais do ser humano e tem recebido atenção da psicologia no intuito de compreender sua relação com os mecanismos de ajustamento e adaptação do ser humano. Segundo Frankl (2003) a falta de sentido para a vida poderia desencadear sintomas como ansiedade, depressão, falta de esperança e declínio físico. Desta forma, a promoção do sentido da vida pode ser uma importante estratégia preventiva em saúde mental. 
Tendo em conta essa perspectiva, o objetivo do presente artigo foi identificar as principais contribuições da logoterapia e análise existencial no desenvolvimento de ações de prevenção e na promoção de saúde mental. Para tanto, este texto está organizado em três seções. A primeira seção apresenta reflexões sobre a relação entre sentido da vida e saúde mental. A segunda aborda o sentido da vida e prevenção em saúde mental a partir da logoterapia. A terceira seção descreve exemplos de intervenções preventivas em logoterapia.

\section{Sentido da vida e Saúde Mental}

Atualmente, o sentido da vida tem recebido ampla atenção empírica, refletindo em "um avanço teórico e metodológico sobre o construto e sua relação com outros construtos psicológicos já existentes: satisfação com a vida, felicidade, esperança, otimismo" (Damásio, 2013, p. 22).

A compreensão do sentido da vida como um construto multidimensional é defendida por Reker e Wong (1988), que o definiram a partir da constituição de três elementos: (a) um componente cognitivo, envolvendo as crenças e a compreensão das experiências vividas pelo indivíduo; (b) um componente motivacional, que aponta para um sistema de valores que impelem o indivíduo na busca e realização de metas pessoais e (c) um componente afetivo, relacionado à convicção de que a vida vale à pena, levando o indivíduo a uma sensação de bem-estar. Essa visão é compartilhada por Rosenmayr (1985) que definiu sentido da vida como um componente cognitivo, no qual a pessoa percebe uma relação entre a definição de seus objetivos pessoais e os recursos e estratégias que possam ser utilizadas na busca da realização dos mesmos. Em consequência disso, haveria uma percepção de satisfação com a vida e sensação de felicidade. O sentido da vida está associado a ter um propósito, ter metas significativas e um senso de direção, saber para onde se quer ir e o que esperar da vida. $\mathrm{O}$ 
sistema de crenças e valores de uma pessoa funciona como guia, para que ela seja capaz de definir quais metas ela deve perseguir e em quais projetos deve se engajar (Reker, 1997).

De acordo com Steger (2009), é preciso cautela ao incluir componentes afetivos como estruturantes no construto sentido da vida. Para ele, os elementos cognitivos e motivacionais são os responsáveis por estabelecer a diferença entre sentido da vida e os demais construtos psicológicos existentes. Ainda para o autor em questão, aspectos emocionais como felicidade e satisfação com a vida são consequências da realização existencial e não a realização em si, ou seja, as pessoas que percebem um significado para suas vidas experimentam a sensação de felicidade, em decorrência da sensação de realização existencial. Dessa forma, o sentido da vida poderia ser definido como o quanto a pessoa percebe sua vida como significativa, bem como a existência de um propósito pessoal que ratifique esse grau de significância na vida (Steger, 2009).

Embora um pouco divergente da perspectiva apresentada por Reker e Wong (1988), principalmente no que diz respeito a considerar aspectos afetivos na compreensão do sentido da vida, a ideia defendida por Steger (2009) tem encontrado respaldo em alguns estudos propostos por outros teóricos. Este é o caso de Rosenmayr (1985), quando afirma que a felicidade surge como consequência da realização, e de King, Hicks, Krull, e Del Gaiso (2006), que demonstraram que indivíduos com altos níveis de felicidade tendiam a ver suas vidas como significativas, porém os níveis de percepção de sentido não foram capazes de predizer os níveis de felicidade.

De forma complementar a essa abordagem estrutural do sentido da vida, outros teóricos (Baumeister, 1991; Sommerhalder, 2009) têm desenvolvido estudos com foco nas fontes de sentido, ou seja, compreender em quais dimensões da vida se localizam as motivações para o viver. Segundo Baumeister (1991) o sentido da vida pode ser definido como a importância que a pessoa dá os eventos de vida, independente do impacto que este 
evento possa causar. Dessa forma, a percepção de sentido pode ser influenciada por fatores internos - experiência de vida, recursos pessoais, espiritualidade - e externos - possiblidades de trabalho e lazer, expectativa de vida saudável e realização de necessidades básicas (Sommerhalder, 2009). Especificamente, a vida tende a ser percebida como tendo sentido quando é possível para a pessoa vivenciar: autoconhecimento, compromisso social, conexão com a natureza, criatividade, saúde, espiritualidade, religiosidade explícita, desafios, liberdade, cuidado de si e do outro, dentre outros (Schnell, 2009).

A falta de sentido tem sido relacionada a desfechos negativos em saúde mental, como depressão (Mascaro \& Rosen, 2006) uso de álcool (Immonen, Valvanne, \& Pitkälä, 2011), drogadição (Henrion, 2002) e ideação suicida (Edwards \& Holden, 2001). Esses dados sugerem que o sentido da vida seja um elemento importante no desenvolvimento e utilização de recursos internos protetivos, a partir de uma atribuição de significado existencial às situações vividas. Damásio, Melo e Silva (2013), conduzindo um estudo com professores, encontraram resultados positivos, considerando o sentido da vida como moderador de bemestar psicológico e de qualidade de vida. Esses resultados encontram respaldo em estudos internacionais que colocam o sentido da vida como um indicador do funcionamento psicológico positivo (Ho, Cheung, \& Cheung, 2010) e uma variável importante para a percepção de satisfação com a vida (Scollon \& King, 2004).

\section{Sentido da Vida, Logoterapia e Prevenção em Saúde Mental}

Embora seja objeto de estudos atuais, o interesse da psicologia pela compreensão do construto sentido da vida não é recente. Viktor Frankl foi o pioneiro nos questionamentos pelo sentido da vida, ao criar a logoterapia, escola que tem como principal fundamento o sentido da existência humana e a busca da pessoa por esse sentido. A logoterapia busca definir quem é o homem, dessa forma Frankl propõe um projeto antropológico para 
compreensão do ser humano que incluam os aspectos saudáveis e positivos da existência. Ainda, segundo o autor em questão, essa necessidade de encontrar um sentido para sua existência é uma característica especificamente humana, sendo sua principal força motivadora (Frankl, 2008).

Os aspectos fundamentais que sustentam a logoterapia são: (1) liberdade de vontade, revela que o homem é um ser livre e responsável para decidir diante das possibilidades de que a vida dispõe. A vivência dessa liberdade permite ao homem ir se libertando dos condicionamentos biológicos, sociais e psicológicos; (2) a vontade de sentido, motivação primária e autêntica do ser humano; é o interesse contínuo do homem pelo significado da sua vida e (3) o sentido da vida, que consiste no caráter incondicional dos valores que conferem sentido à vida (Aquino, 2013). Cada ser humano tem (ou deveria ter) um sentido único e exclusivo para sua própria existência (Frankl, 2003).

Ao considerar a busca de sentido como um fator protetivo, Frankl (2005) sugere uma relação estreita entre essa motivação e a compreensão atual de promoção da saúde mental. De fato, a logoterapia dá ênfase os fenômenos especificamente humanos (consciência, liberdade, responsabilidade, dentre outros), que seriam sempre construtivos e fontes saudáveis para a vida do ser humano. Em consonância com essa concepção Acevedo (1985) considera que a saúde mental, de forma geral, pode ser compreendida como "o desenvolver do ser em sua essência e sentido" (p. 47). O referido autor expande esse conceito para além da ausência de enfermidade, incluindo aspectos como, o sentido da vida, possibilidade de escolha da própria história vital, expressar-se por meio do diálogo, estabelecer vínculos afetivos, dentre outros. Ideia similar pode ser encontrada no pensamento de Lukas (1992), quando aventa que há uma relação direta entre orientação para um sentido da vida e a saúde psíquica de um indivíduo.

Segundo a logoterapia, a saúde não estaria relacionada nem com o bem estar completo nem com o conceito de homeostase, mas com a tensão existencial entre o "ser" e o "dever- 
ser”. Dessa forma, a ausência de tensão e o ócio não seriam sinônimos de saúde mental. Na medida em que o ser humano perde de vista essa tensão, emergem as vontades de poder e de prazer de forma exacerbadas, resultantes de uma sensação de vazio e frustração existencial (Frankl, 2008).

Nessa perspectiva, o princípio da homeostase resultaria em uma compreensão quietista da vida, ou seja, na procura da redução de tensões; como consequência, resultaria em uma atitude de apatia. Dessa forma, do ponto de vista da logoterapia, um provável critério da saúde psíquica requer uma adesão aos próprios compromissos e responsabilidades, posto que a fuga de tensões se constitui, em última instância, uma postura neurótica. (Fizzotti, 1998).

A Logoterapia se apresenta como uma reflexão privilegiada para os estudos de prevenção, pois parte de uma visão antropológica de que há um núcleo são que permanece intacto diante da enfermidade e que facilita a expressão de manifestações saudáveis. Desta forma, toda prevenção repousa na dimensão noológica do indivíduo, capacidade esta que pode ser entendida como seu núcleo são, a instância que permanece intacta apesar das adversidades, onde está a liberdade/responsabildiade e todos aqueles aspectos que são exclusivamente humanos, atos intencionais e preocupação com valores, os quais são inerentes ao ser humano (Ortiz, 2006).

A prevenção, a partir da visão logoterápica, pode ser compreendida como uma atividade coletiva que objetiva ampliar as características especificamente humanas, promovendo posturas que favoreçam uma maior resiliência e proporcionando descobertas de razões e motivos para viver. Por conseguinte, resultaria em adoção de medidas protetivas que restaurem, mantenham e/ou fortaleçam o bem-estar subjetivo.

Os trabalhos iniciais da logoterapia surgiram no campo da psicologia preventiva em resposta às circunstâncias vividas em Viena, no pós-Primeira Guerra Mundial, e foram 
direcionadas a jovens secundaristas que apresentavam sofrimento psicológico como depressão, conflitos com os pais e comportamentos suicidas, dentre outros (Frankl, 2005).

Frankl foi um dos pioneiros em empreender ações profiláticas a favor da juventude, constituindo centros de aconselhamentos (Frankl, 2005), podendo ser considerado um dos precursores da psicologia preventiva (Gismondi, 1998). Na Áustria, em plena década de 1920, o autor em foco compreendia que (1) "As necessidades econômicas de um povo causam crises gerais no plano psicológico" (Frankl, 2000, p. 45), logo, (2) os jovens e adolescentes seriam os mais vulneráveis, por não terem uma perspectiva de emprego no futuro, ocorrendo (3) uma associação entre o desemprego e a sensação de falta de valor da vida. Por sua vez, essa associação (4) gerava um alto índice de suicídio na Áustria. Nessa perspectiva tais centros de aconselhamentos deveriam contar com a colaboração da imprensa, da família e da escola com o intuito de romper essa associação, por meio do engajamento do jovem em trabalhos voluntários.

Segundo Frankl (2009), a vontade de encontrar uma razão pela qual valha a pena viver torna-se imperativo para o indivíduo e também se constitui como um fator de proteção à vida. Ter a consciência de sua finitude faz com que o ser humano sinta a necessidade de buscar o sentido de sua existência (Aquino, 2013), por conseguinte, há uma atração natural entre o homem e os valores (Lukas, 1989).

Ainda de acordo com Frankl (2011), mesmo não havendo um sentido universal da vida, considerando que este é situacional, único e individual, existem valores que são partilhados por seres humanos em diferentes momentos históricos e contextos sociais; mas aqueles que são únicos e idiossincráticos são denominados de sentidos, por possuírem um caráter pessoal e situacional (Frankl, 2003). Tais valores são denominados de vivenciais (por exemplo, vivenciar sentimentos em relação a pessoas, natureza ou obras artísticas), criativos (por exemplo, construir obras artísticas ou científicas) e atitudinais (por exemplo, posicionar- 
se perante o sofrimento como sendo inevitável). Sendo o sentido da vida um componente fundamental do bem-estar, a ausência deste pode levar o homem a experimentar o que Frankl chamou de vazio existencial, capaz de gerar afetos negativos, a exemplo da depressão e outros problemas psicossociais tais como: drogadição, suicídio e agressão (Frankl, 2005, 2008).

Considerando a concepção que divide a prevenção em (a) universal - intervenções direcionadas ao público em geral; (b) seletiva - ações cujo foco são subgrupos da população expostos a fatores de risco para algum transtorno e (c) indicada - voltada para pessoas com sinais ou sintomas iniciais de um dado transtorno ou desordem, porém sem ter ainda um diagnóstico específico (Muñoz, Mrazek, \& Haggerty, 1996), propõe-se um modelo para a compreensão da prevenção de acordo com o pensamento de Frankl (2011) e Lukas (1992). Fundamentalmente o processo de prevenção deve se pautar na atitude, pois essa será fundamental para o desencadeamento de posturas que, por conseguinte, determinarão a proteção ou um perigo para a saúde mental, como exposto na Figura 1. 


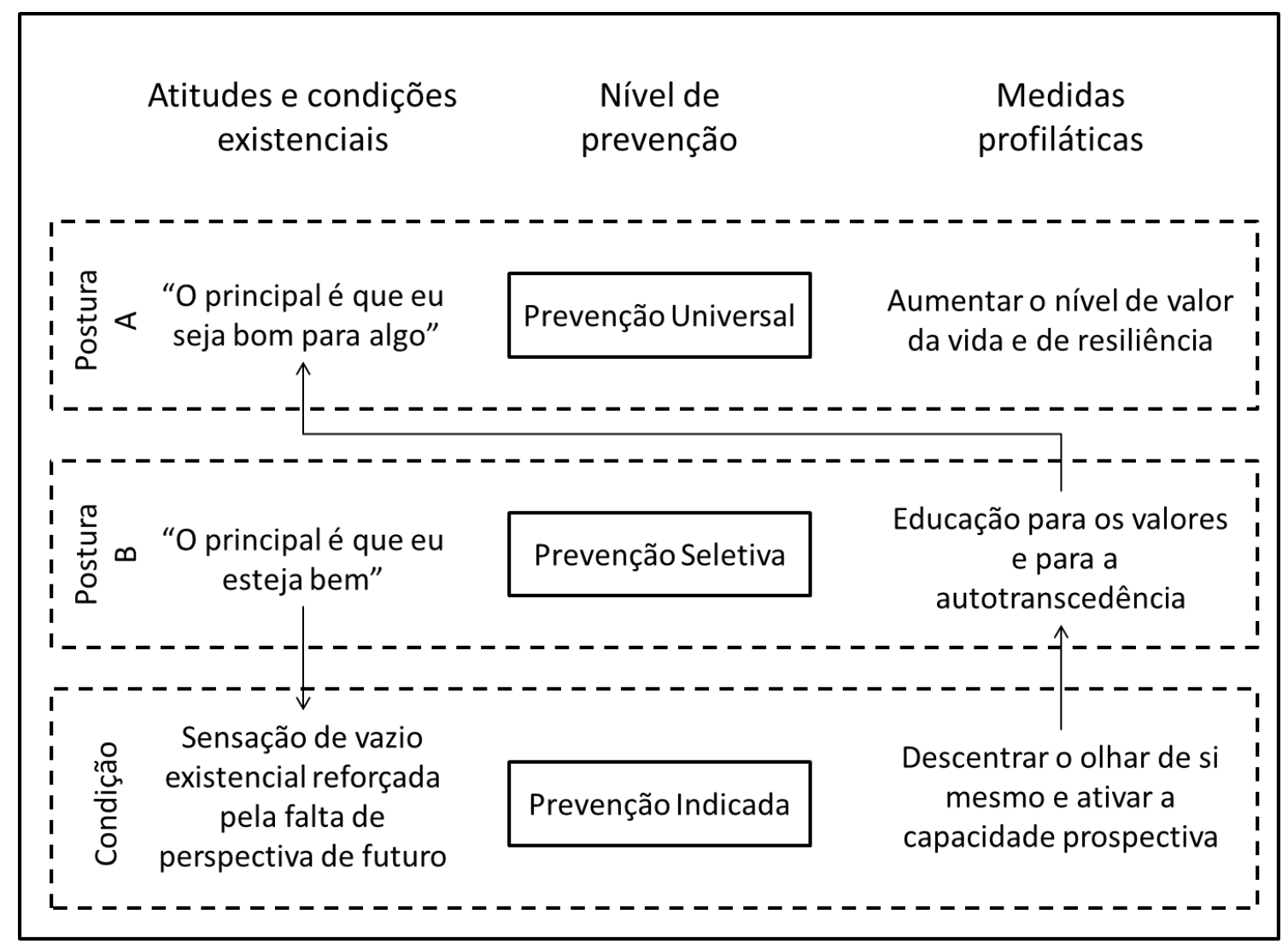

Figura 1. Modelo de prevenção em Logoterapia.

Como se pode observar na Figura 1, as intervenções de base logoterápica devem priorizar, sobretudo, a mobilização para a postura "A", por colocar ênfase na autotranscendência do ser humano ("ser bom para algo"). Por conseguinte essa postura aumenta sensação de valor da vida protegendo contra a frustração existencial. Já o olhar para si mesmo, reforça o egocentrismo, o que corresponderia a um maior perigo para a saúde mental (Postura B). Destarte, fundamentalmente consiste em uma educação que leve a descoberta de valores que proporcionem tanto uma razão para viver quanto o desenvolvimento de uma postura autotranscendente.

Assim, torna-se fundamental o desenvolvimento de medidas profiláticas que apontem para uma prevenção baseada nos fundamentos antropológicos da análise existencial de Viktor Frankl, conforme propõe Aquino (2015). Nessa perspectiva, a prevenção na logoterapia é direcionada especificamente ao mal-estar existencial na juventude, sobretudo ao vazio 
existencial. A prevenção universal deve ser eminentemente uma educação para a promoção do sentido que maximize seus níveis de valor da vida e de resiliência, preferencialmente direcionada a um maior número de pessoas (escola, comunidade etc.), estando ou não expostas a fatores de risco. Já a prevenção seletiva é direcionada a uma população sob determinados riscos, sendo necessária uma intervenção mais específica, com foco na educação para os valores e autotranscedência ("ser bom para algo"). Por fim, a prevenção indicada, deve ser oferecida à população que apresente a sensação de vazio existencial, reforçada pela falta de perspectiva de futuro. Embora não se caracterize como um transtorno, o vazio existencial é potencialmente patogênico. Dessa forma, a intervenção tem o objetivo de descentrar o olhar de si mesmo e ativar a capacidade prospectiva. Nessas duas últimas etapas, devem-se promover duas capacidades específicas nos jovens: a liberdade e a responsabilidade (Gismondi, 1998). Tendo em vista as repercussões do sentido da vida para a saúde mental, cabe agora apontar as principais contribuições da logoterapia nas práticas de prevenção e promoção da saúde, o que é discorrido a seguir.

\section{Práticas Preventivas Baseadas na Logoterapia}

Segundo a logoterapia, uma característica comum a todos os seres humanos psiquicamente saudáveis é o fato de que suas ações estão voltadas para algo ou alguém que transcendam a si mesmas, como, por exemplo, a dedicação a uma causa ou a uma pessoa amada (Frankl, 2011). Essa capacidade é denominada de autotranscendência, dimensão própria do ser humano decorrente de sua abertura para o mundo (Frankl, 2005). Destarte, a prevenção deve fomentar a busca de sentido no mundo calcada em valores e significados pessoais (Ortiz, 2006).

Outra característica antropológica é o autodistanciamento, ou seja, a capacidade especificamente humana de se distanciar de si mesmo e das situações. Por meio dela, o ser 
humano se distancia daquilo que o condiciona (psicofísico ou ambiente) e toma uma postura mais adequada, que, de forma geral, preserva a saúde mental apesar das condições desfavoráveis (Frankl, 2005).

Entretanto, as pessoas que perderam a sua saúde mental, de forma geral, colocam como centro de suas preocupações o seu próprio "estado de espírito". Dessa forma, a principal meta da promoção do sentido é fortalecer a capacidade de percepção de valores e sentidos que estejam no mundo, desenvolvendo a autotranscendência (Lukas, 1992), o que, por consequência, proporcionaria maiores níveis de bem estar e satisfação com a vida.

Esse pressuposto tem sido cada vez mais utilizado por profissionais da área de saúde e educação como base teórica para elaboração e execução de trabalhos de prevenção e promoção da saúde (Aquino, 2012). Uma alternativa para o desenvolvimento desse tipo de trabalho é abordagem de grupos. As grupoterapias, além de apresentarem vantagens na relação custo benefício, são estratégias propícias ao desenvolvimento de novas formas de pensar, sentir e agir frente à própria saúde, sendo muito utilizada pelas diversas profissões da área de saúde (Murta, 2008). Sob uma perspectiva da logoterapia, Frankl (2005) relata que "um grupo de encontro adequadamente concebido pode com certeza oferecer um contexto de assistência mútua para a discussão do sentido da vida" (p. 70). Desta forma, percebe-se a aplicabilidade da logoterapia nas intervenções em grupo, onde o participante é estimulado a expor suas experiências vividas, gerando discussões que fomentem a busca pelo sentido vital do ser humano (Frankl, 2005), como nos exemplos descritos a seguir.

Cho (2008) descreve uma intervenção cujo objetivo foi promover o sentido da vida e melhorar a saúde mental de mulheres casadas ou divorciadas de maridos dependentes de álcool. Participaram da pesquisa 19 mulheres no grupo experimental e 21 no grupo controle. A intervenção ocorreu em pequenos grupos, com sessões semanais de 2 horas cada cuja proposta era escrever uma logo-autobiografia, além de partilhar experiências e sentimentos a 
partir da intervenção. Cada sessão do programa foi composta de quatro fases (a) aquecimento - onde era apresentado o tema do dia e reforçada a motivação para a escrita; (b) redação das autobiografias de acordo com o tema do dia, a partir de uma revisão da vida; (c) encontrando o significado - onde se partilhava as experiências, refletia sobre os valores inerentes ao tema e discutia estratégia de modificação de atitudes pessoais - e (d) partilha e encerramento com técnicas para melhorar a autoestima e coesão do grupo. Os resultados mostraram mudanças estatisticamente significativas nos escores de somatização, sintomas depressivos e hostilidade, no grupo experimental. Esses achados sugerem que o programa de logoautobiografia foi benéfico para esta população, bem como se mostrou adequado para melhorar a saúde mental de pessoas que sofrem impactos indiretos do uso e abuso de álcool.

Em outra experiência grupoterápica com usuários de um Centro de Atenção Psicossocial (CAPS) de semi-internação, Leonardi (2011) utilizou a logoterapia como fundamentação teórica para a criação de uma nova abordagem em musicoterapia: a logomúsica. 15 usuários psicóticos e não-psicóticos participaram desse estudo, no município de Ribeirão Preto - SP. O processo do grupo teve a duração de 10 meses em encontros semanais com uma hora de duração. Foram realizadas entrevistas semi-estruturadas, observações antropológicas, implantação de ciclos noéticos (dimensão espiritual), criação coletiva de espetáculo poético-musical, mostra coletiva do espetáculo poético-musical e roda de conversa comunitária. Os resultados, observados nas partilhas durante as rodas de conversa, mostraram imagens de empoderamento na saúde - a partir do desenvolvimento de novas habilidades, redescoberta de uma nova visão de si mesmos e novos sentidos para a vida dos participantes.

Reinhold (2004) realizou uma pesquisa sobre prevenção ao burnout em professores. Por meio de delineamento experimental de pré-teste e pós-teste em dois grupos comparativos, sem grupo controle, envolvendo dois tipos de treinamento de gerenciamento de stress: o TGS 
- Treinamento para Gerenciamento de Stress, consistindo numa adaptação de treinamentos descritos na literatura e o TGSs - Treinamento para Gerenciamento de Stress com abordagem de sentido, compreendendo esses mesmos aspectos, porém acrescido de procedimentos de busca de sentido e clarificação de valores, a partir da visão de Frankl e da logoterapia. Esse estudo contou com a participação de 28 professoras do ensino fundamental de um município do interior de São Paulo. Foram realizadas oito sessões semanais com duas horas cada e uma sessão de acompanhamento. A diferença entre os dois treinamentos consistia na abordagem de questões ligadas ao sentido, nos últimos 20 minutos das sessões do grupo que recebeu o TGSs. Dentre os achados, a pesquisa mostrou uma correlação negativa entre sintomas de stress e percepção de sentido e correlação positiva entre sintomas de stress e despersonalização, uma das dimensões do burnout. Outro achado do estudo é que os participantes do grupo TGS apresentaram maior tendência a burnout que os participantes do grupo TGSs.

Em estudo sobre prevenção ao vazio existencial, Aquino, Silva, Figueiredo, Dourado e Farias (2011), descrevem uma intervenção com adolescentes como estratégia de prevenção em saúde mental a partir da promoção do sentido da vida. A intervenção foi oferecida a 33 adolescentes de uma escola da rede pública de Campina Grande - PB, com idade entre 14 e 18 anos. O delineamento da pesquisa foi quase-experimental, com aplicação de pré-teste e pós-teste. Os resultados sugerem uma adequabilidade e eficácia da intervenção. Os resultados mostraram que houve um aumento no nível de realização existencial e uma diminuição nos níveis de desespero e de vazio existencial, entre os participantes do grupo experimental. No fator desespero existencial, observou-se a ocorrência de uma diferença significativa entre os escores médios do pré-teste e pós-teste apenas para o grupo experimental. Para o fator realização existencial, verificou-se um aumento significativo entre as médias do grupo 
experimental, o que foi também observado no grupo controle. Já o fator vazio existencial apresentou diferenças significativas entre as duas medidas apenas para o grupo experimental.

Sobre a prevenção do suicídio, Lukas (1992), em uma perspectiva da logoterapia, considera que se torna necessário prevenir o surgimento da ideação suicida, pois esta sempre precede o comportamento. A ideia reduz a consciência do valor da vida e é desencadeada por meio de modelos. Assim, no âmbito social, deve-se tentar minimizar os modelos de suicídio que geram a ideação e aumentar a sensação de sentido na vida, sem a qual emerge o sentimento de desvalor acentuado pelo vazio existencial. No entanto, uma frustração existencial não é necessariamente a causa, mas, por outro lado, a realização de sentido é um forte componente para a prevenção: "numa vida vazia e sem sentido falta o porquê de viver, e sem uma resposta para a pergunta 'por que viver?', também não há resposta para a pergunta 'por que não morrer?'” (Lukas, 1992, p. 190).

\section{Considerações finais}

O objetivo principal deste estudo foi descrever conceitualmente o sentido da vida, suas implicações para a promoção da saúde mental e as contribuições da logoterapia para o desenvolvimento de ações de prevenção.

Investir em ações de prevenção e promoção da saúde mental é uma demanda atual e necessária para o desenvolvimento da prevenção como ciência e da atenção à saúde mental no Brasil. Estratégias desse tipo são menos onerosas que intervenções com foco na reparação (WHO, 2004). As evidências de eficácia de programas de prevenção no âmbito da saúde mental, descritos em diversos estudos nacionais e internacionais reforçam a importância desse investimento.

Considerado um elemento importante no desenvolvimento de fatores de proteção para a pessoa, o sentido da vida tem recebido grande atenção de estudiosos, uma vez que a falta de 
sentido tem sido relacionada a desfechos negativos em saúde mental. Assim, desenvolver ações com foco na promoção do sentido da vida tem se mostrado uma estratégia viável para a prevenção de tais desfechos.

Nessa perspectiva, considera-se que a logoterapia, ao trabalhar a liberdade e responsabilidade do indivíduo em suas escolhas, bem como a promoção da busca de sentido, apresenta uma ferramenta adequada nesse trabalho de promoção e prevenção, pois acredita que em cada ser humano existe uma dimensão que pode permanecer sã, apesar das adversidades da vida. Esta postura reforça a autonomia do indivíduo no cuidado com a sua saúde, ainda que aspectos culturais, econômicos, sociais, políticos e históricos devam, necessariamente, também ser considerados. Isso pode ser constatado com os resultados exitosos alcançados nas ações citadas anteriormente, o que sugere que a logoterapia e análise existencial, com seu arcabouço teórico, podem embasar a elaboração de novas ações preventivas em saúde mental, contribuindo assim para o desenvolvimento da ciência da prevenção.

Espera-se que este estudo fomente reflexões que resultem em práticas voltadas para a prevenção e promoção da saúde mental, com foco no sentido da vida, de modo maximizar os fatores de proteção na pessoa e diminuir a incidência de desfechos negativos em saúde mental. Desta forma, mais pessoas poderiam ser beneficiadas com ações planejadas, implementadas e avaliadas de forma sistemática, aumentando a qualidade dos serviços oferecidos à comunidade. 


\section{Referências}

Acevedo, G. (1985). El modo humano de enfermar desde la perspectiva de la logoterapia de Viktor Frankl. Buenos Aires, Argentina: Centro Viktor Frankl para la difusion de la logoterapia.

Abreu, S. O. (2012). Prevenção primária em saúde mental no Brasil na perspectiva da literatura e de especialistas da área. Dissertação de mestrado, Universidade de Brasília, Brasília, DF, Brasil. $\quad$ Recuperado em 05/12/2013 http://repositorio.unb.br/bitstream/10482/11952/1/2012_SamiaAbreuOliveira.pdf.

Aquino, T. A. A. (2015). Sentido da vida e valores no contexto da educação: Uma proposta de intervenção à luz do pensamento de Viktor Frankl. São Paulo: Paulinas.

Aquino, T. A. A. (2013). Logoterapia e análise existencial. São Paulo: Paulus.

Aquino, T. A. A. (2012). Educação para o sentido da vida. Revista Logos e Existência, 1, $160-172$.

Aquino, T. A. A., Silva, J. P., Figueiredo, A. T. B., Dourado, E. T. S., \& Farias, E. C. S. (2011). Avaliação de uma proposta de prevenção do vazio existencial com adolescentes. Psicologia: Ciência e Profissão, 31(1), 146-159.

Baumeister, R. F. (1991). Meanings of life. New York: The Guilford Press.

Cho, S. (2008). Effects of logo-autobiography program on meaning in life and mental health in the wives of alcoholics. Asian Nursing Research, 2(2), 129-139.

Damásio, B. F. (2013). Sentido de vida e bem-estar subjetivo: interações com esperança, otimismo, autoeficácia e autoestima em diferentes etapas do ciclo vital. Tese de doutorado, Universidade Federal do Rio Grande do Sul, RS, PB, Brasil. Recuperado em $20 / 02 / 2014$

http://www.lume.ufrgs.br/bitstream/handle/10183/80120/000903755.pdf?sequence=1. 
Damásio, B. F., Melo, R. L. P., \& Silva, J. P. (2013). Sentido de vida, bem-estar psicológico e qualidade de vida em professores escolares. Paidéia, 23(54), 73-82.

Edwards, M. J. \& Holden, R. R. (2001). Coping, meaning in life, and suicidal manifestations: Examining gender differences. Journal of Clinical Psychology, 57(12),1517-1534.

Fisak, Jr, B. J., Richard, Dan., \& Mann, A. (2011). The prevention of child and adolescent anxiety: A meta-analytic review. Prevention Science, 12, 255-268.

Fizzotti, E. (1998). Abraham Maslow e Viktor E. Frankl: os ritos de cura como autorrealização e como busca de sentido. In A. N. Terrin (Ed.), Liturgia e terapia: a sacralidade a serviço do homem na sua totalidade (pp. 235-275). São Paulo: Paulinas.

Frankl, V. E. (2000). Las raíces de la logoterapia: Escritos juveniles 1923 - 1942. Buenos Aires: San Pablo.

Frankl, V. E. (2003). Psicoterapia e sentido da vida: Fundamentos da logoterapia e análise existencial. São Paulo: Quadrante.

Frankl, V. E. (2005) Um sentido para a vida. Petrópolis: Vozes.

Frankl, V. E. (2008) Em busca de sentido. Petrópolis: Vozes.

Frankl, V. E. (2009) A presença ignorada de Deus. Petrópolis: Vozes.

Frankl, V. E. (2011) A vontade de sentido: Fundamentos e aplicações da logoterapia. São Paulo: Paulus.

Gillham, J. E., Hamilton, J., Freres, D. R., Patton, K., \& Gallop, R. (2006). Preventing depression among early adolescents in the primary care setting: a randomized controlled study of the Penn Resiliency Program. Journal of Abnormal Child Psychology, 34 (2), $203-219$.

Gismondi, A. (1998). Logoterapia e prevenzione del disagio esistenziale giovanile. En: Fizzotti, E., \& Gismondi, A. (Eds). Giovani, vuoto esistenziale e ricerca de senso. Roma: Libreeia Ateneu Salesiano. 
Haditabar, H., Far, N. S., \& Amani, Z. (2013). Effectiveness of logotherapy concepts training in increasing the quality of life among students. International Journal of Psychology and Behavioral Research, 2(4), 223-230.

Hawkins, J. D., Catalano, R. F., \& Arthur, M. (2002). Promoting science-based prevention in communities. Addictive Behaviors, 27(6), 951-976.

Henrion, R. (2002). Alcohol use disorders: Alcohol dependence. International Forum for Logotherapy, 25(1), 30-38.

Ho, M. Y., Cheung, F. M., \& Cheung, S. F. (2010). The role of meaning in life and optimism in promoting well-being. Personality and Individual Differences, 48(5), 658-663.

Immonen, S., Valvanne, J., \& Pitkälä, K.,H. (2011). Older adults' own reasoning for their alcohol consumption. International Journal of Geriatric Psychiatry, 26, 1169-1176.

Kang, K., Im, J., Kim, H., Kim, S., Song, M., \& Sim, S. (2009) The effect of logotherapy on the suffering, finding meaning, and spiritual well-being of adolescents with terminal cancer. Journal of Korean Academy of Nursing, 15(2), 136-144.

King, L. A., Hicks, J. A., Krull, J., \& Del Gaiso, A. (2006). Positive affect and the experience of meaning in life. Journal of Personality and Social Psychology, 90, 179196.

Leonardi, J. (2011). Logomúsica: a criação de um novo approach musicoterápico como veículo na promoção de saúde mental. Tese de doutorado, Universidade de São Paulo, São Paulo, SP, Brasil. Recuperado em 04/06/2014 http://www.teses.usp.br/teses/disponiveis/22/22131/tde-31102011-084343/en.php.

Lukas, E. (1989) Mentalização e saúde: A arte de viver e Logoterapia . Petrópolis: Vozes.

Lukas, E. (1992). Assistência logoterapêutica: Transição para uma psicologia humanizada. Petrópolis: Vozes.

Mascaro, N. \& Rosen, D. H. (2006). The role of existential meaning as a buffer against stress. Journal of Humanistic Psychology, 46(2), 168-190. 
Matos, M. G. \& Spence, S. (2008). Prevenção e saúde positiva em crianças e adolescentes. Em M. G. Matos (Ed.), Comunicação, gestão de conflitos e saúde na escola (pp. 56-73). Lisboa: FMH.

Muñoz, R. E., Mrazek, P. J., \& Haggerty, R. J. (1996). Institute of medicine report on prevention of mental disorders. American Psychologist . 51, 1116-1122.

Murta, S.G. (2008). A prática grupoterápica sob o enfoque psicoeducativo: uma introdução. Em S. G. Murta (Org.), Grupos psicoeducativos: Aplicações em múltiplos contextos (pp. 13-27). Goiânia: Porã Cultural.

Murta, S. G., Rosa, I. O., Menezes, J. C. L., Ribeiro, M. R. S., Borges, O. S., Paulo, S. G., Oliveira, V., Ribeiro, D. C., Del Prette, A., \& Del Prette, Z. (2012). Direitos sexuais e reprodutivos na escola: avaliação qualitativa de um estudo piloto. Psicologia: Teoria e Pesquisa, 28(3), 335-344.

Ortiz, E. M. (2006). Hacia uma prevención com sentido. Bogotá (COL): Colectivo Aqui y Ahora.

Reinhold, H. H. (2004). O sentido da vida: Prevenção do stress e burnout do professor. Tese de doutorado, Pontifícia Universidade Católica de Campinas, Campinas, SP, Brasil. Recuperado em $\quad 15 / 10 / 2013 \quad$ www.bibliotecadigital.puccampinas.edu.br/tde busca/arquivo.php?codArquivo=250.

Reker, G. T. (1997). Personal meaning, optimism, and choice: Existential predictors of depression in community and institutional elderly. The Gerontologist, 37(6), 709-716

Reker G. T. \& Wong P. T. P. (1988). Aging as an individual process: Toward a theory of personal meaning. In Birren J. E., Bengtson V. L. (Eds.), Emergent theories of aging (pp. 214-246). New York, NY: Springer. 
Rosenmayr, L. (1985). Changing values and positions of aging in Western culture. In J. E. Birren \& K. W. Schaie (Eds.), Handbook of the psychology of aging (2nd ed., pp. 190215). New York: Van Nostrand Reinhold.

Schnell, T. (2009). The Sources of Meaning and Meaning in Life Questionnaire (SoMe): Relations to demographics and well-being. Journal of Positive Psychology, 4(6), 483-499.

Scollon, C. N., \& King, L. A. (2004). Is the good life the easy life? Social Indicators Research, 68(2), 127-162.

Soliday, E., Garofalo, J. P., \& Rogers, D. (2004) Expressive writing intervention for adolescents somatic symptoms and mood. Journal of Clinical Child and Adolescent Psychology, 4 (33), 792-801

Sommerhalder, C. (2010). Sentido da vida na fase adulta e velhice. Psicologia: Reflexão e Crítica, 23(2), 270-277.

Steger, M. F. (2009). Meaning in life. In S. J. Lopez (Ed.), Oxford handbook of positive psychology (2nd ed., pp. 679-687). Oxford: Oxford University Press.

Stice, E., Rohde, P., Gau J., \& Shaw H. (2012). Effect of a dissonance-based prevention program on risk for eating disorder onset in the context of eating disorder risk factors. Prevention Science, (13), 129-139.

Ulusoy, Y. \& Duy, B. (2013). Effectiveness of a psycho-education program on learned helplessness and irrational beliefs. Educational Sciences: Theory \& Practice, 13(3), $1440-1446$.

Verma, R. K., Pulerwitz, J., Mahendra, V., Khandekar, S., Barker, G., Fulpagare, P., \& Singh, S. K. (2006) Challenging and changing gender attitudes among young men in Mumbai, India. Reproductive Health Matters, 14, 135-143. 
World Health Organization (2004). Prevention of mental disorders - effective interventions and policy options. Paris, França. Retirado de: http://www.who.int/mental_health/evidence/en/prevention_of_mental_disorders_sr.pdf. 
Manuscrito 3

Avaliação de resultados e processo de uma intervenção para prevenção do vazio existencial entre adolescentes. 


\section{Resumo}

O objetivo deste estudo foi avaliar o processo de implementação e os resultados alcançados em uma intervenção para prevenção do vazio existencial entre adolescentes. Participaram da pesquisa 47 adolescentes de ambos os sexos, em grupo, com idades entre 15 e 17 anos, distribuídos em duas condições: experimental $(\mathrm{N}=22)$ e controle $(\mathrm{N}=25)$. A avaliação de processo incluiu medidas de satisfação, validade social, engajamento e compreensão das atividades por parte dos adolescentes. Foram realizadas também avaliações de pré e pós testes para as variáveis presença de sentido, busca de sentido, afetos positivos, afetos negativos e elaboração de metas. Os resultados revelaram um aumento na percepção de sentido de vida; diminuição de afetos negativos e a existência de planos futuros específicos, indicando evidências favoráveis à eficácia da intervenção. Foi observado ainda como positivo o engajamento dos adolescentes, a satisfação e a percepção de relevância da intervenção. Sugerem-se novos estudos, experimentais, com amostras maiores e avaliação de follow-up. Palavras-chave: sentido da vida, promoção da saúde, adolescentes, grupoterapia 


\begin{abstract}
The objective of this study was to evaluate the implementation process and achievements in an intervention for prevention of existential emptiness among adolescents. The participants were 47 adolescents of both sexes in the group, aged between 15 and 17 years, distributed in two groups: experimental $(\mathrm{N}=22)$ and control $(\mathrm{N}=25)$. The process of evaluation included satisfaction measures, social validity, engagement and understanding of activities by the teenagers. Also assessments were performed pre and post tests for the presence of meaning, search for meaning, positive affect, negative affect and development goals. The results revealed an increase in the perception of meaning in life; decrease of negative affects and the existence of specific future plans, indicating evidence favorable to the effectiveness of the intervention. It was also noted as positive the engagement of adolescents, satisfaction and perceived relevance of the intervention. Suggest new studies, experimental, with larger samples and evaluation of follow-up.
\end{abstract}

Keywords: meaning in life, health promotion, teenagers, group therapy 


\section{Avaliação de resultados e processo de uma intervenção para prevenção do vazio existencial entre adolescentes.}

O Brasil possui cerca de 10,3 milhões de jovens adolescentes entre 15 e 17 anos, segundo dados da Secretaria Nacional de Juventude - SNJ (2014a). Estudo de Malta et al. (2011), revelou que entre adolescentes escolares do nono ano, 71,4\% já haviam experimentado álcool ao menos uma vez, 27,3\% faziam uso regular de álcool e cerca de 8,7\% já haviam experimentado outras drogas. Dados obtidos por Nascimento e Avallone (2013) em estudo com adolescentes estudantes do $9^{\circ}$ ano do ensino fundamental ao $3^{\circ}$ ano do ensino médio apontam para cenário semelhante. Esses dados revelaram que $27 \%$ dos adolescentes faziam uso abusivo de substâncias psicoativas e 5\% eram dependentes. No que diz respeito à depressão, estudos nacionais encontraram indícios depressivos clinicamente significativos em 5,3\% e 5,1\% das amostras adolescentes (Baptista, Baptista, \& Dias, 2001; Bardagi, 2002). Esses índices se aproximam do encontrado por Reppold e Hutz (2003), entre adolescentes do Rio Grande do Sul, com idades entre 14 e 15 anos, que foi de 5,7\%. Entre os jovens chega a 42,7\% (Salle, Segal, \& Sukiennik, 1996). Um quadro clínico de depressão, se agravado, pode desencadear ideias e tentativas de suicídio. A taxa de suicídio na população jovem brasileira chega a 5,6 por 100 mil habitantes, de acordo com os dados de Waiselfisz (2014). Toda essa sintomatologia, associada a variáveis contextuais - falta de perspectivas de educação e trabalho, por exemplo - pode ser desencadeada ou maximizada pela sensação de que a vida carece de um significado ou sentido (Frankl, 2005).

Esse cenário resulta em uma preocupação do poder público com esse "capital humano e social" que deve ser preservado, considerando o desenvolvimento socioeconômico do país e da própria população que sofre com o vazio de políticas públicas de caráter preventivo (SNJ, 2014b). Essa escassez de estratégias de prevenção em saúde mental no Brasil pode ser confirmada pela pequena produção científica, revelada por estudos nacionais (Murta, 2007; 
Löhr, Pereira, Andrade, \& Kirchner, 2007; Abreu, 2012). Em pesquisa sobre a construção do conhecimento em programas de prevenção em saúde mental no Brasil, Abreu (2012) apresenta um mapeamento de 4.131 publicações, que indicavam como foco de estudo a prevenção. Desse universo, somente $651(15,76 \%)$ faziam referência à prevenção em saúde mental. No entanto, excluindo as resenhas, os estudos repetidos e os que indicavam tratamento de algum transtorno psiquiátrico, apenas 374 publicações, de fato, referiam-se a estudos em prevenção em saúde mental. Destes, 25 artigos descreviam 42 programas sistematicamente avaliados. Essa realidade indica a necessidade de maior investimento em ações de promoção e prevenção, pois fortalecem os fatores de proteção, diminuem o risco de adoecimento, além de representar menor custo com ações com fins de remediação (WHO, 2011). Se considerarmos ações de prevenção com foco no sentido da vida, essa escassez relatada por Abreu (2012) se acentua.

Tendo em vista adolescentes como público-alvo, foi encontrado apenas um estudo descrevendo uma intervenção para prevenção do vazio existencial (Aquino, Silva, Figueiredo, Dourado, \& Farias, 2011). De certa forma, pensar em ações de promoção do sentido da vida implica em compreender como este constructo incide na saúde mental das pessoas e na percepção de bem-estar por parte destas. Para tanto, são apresentados a seguir conceitos-base de bem-estar e sua relação com o constructo sentido de vida, tomando-se por base as contribuições da Logoterapia de Viktor Frankl.

\section{Bem-estar subjetivo e sentido da vida}

As concepções mais atuais sobre bem-estar podem ser organizadas em duas perspectivas: bem-estar subjetivo (BES) e bem-estar psicológico (BEP). O BES seria composto por uma dimensão cognitiva - a percepção que o indivíduo tem dos níveis de satisfação com a vida - e uma dimensão emocional - a vivência, pelo indivíduo, de emoções positivas e negativas (Diener, Suh, \& Oishi, 1997). Em contraposição a esta concepção, Ryff 
e Keyes (1995) propõem o conceito de BEP, no qual se destacam o funcionamento positivo e as potencialidades humanas relacionadas entre si: autonomia, propósito de vida, domínio do ambiente, crescimento pessoal, autoaceitação e relacionamento positivo com os outros. Essa compreensão tem sido fortalecida pelos pressupostos da psicologia positiva (Seligman \& Csikszentmihalyi, 2000). Para esses autores, uma ciência que se preocupe com a experiência subjetiva positiva, com as forças positivas individuais e com as instituições positivas, como democracia, liberdade, família, pode contribuir mais para a prevenção e manutenção de uma boa saúde mental.

Segundo Seligman (2011) a teoria do bem-estar, proposta pela psicologia positiva, é composta por cinco elementos: (1) emoção positiva, definidas como emoções que contribuem para o bem-estar e felicidade na vida; (2) engajamento, que compreende o esforço investido em uma situação, projeto ou tarefa; (3) relacionamentos positivos, que referem-se a vivenciar sentimentos de empatia e afeição pelas pessoas, capacidade de amar e de se identificar com o outro; (4) realização, que diz respeito ao domínio de habilidades que leve o indivíduo a alcançar objetivos significativos e (5) sentido da vida, que consiste em encontrar um significado para o que se faz. Este último elemento, o sentido da vida, tem se constituído como objeto de estudo em investigações dentro da ciência psicológica (Aquino et al., 2015; Damásio, 2013; Leonardi, 2011; Gomes, 2009; Steger, 2009; Reinhold, 2004). Estudos internacionais têm demonstrado correlações positivas entre presença de sentido e bem-estar subjetivo (Doğana, Sapmaz, Tel, Sapmaz, \& Temizel, 2012; Debats, Lubbe \& Vezeman, 1993) e entre sentido da vida e satisfação com a vida (Bonebright, Clay, \& Ankenmann, 2000).

O interesse da psicologia nas investigações sobre o sentido da vida se acentuou especialmente após a Segunda Guerra Mundial, com Viktor Frankl. Em suas experiências nos campos de concentração por onde passou, Frankl observou que as pessoas que não tinham um 
propósito definido para suas vidas, morriam mais cedo do que aqueles que percebiam um significado para suas vidas (Frankl, 2011). Para o autor em questão, o sentido da vida pode ser compreendido como a motivação primária do ser humano, funcionando como um fator de proteção interno do indivíduo.

Frankl (2005) foi o criador de uma escola psicoterápica denominada Logoterapia, que busca compreender o ser humano a partir de três dimensões: (1) a dimensão somática, (2) a dimensão psíquica e (3) a dimensão espiritual ou noética (do grego noos, noetos = mente ou espírito). A dimensão somática refere-se aos fenômenos corporais, orgânicos do homem e sua estrutura vital fisiológica. A dimensão psíquica revela-se na existência do homem em suas disposições, impulsos, instintos, sensações, desejos, bem como seus aspectos cognitivos e padrões de comportamentos adquiridos. Já a dimensão espiritual é aquela da qual se derivam os fenômenos especificamente humanos, responsável pelas tomadas de posição do ser humano diante das circunstâncias da vida e onde estão sua intencionalidade, senso ético e compreensão de valores (Lukas, 1989). Segundo a compreensão da logoterapia, essa última dimensão permanece sã, independente da situação vivenciada pelo homem.

Esse sistema de psicoterapia está fundamentado em três perspectivas intercomplementares: a liberdade da vontade, a vontade de sentido e o sentido da vida. A liberdade de vontade, segundo Frankl (2005), é dada ao homem, pelo menos potencialmente e se opõe ao determinismo. Ela revela que o homem é um ser livre e responsável para decidir diante das possibilidades de que a vida dispõe, mesmo que em determinados momentos essa liberdade possa sofrer restrições. Para o autor em questão, “o homem não é livre de certas condições. Mas é livre para tomar posições diante delas” (Frankl, 2005, p. 42). A vivência dessa liberdade abre a possibilidade do homem diminuir os limites impostos à sua liberdade por condicionamentos biológicos, sociais e psicológicos. Na vontade de sentido está o que Frankl $(2005,2011)$ nomeou como motivação primária e autêntica do ser humano. Refere-se 
a um interesse inerente e contínuo do homem pelo significado da sua vida. Já o sentido da vida consiste no caráter incondicional da vida (Aquino, 2013; Lukas, 1989). Cada ser humano tem (ou deveria ter) um sentido específico e exclusivo para sua própria existência, posto que esse sentido é pessoal e situacional. Pode estar relacionado tanto a uma situação singular quanto a sentidos universais (Frankl, 2003). O sentido difere de pessoa para pessoa, considerando também o momento que cada um vivencia. Portanto, o mais importante não é o sentido da vida de um modo geral, mas o sentido específico da vida da pessoa em dado momento. O sentido da vida é uma descoberta pessoal (Frankl, 2011).

Embora Frankl enfatize que a motivação primária do homem é encontrar um sentido para a sua existência, essa vontade de sentido pode ser frustrada em sua busca, gerando o que o autor nomeou vazio existencial (Frankl, 2011; Aquino, 2013), que se caracteriza como uma sensação de falta de sentido para a vida; a percepção de que a existência carece de um propósito. "O vazio existencial manifesta-se principalmente num estado de tédio" (Frankl, 2011 p. 131), desorganizando a vida do indivíduo, colocando-o numa situação onde não sabe nem mesmo o que deseja fazer. Assim, ele passa a viver em um conformismo (deseja fazer o que os outros fazem) ou em um totalitarismo (deseja fazer o que os outros querem que faça), impactando negativamente em sua liberdade de vontade (Frankl, 2011, 1990).

O vazio existencial apresenta uma sintomatologia, que Frankl (2005) denominou de tríade da neurose de massa: depressão, agressão e toxicodependência. No entanto, o autor reconhece que existem outras formas de expressão do vazio existencial. A vontade de sentido frustrada pode manifestar-se, de forma mascarada, através de uma busca exagerada pelo prazer ou pelo poder. $\mathrm{O}$ autor em questão ainda aponta como possível sintoma, o que chamou de neurose dominical, a sensação de falta de sentido que o indivíduo experimenta quando cessa a rotina do trabalho semanal, e o vazio se torna manifesto (Frankl, 2011). 
A etiologia do vazio existencial pode ser atribuída a perdas que o ser humano sofreu no decorrer de sua evolução: a perda dos instintos e da tradição. A natureza instintiva do homem era responsável por regular determinados comportamentos que asseguravam sua existência. Com essa perda o homem precisou construir a si próprio, fazer opções. Por outro lado, as tradições indicavam como o homem devia agir, transmitindo-lhe valores que serviam como guia para sua ação (Frankl, 2011; Aquino, 2013). Apesar do declínio das tradições é possível encontrar o sentido, uma vez que este é situacional, único e individual, não seriam transmitidos pelas tradições. Somente os valores, que segundo Frankl (2005) poderiam ser definidos como significados universais podem ser influenciados por esse declínio.

De acordo com Frankl (2005), há uma hierarquia de valores que podem dar sentido às ações e vida do homem. Assim sendo, os valores se apresentam como vias para encontrar o sentido da vida, através do que Frankl chamou de: valores de criação, que incluem encontrar sentido através de um ato, criação ou produção de uma obra; valores de experiência, que consistem em encontrar o sentido ao vivenciar algo ou alguém em sua originalidade; e valores de atitudes, que se manifestam pela forma como se posiciona diante de um sofrimento inevitável ou situações limite que fogem à capacidade humana de superá-la, encontrando desta forma, um sentido onde parecia não haver (Frankl, 2005, 1990; Xausa, 1986).

A postura axiológica da logoterapia sugere que o sentido da vida não deve ser procurado dentro da pessoa humana, tendo em conta que os valores se encontram no mundo. Por conseguinte, o homem deveria se abrir para o mundo, dirigir-se para algo ou alguém externo, diferente de si mesmo. Esta característica, inerente ao ser humano, Frankl (2005) denominou de autotranscendência. Aqui reside a principal diferença entre a logoterapia e as abordagens humanistas, pois Frankl não reconhece a autorrealização como a meta mais alta da existência humana e sim, a autotranscendência. O homem se humaniza à medida que se 
volta para o outro, para uma causa, que possua um caráter de missão. (Frankl, 2011, 2005, 1990; Lukas, 1989).

\section{Prevenção ao vazio existencial}

A prática preventiva em Logoterapia teve início com a criação dos postos de aconselhamento para a juventude, idealizados por Frankl, com o objetivo de reduzir o número de suicídios entre jovens da Europa Central (Aquino, Damásio, \& Silva, 2012). Como um sistema terapêutico que sempre trabalha com a dimensão saudável do ser humano, a prevenção a partir da visão da logoterapia objetiva oferecer às pessoas condições de enfrentarem os desafios e adversidades da vida. A justificativa para proteger-se se sustenta no fato da vida possuir um significado, um sentido (Lukas, 1992). O sentido possui um valor protetivo para o psicofísico, tendo em conta que é uma condição necessária para a sobrevivência do ser humano (Frankl, 2011).

A partir desta perspectiva, Aquino et al. (2011) desenvolveram e avaliaram uma proposta para prevenção do vazio existencial junto a 33 adolescentes de uma escola da rede pública de Campina Grande, Paraíba. Realizou-se um estudo quase-experimental, em que os participantes da condição experimental receberam uma intervenção de 15 encontros com as seguintes temáticas: a dimensão do espírito humano; vontade de sentido; liberdade versus responsabilidade; autotranscendência; conformismo versus totalitarismo; descobrindo nosso valor como ser humano; encontrar sentido em situações-limite; dizer sim para a vida apesar de tudo; o suprassentido; a descoberta de sentido e projeto de vida. Os participantes das condições experimental e controle foram expostos a avaliações de pré e pós-teste, por meio do Teste de Propósito de Vida, de Crumbaugh e Maholich (1964), adaptado e validado à realidade brasileira por Aquino et al. (2009). Esse instrumento avalia o grau de vazio existencial, desespero existencial, bem como o nível de realização de sentido na vida. 
Os resultados mostraram que houve um aumento no nível de realização existencial e uma diminuição nos níveis de desespero e de vazio existencial, entre os participantes do grupo experimental. Para o fator realização existencial, verificou-se um aumento significativo entre as médias tanto do grupo experimental, quanto do grupo controle. Os dois grupos, portanto, aumentaram a sensação de sentido de vida. A mudança observada no grupo controle pode ser resultado de uma relação mais próxima entre os participantes das duas condições, experimental e controle, uma vez que, frequentando a mesma sala de aula, partilhavam de espaços de convivência comum, durante a realização da pesquisa. Esse fato sinalizou a necessidade de novos estudos que controlassem a difusão entre tratamentos (Kazdin, 2010) para obtenção de conclusões mais claras. Não foram realizadas avaliação de processo e de follow-up nesse estudo.

Resultados como os obtidos por Aquino et al. (2011) se somam aos de outras poucas intervenções com foco na promoção do sentido vida para adolescentes, que têm encontrado resultados positivos, associados a uma melhora na qualidade de vida de adolescentes (Haditabar, Far, \& Amani, 2013) e ao aumento no bem-estar psicológico em pacientes com diagnóstico de câncer (Kang et al., 2009). São igualmente escassos na literatura nacional estudos de intervenções para promoção de sentido da vida em adolescentes. Além da proposta de Aquino et al. (2011), foram encontrados apenas estudos em populações adultas, com resultados positivos para a promoção da autonomia e aumento da qualidade de vida de pacientes psicóticos (Leonardi, 2011) e prevenção do burnout em professores (Reinhold, 2004). Portanto, são ainda poucos os estudos nacionais com propósitos preventivos e de promoção de sentido da vida em fases iniciais do ciclo da vida. Deste modo, novos estudos de avaliação da intervenção realizada por Aquino et al. (2011), assim como o desenvolvimento de outros programas com finalidade similar, poderiam expandir as evidências disponíveis acerca dos benefícios desta modalidade de intervenção preventiva de vazio existencial e promotora de bem-estar entre adolescentes. 
Tendo em conta as considerações supracitadas, o objetivo geral deste estudo foi replicar a intervenção para prevenção do vazio existencial entre adolescentes, proposta por Aquino et al. (2011), ampliando sua avaliação, com foco no seu processo de implementação e resultados. A avaliação de processo associada à avaliação de resultado permite compreender como a intervenção foi conduzida e recebida pelos participantes. Adicionalmente, a avaliação de processo facilita a interpretação dos resultados e lança luz sobre dimensões a serem aprimoradas em implementações posteriores do programa (Berkel, Mauricio, Schoenfelder, \& Sandler, 2011). Neste sentido, foram objetivos específicos deste estudo, no que diz respeito à avaliação de resultado: (a) aferir, ao início e ao final da intervenção os escores de busca e presença de sentido entre os adolescentes participantes e não participantes da intervenção; (b) averiguar nas medidas de pré e pós-teste, os índices de afetos positivos e negativos entre os adolescentes participantes e não participantes da intervenção. Quanto à avaliação de processo, buscou-se: (c) identificar no discurso dos adolescentes participantes elementos que apontem para a elaboração de projetos de vida; (d) avaliar a compreensão das atividades propostas e o engajamento dos adolescentes nestas; (e) verificar o significado atribuído pelos adolescentes à intervenção e a importância desta para a sua vida cotidiana e (f) descrever a satisfação dos adolescentes em relação à intervenção.

\section{Método}

\section{Participantes}

Inicialmente foram convidados para participar do estudo 102 adolescentes, de ambos os sexos, com idades entre 15 e 17 anos. Os participantes foram recrutados em uma instituição sem fins lucrativos, da cidade de Brasília-DF, que presta serviços socioassistenciais a crianças, adolescentes, jovens e seus familiares. Todos os adolescentes estavam inseridos no Serviço de Educação Socioprofissional e Promoção de Inclusão 
Produtiva para Jovens de 14 a 24 anos, programa executado pela instituição e que tem como objetivos gerais a formação pessoal e a preparação para o mundo do trabalho de adolescentes e jovens em situação de risco e vulnerabilidade social.

Os adolescentes foram distribuídos nos grupos experimental (GE) e controle (GC) por conveniência, isto é, por pertencerem à mesma turma e estarem disponíveis para participar da intervenção. Não houve randomização da amostra, utilizando-se desta forma um delineamento quase-experimental (Kazdin, 2010). Durante a intervenção não havia contato entre os participantes do GE e GC, pois cada grupo frequentava a instituição uma vez por semana, em dias diferentes. Para a amostra final foram considerados somente os dados dos participantes que responderam às avaliações de pré e pós-teste, totalizando 25 adolescentes no GC e 22 adolescentes no GE. 11 adolescentes do sexo masculino e 11 do sexo feminino, com idades entre 15 e 17 anos $(\mathrm{dp}=0,468)$, compuseram o GE, enquanto que no GC, 12 adolescentes do sexo masculino e 13 do sexo feminino, com idades entre 16 e 17 anos $(\mathrm{dp}=$ $0,490)$.

\section{Instrumentos}

Questionário de Avaliação Sociodemográfica (Anexo A). Composta por 25 perguntas fechadas, utilizada para coletar dados sobre gênero, idade, filiação, condições de moradia, bens de consumo, classe social e rede de apoio social dos participantes.

Questionário de Sentido da Vida (Anexo B). Instrumento originalmente proposto por Steger et al. (2006) e validado no Brasil por Damásio (2013), composto por 10 itens que objetiva avaliar os índices de busca e presença de sentido na vida, respondidos em uma escala de 1 (totalmente falsa) a 7 (totalmente verdadeira). A validação deste instrumento para o Brasil se deu com uma população de 3020 participantes, com idades entre 18 e 91 anos, em 22 estados brasileiros, que demonstrou que ambas as escalas - presença de sentido (Eu entendo o sentido 
de minha vida) e busca de sentido (Estou buscando sentido na minha vida) - apresentaram excelentes propriedades psicométricas, com alfa de Cronbach $(\alpha)=0,88$ e $(\alpha)=0,85$, respectivamente.

Escala de Afetos Positivos e Negativos (Anexo C). Instrumento originalmente elaborado por Diener e Emmons (1984) para avaliar a valência dos afetos formada por nove adjetivos, sendo quatro positivos (feliz, alegre, satisfeito e divertido) e cinco negativos (deprimido, preocupado, frustrado, raivoso e infeliz). Foi validado no Brasil por Chaves (2003), com o objetivo de equilibrar o número de adjetivos para ambos os tipos de afetos, acrescentou em sua pesquisa mais um adjetivo para o afeto positivo: otimista. A escala de 10 itens, respondidos numa escala de sete pontos, variando de 1 (Nada) a 7 (Extremamente), foi validada numa amostra de 306 participantes da cidade de João Pessoa-PB, com idade a partir de 18 a 84 anos. Os coeficientes de confiabilidade foram 0,81 e 0,78 para os afetos positivos e negativos, respectivamente (Chaves, 2003).

Diário de Emoções (Anexo D). Instrumento elaborado pelo pesquisador para esse estudo, composto por tabela com 15 desenhos representando sete emoções positivas, sete emoções negativas e uma desconhecida, escolhidas de forma aleatória e submetida a consulta de um grupo de adolescentes e profissionais clínicos, com o objetivo de avaliar ao final de cada encontro, a satisfação dos participantes em relação à intervenção, a partir do relato de emoções experimentadas na sessão.

Árvore da Minha Vida (Anexo E). Instrumento criado pelo pesquisador para o presente estudo, com o objetivo de avaliar a validade social da intervenção, definida como a percepção de relevância dos procedimentos da intervenção pelos participantes (Lane \& BeebeFrankenberger, 2004). Os participantes foram convidados a preencher os espaços em branco nas folhas da árvore, com os conteúdos da intervenção, avaliados como significativos para suas vidas. 
Carta a um Amigo. Utilizou-se uma folha em branco para redigir uma carta a um amigo, após uma visualização criativa para promover uma sensibilização e consciência corporal nos participantes $\mathrm{O}$ objetivo dessa técnica foi avaliar a perspectiva de futuro na elaboração de planos, sonhos e metas, indicando elementos na construção de um projeto de vida dos adolescentes.

Diário de Campo. Consistia em uma caderneta de anotações onde o pesquisador registrava falas dos participantes que considerava significativas, além de suas percepções sobre o processo grupal. O diário foi utilizado para avaliar a compreensão das atividades propostas e o engajamento dos participantes nessas atividades foram utilizados, juntamente com os registros das sessões. Serviu também para fundamentar os ajustes metodológicos no decorrer da intervenção.

\section{Procedimentos}

Recrutamento. O processo de recrutamento dos participantes foi composto por seis tentativas, em diferentes instituições educacionais para adolescentes, das quais apenas a última tentativa foi exitosa. Inicialmente, o público alvo da pesquisa era composto por jovens universitários, em seu primeiro ano de universidade. A principal dificuldade apontada pela universidade para aceitar a pesquisa foi o tempo de duração da intervenção, previsto inicialmente para 15 encontros. Em vista disto, optou-se por alterar o público-alvo e direcionar a intervenção para adolescentes em ensino médio, ao mesmo tempo em que se reduziu a duração da intervenção. Após sua redução para 11 sessões, a mesma dificuldade foi apontada por outras quatro instituições contatadas em seguida, devido à grade curricular extensa. Por fim, após nova adaptação na quantidade de sessões, contemplando o conteúdo original e reduzindo o seu número para seis sessões, o programa foi oferecido a uma sexta instituição, a qual concordou em participar do estudo. 
Coleta de Dados. Ambos os grupos, experimental e controle, responderam às medidas de pré e pós-teste. Ao grupo experimental foi oferecida uma intervenção, no formato grupal centrada na leitura de poemas, fábulas e parábolas provenientes da literatura geral e reflexões baseadas em uma relação dialógica. A intervenção se desenvolveu em seis encontros de 150 minutos cada, com periodicidade semanal, totalizando 15 horas, distribuídas em um mês e meio.

O GE foi composto por duas turmas de adolescentes, que esncontravam em dias distintos da semana. A fim de assegurar que os grupos receberiam a mesma intervenção foi elaborado um roteiro prévio com temas e técnicas específicas de cada encontro, buscando favorecer a fidelidade ao conteúdo da intervenção original (Aquino, 2015; Aquino et al., 2011). O roteiro dos encontros está descrito integralmente em Aquino (2015) e sumarizado na Tabela 1.

Tabela 1

Roteiro da Intervenção para Prevenção do Vazio Existencial

Tema Objetivo Técnicas

\begin{tabular}{|c|c|c|}
\hline $\begin{array}{l}\text { Sessão } 1 \text { - A dimensão do } \\
\text { espírito humano e vontade } \\
\text { de sentido. }\end{array}$ & $\begin{array}{l}\text { Avaliação de pré-teste; } \\
\text { Refletir sobre a dimensão } \\
\text { especificamente humana, } \\
\text { sobre o estilo de vida dos } \\
\text { participantes e sobre a } \\
\text { motivação do ser humano } \\
\text { perante a sua existência } \\
\text { finita. }\end{array}$ & $\begin{array}{l}\text { - Apresentação da proposta de } \\
\text { intervenção; } \\
\text { - Técnica de apresentação pessoal; } \\
\text { - Aplicação do pré-teste; } \\
\text { - Textos: "A águia e a galinha" e "Um } \\
\text { - Sábio e um equilibrista"; } \\
\text { - Diário de Emoções. }\end{array}$ \\
\hline $\begin{array}{l}\text { Sessão } 2 \text { - Liberdade x } \\
\text { responsabilidade e } \\
\text { Autotranscendência. }\end{array}$ & $\begin{array}{l}\text { Refletir sobre as dimensões } \\
\text { do existir humano: a } \\
\text { liberdade e a } \\
\text { responsabilidade e o } \\
\text { conceito de } \\
\text { autotranscendência, para } \\
\text { Viktor Frankl. }\end{array}$ & $\begin{array}{l}\text { - } \quad \text { Aquecimento; } \\
\text { - Textos: "A estrada que não tomei" e } \\
\text { "Os dois meninos"; } \\
\text { - Técnica "O que estou fazendo? O } \\
\text { - que posso fazer?"; } \\
\text { - Diário de Emoções. }\end{array}$ \\
\hline $\begin{array}{l}\text { Sessão } 3 \text { - Conformismo x } \\
\text { totalitarismo e } \\
\text { descobrindo nosso valor } \\
\text { como ser humano }\end{array}$ & $\begin{array}{l}\text { Discutir sobre esses dois } \\
\text { sintomas do vazio } \\
\text { existencial que } \\
\text { caracterizam a sociedade } \\
\text { atual e Ampliar a } \\
\text { consciência sobre o valor }\end{array}$ & $\begin{array}{l}\text { - Aquecimento; } \\
\text { - Textos: "A roupa nova do rei”, “O } \\
\text { menininho e flor vermelha” e } \\
\text { "Assembleia das ferramentas"; } \\
\text { - Técnica: Qualidade e valores; } \\
\text { - Diário de Emoções }\end{array}$ \\
\hline
\end{tabular}




\begin{tabular}{|c|c|c|}
\hline & $\begin{array}{l}\text { da vida e a dignidade do } \\
\text { ser humano. }\end{array}$ & \\
\hline $\begin{array}{l}\text { Sessão } 4 \text { - Encontrar } \\
\text { sentido em situações- } \\
\text { limite e dizer sim para a } \\
\text { vida apesar de tudo. }\end{array}$ & $\begin{array}{l}\text { Refletir sobre as } \\
\text { possibilidades de sentido } \\
\text { nas situações imutáveis da } \\
\text { vida e sobre as posturas e } \\
\text { atitudes perante as } \\
\text { dificuldades da vida. }\end{array}$ & $\begin{array}{l}\text { - } \quad \text { Aquecimento; } \\
\text { - Textos: "As duas jóias" e “O } \\
\text { alpinista"; } \\
\text { - Diário de Emoções }\end{array}$ \\
\hline $\begin{array}{l}\text { Sessão } 5 \text { - O suprassentido } \\
\text { e a descoberta de sentido }\end{array}$ & $\begin{array}{l}\text { Refletir sobre a } \\
\text { incondicionalidade do } \\
\text { sentido da vida. }\end{array}$ & $\begin{array}{l}\text { - Aquecimento; } \\
\text { - Textos "Criador e criatura" e "Tudo } \\
\text { depende só de mim"; } \\
\text { - Técnica: Quebra-cabeça; } \\
\text { - Diário de Emoções }\end{array}$ \\
\hline $\begin{array}{l}\text { Sessão } 6 \text { - Projeto de vida, } \\
\text { avaliação final e pós-teste. }\end{array}$ & $\begin{array}{l}\text { Estimular os participantes a } \\
\text { construir seu projeto de } \\
\text { vida, avaliação de pós } \\
\text { teste. }\end{array}$ & $\begin{array}{l}\text { - Aquecimento; } \\
\text { - Texto "O escultor"; } \\
\text { - Técnicas "O relógio de areia", "Carta } \\
\text { a um Amigo", } \\
\text { - Diário de Emoções; } \\
\text { - Árvore da vida; } \\
\text { - } \quad \text { Aplicação de pós-teste. }\end{array}$ \\
\hline
\end{tabular}

Foram utilizadas técnicas de dinâmicas de grupo, exercícios corporais para aquecimento e relaxamento, visualização criativa e diálogo socrático. De modo geral, as sessões eram compostas por atividades em pequenos grupos e atividades individuais. Inicialmente, os adolescentes eram instruídos sobre o tema e objetivos do dia e recebiam os textos para leitura ou assistiam a vídeos, com perguntas norteadoras para reflexão. Em seguida, todos compartilhavam suas respostas, estimulados pelo pesquisador a estabelecerem um paralelo com o momento que cada um vivenciava. Ao final de cada uma das sessões os participantes foram convidados a avaliar sentimentos e satisfação em relação à sessão e estimulados a continuar a reflexão no decorrer da semana. Com o objetivo de tornar a intervenção mais atrativa algumas atividades que previam leitura de textos foram substituídas por vídeos e animações, preservando o conteúdo do texto proposto.

$\mathrm{Na}$ última sessão, para avaliar a existência de metas, planos e objetivos futuros, utilizou-se uma técnica criada pelo pesquisador, a partir de sua vivência pessoal e 
profissional, onde foi solicitado aos adolescentes que projetassem suas vidas em 20 anos no futuro, imaginando o que poderia ter acontecido nesse intervalo de tempo. Logo após, foram solicitados a escrever uma carta a um amigo, com quem não tivessem tido contato durante todo esse período da vida, contando-lhe como estavam naquele momento e o que havia acontecido em suas vidas.

Análise de Dados. Para a análise qualitativa foi utilizado a análise temática, cuja categorização dos conteúdos registrados no decorrer da intervenção seguiram o modelo proposto por Braun e Clarke (2006). Inicialmente os dados foram lidos várias vezes separadamente, sendo destacados os temas que se sobressaíam nas falas dos adolescentes; em seguida esses temas foram sendo revistos e agrupados em categorias estabelecidas pelo pesquisador. Um segundo pesquisador foi consultado com o objetivo de estabelecer a diferenciação das categorias. Por fim, foram quantificadas as frequências desses temas nos relatos dos participantes. Para gerar a nuvem de palavras foi utilizado o Wordle, aplicativo on line que destaca as palavras que aparecem mais vezes em um texto.

Para os dados quantitativos, utilizou-se o SPSS (versão 18) para, inicialmente tabular os dados e extrair os escores brutos dos fatores da escala. Para o presente estudo, utilizaramse estatísticas descritivas (médias e desvios padrões). Com a finalidade de verificar diferenças entre as medidas (presença de sentido, busca de sentido, afetos positivos e afetos negativos) no pré-teste e no pós-teste, empregou-se o Teste $t$ para medidas repetidas em função dos grupos constituídos: GE e GC.

\section{Considerações éticas.}

A pesquisa foi registrada no Comitê de Ética em Pesquisa do Instituto de Ciências Humanas da UnB, sob o número 37157214.5.0000.5540 (Anexo F). Os participantes foram informados sobre a confidencialidade dos dados individuais, assinaram um termo de 
assentimento (Anexo $G$ ) e seus pais assinaram um termo de consentimento livre e esclarecido (Anexo $H)$.

\section{Resultados}

\section{Caracterização sociodemográfica}

A Tabela 2 mostra a caracterização da amostra de acordo com as condições de cada grupo de adolescentes. Dentre os dados apresentados, chama a atenção a alta percentagem de adolescentes que não participam de nenhum grupo: GE 1 (30,8\%), GE 2 ( 44,4\%) e GC (40\%) com uma média de participação de 1,31 grupos no GE 1 (DP 1,251), 0,56 grupo no GE $2(D P$ 0,527) e 0,80 grupo no GC (DP 0,816). Quanto à classificação socioeconômica, destaca-se a quantidade de participantes que estão nas classes B e A, de acordo com Critério de Classificação Brasil 2015 da Associação Brasileira de Empresas de Pesquisas - ABEP. Adotando somente o critério de renda per capita da própria ABEP, todos os participantes estariam inseridos nas classes D/E (renda per capita abaixo de $\mathrm{R} \$ 639,78$ ).

Tabela 2

Caracterização da amostra quanto aos dados sociodemográficos, conforme a condição dos grupos.

\section{Variáveis}

Gênero

Feminino

Masculino

Idade

Média

Desvio Padrão

Participação em Coletivos Juvenis

Quant. Coletivos (\%)

Nenhum

Um

Dois

Três

Quatro

Média

Desvio Padrão

Tipos de Coletivos Juvenis

Religiosos

Esportivos

Estudantis

GE

11

11

15,86

0,468

$8(36,4 \%)$

$9(40,9 \%)$

$3(13,6 \%)$

$1(4,5 \%)$

$1(4,5 \%)$

1,00

1,069

11

7

2
13

12

16,64

0,490

\section{(2)} GC 
Outros

Classe Socioeconômica*

Classe A

Classe B1

Classe B2

Classe $\mathrm{C} 1$

Classe $\mathrm{C} 2$

Classe D/E
1

2

2

11

3

4
1

1

3

10

7

3

*Classificação seguindo questionário proposto pelo Critério de Classificação Brasil 2015, da Associação Brasileira de Empresas de Pesquisas - ABEP.

\section{Avaliação de Resultados}

Procurou-se inicialmente conhecer as pontuações médias no pré e pós-teste das variáveis do estudo (presença de sentido, busca de sentido, afetos positivos, afetos negativos) tendo em conta os dois grupos constituídos (GE e GC). Através do Teste $t$ para medidas repetidas verificou-se uma mudança estatisticamente significativa no fator presença de sentido, com aumento nas médias desta variável entre o pré e o pós-teste no GE ( $p=0,0001)$, enquanto no GC o aumento não foi significativo. As médias, os desvios-padrão e a significância estatística dos grupos experimental e controle estão apresentados na Tabela 3. O fator busca de sentido não apresentou mudança significativa em nenhum dos grupos.

$\mathrm{Na}$ Tabela 4, estão apresentados os resultados da comparação entre GE e GC dos resultados obtidos por meio da Escala de Afetos Positivos e Negativos. Os dados do GE mostraram uma diminuição significativa $(p=0,026)$ nos escores de afetos negativos, entre pré e pós-teste, ao passo que no GC a mudança não se mostrou significativa. Pode se perceber ainda, de forma significativa $(p=0,0001)$, uma diminuição nos índices de afetos positivos no GC. 
Tabela 3.

Comparação entre os grupos experimental e controle no pré e pós-teste, a partir das variáveis presença de sentido e busca de sentido.

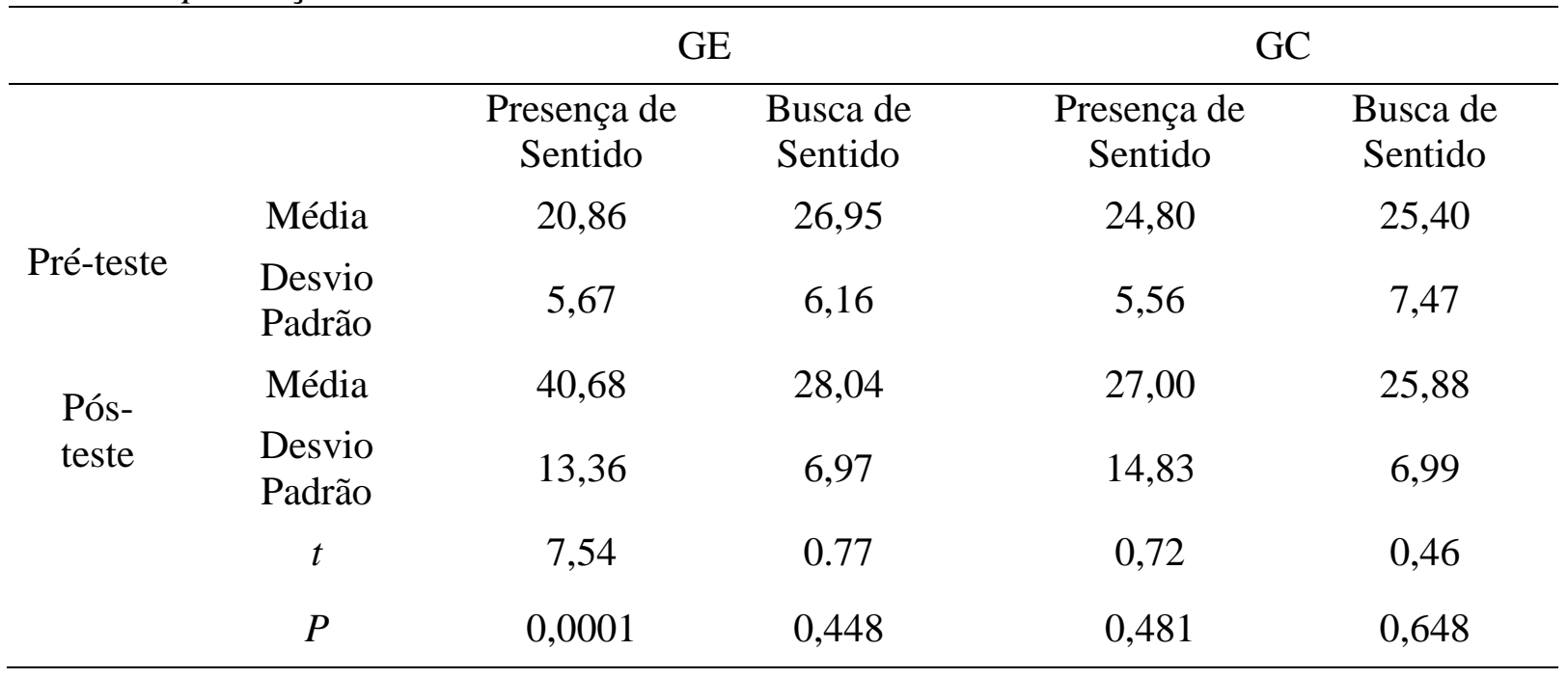

Tabela 4.

Comparação entre os grupos experimental e controle no pré e pós-teste, a partir das variáveis afetos positivos e afetos negativos.

\begin{tabular}{cccccc}
\hline & \multicolumn{2}{c}{ GE } & \multicolumn{2}{c}{ GC } \\
\hline & & Afetos & Afetos & Afetos & Afetos \\
Positivos & Negativos & Positivos & Negativos \\
teste & Média & 25,45 & 14,95 & 24,68 & 14,44 \\
& $\begin{array}{c}\text { Desvio } \\
\text { Padrão }\end{array}$ & 4,44 & 5,82 & 0,96 & 0,99 \\
Pós- & Média & 26,73 & 11,64 & 13,64 & 13,64 \\
teste & Desvio & 5,01 & 3,66 & 0,63 & 0,63 \\
& Padrão & 1,25 & 2,40 & 7,78 & 0,848 \\
& $P$ & 0,226 & 0,026 & 0,0001 & 0,40548 \\
\hline
\end{tabular}

Como parte dos resultados da intervenção e a partir de uma técnica denominada carta a um amigo, analisou-se a presença de elementos que indicassem a construção de um projeto de vida pelos adolescentes participantes. Como visto na Tabela 4, foram identificados planos específicos e inespecíficos ou ausentes. As definições, exemplos e frequência das categorias e subcategorias de relatos constam na Tabela 4. Os dados evidenciaram uma predominância de 
planos específicos $(75-96,2 \%)$ sobre planos inespecíficos ou ausentes $(3-3.8 \%)$. Os planos específicos contemplaram, principalmente, planos de carreira, familiares e de investimento na formação acadêmica.

Tabela 4

Relatos dos participantes que indicam planos futuros.

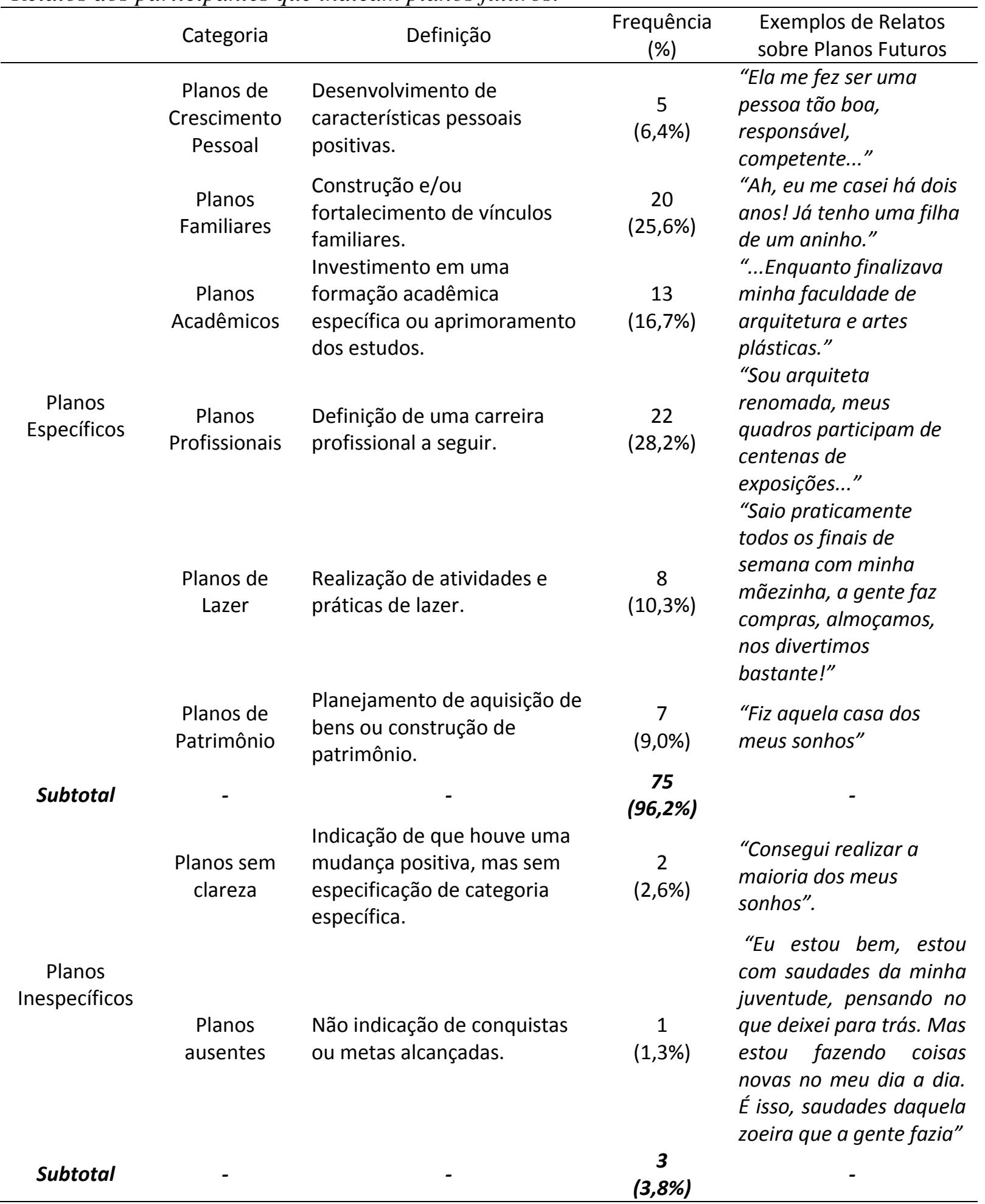




\section{Avaliação de Processo}

No que se refere à compreensão dos procedimentos e o engajamento dos participantes nas atividades propostas, alguns relatos sugerem que os adolescentes compreenderam e se engajaram de forma positiva na intervenção. Esse envolvimento extrapolou o espaço do grupo, o que pode ser percebido na fala de um dos participantes: "essas atividades fazem a gente pensar muito em casa", "dá vontade de chorar, às vezes, quando a gente lembra desses textos". Essa postura de envolvimento na atividade também pode ser observada pelo pesquisador em comportamentos dos adolescentes no grupo, especialmente em atividades que, em sua execução, exigiam uma atitude cooperativa entre eles.

Os relatos dos participantes a partir da Árvore da Minha Vida, onde se avaliou os conteúdos que mais chamaram atenção dos participantes e que foram considerados como importantes para a vida de cada um deles, sugerem um reconhecimento da importância da intervenção e que lições podem ser levadas para o cotidiano dos adolescentes. Na Figura 1 estão representadas as falas dos participantes, com destaque para as palavras mais frequentes em seus relatos. Considerando as palavras que foram citadas por ao menos cinco adolescentes, temos a seguinte frequência: sentido (12), vida (11), escolhas (9), sonhos (7), foco (6), persistência (6), habilidades (5), vontade (5). 


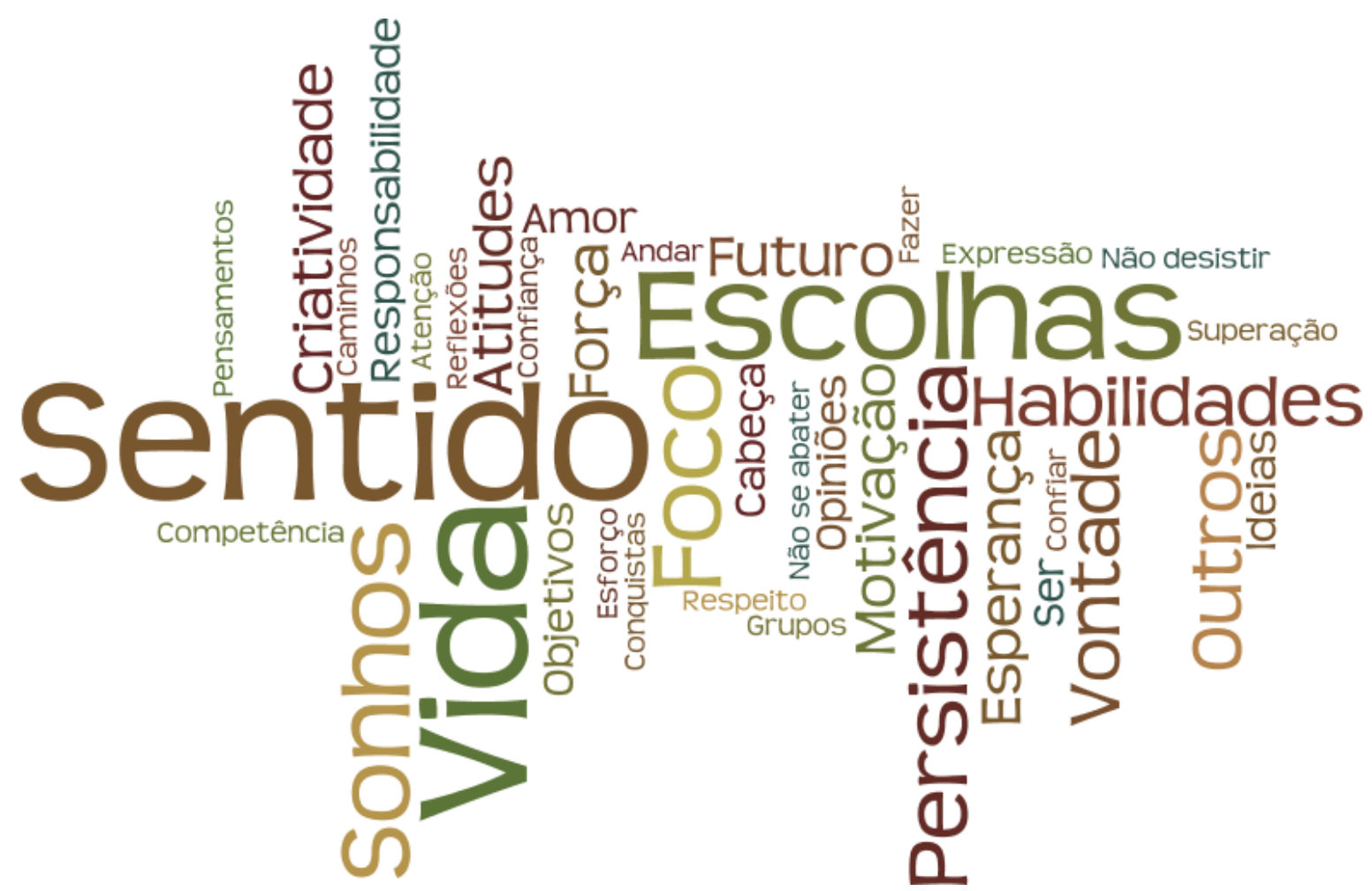

Figural. Nuvem de palavras com destaque para as que apresentaram maior frequência nos discursos dos adolescentes.

Os resultados obtidos no preenchimento do Diário de Emoções, com a finalidade de avaliar a satisfação dos participantes, mostram as emoções experimentadas pelos participantes ao final de cada encontro da intervenção. A frequência total das emoções está apresentada na Figura 2. As emoções mais frequentes foram as positivas (feliz, tranquilo, animado), ao passo que as negativas foram menos frequentes (triste, entediado, amedrontado), incluindo a não identificada (“ainda não sei”), quando o adolescente não sabia dar nome ao sentimento percebido. Conforme descrito na Figura 3, nota-se um aumento gradual das emoções positivas no decorrer da intervenção, certa estabilidade das emoções negativas e um decréscimo nas emoções não identificadas. O pequeno aumento de emoções negativas, observada na última sessão, pode ser justificada pelo sentimento dos participantes frente ao término da intervenção, como sugere a fala de um dos adolescentes: “...estou triste que esteja acabando. Passou tão rápido”. 


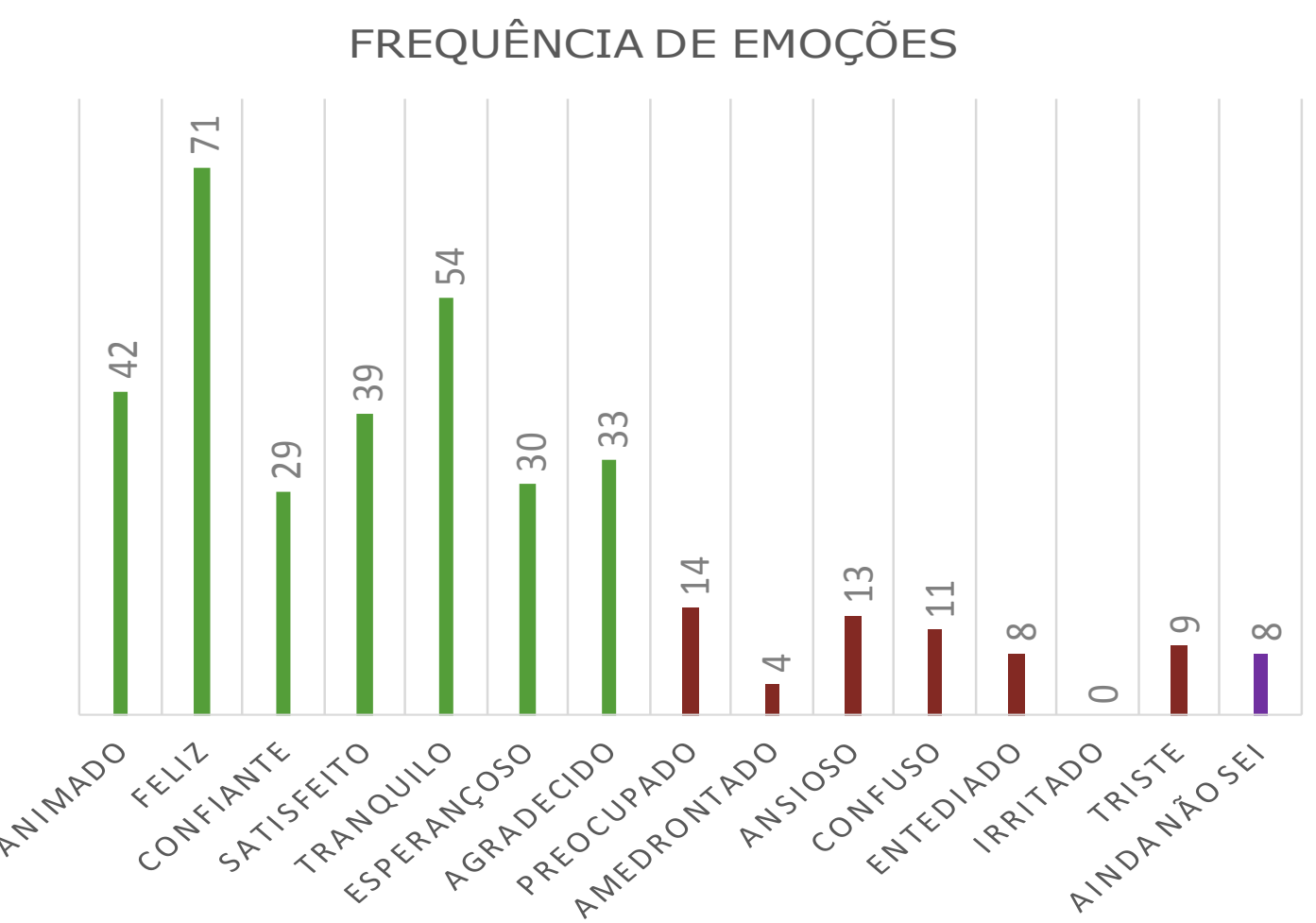

Figura 2. Frequência de emoções na avaliação de satisfação dos participantes em relação à intervenção.

\section{DISTRIBUIÇÃO DAS EMOÇÕES}

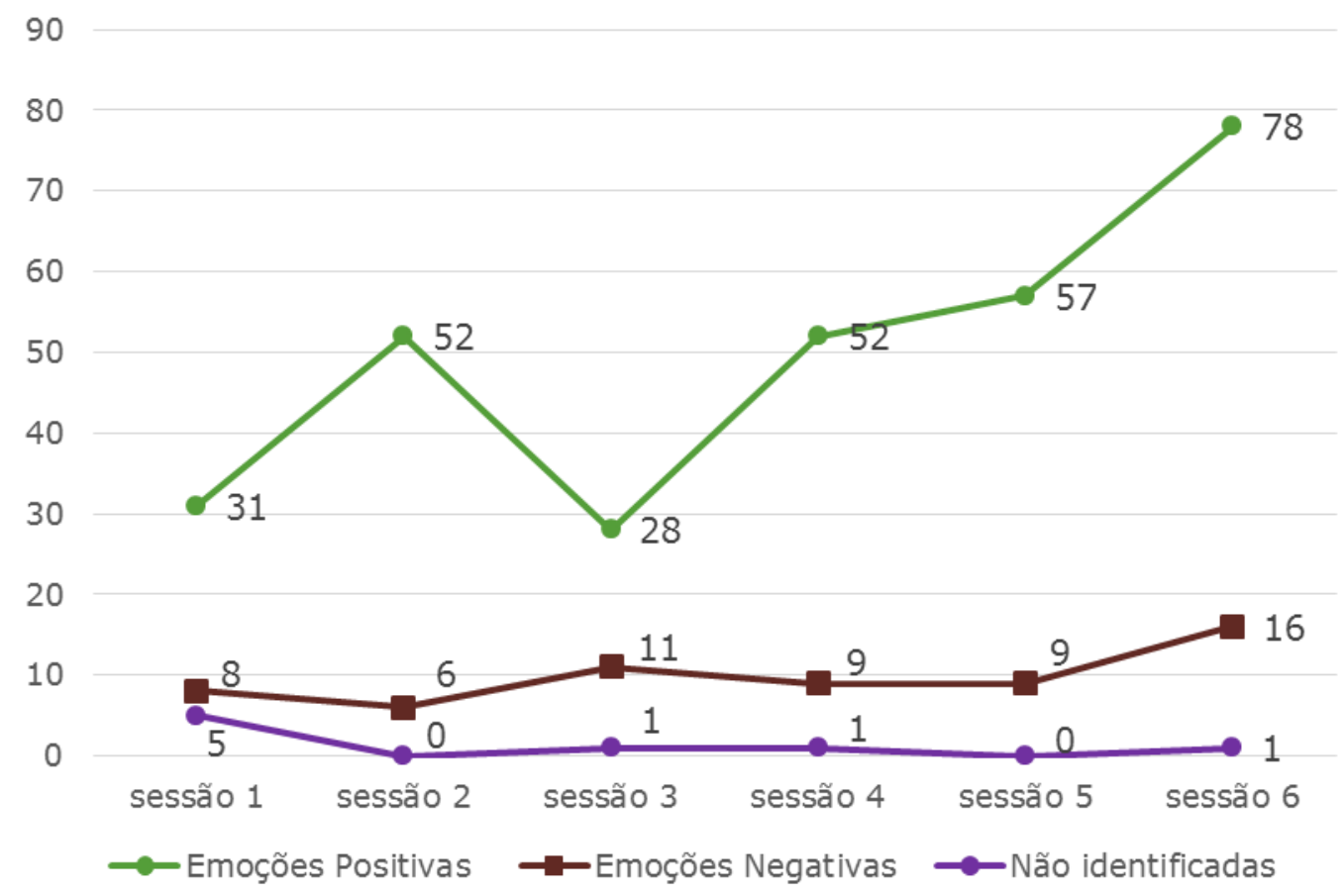

Figura 3. Distribuição das emoções coletadas na avaliação de satisfação do participante a cada sessão. 


\section{Discussão}

O presente estudo objetivou avaliar os resultados e o processo de implementação de uma proposta para a prevenção do vazio existencial entre adolescentes. Verificou-se que, após a intervenção, os participantes do grupo experimental apresentaram mudança significativa na percepção de sentido em suas vidas, em comparação com o grupo controle (GC). Resultados semelhantes foram encontrados por Aquino et al. (2011). Segundo Frankl (2011), um dos indicadores mais fortes da presença de sentido é ter um propósito na vida definido, uma causa ou pessoa pela qual valha a pena viver. Essa compreensão é partilhada por Ryff \& Keyes, (1995) que colocam o propósito de vida como um componente do bemestar psicológico. Para as autoras em questão, o propósito de vida pode ser compreendido como a existência de objetivos na vida, senso de direção, metas significativas e o sentimento de que a vida tem um significado. Frankl (2011) afirma que o vazio existencial se caracteriza pela sensação de que a vida está sem sentido ou sem um propósito definido, limitando suas possibilidades futuras. Dessa forma, promover o sentido da vida equivale a minorar essa percepção de vazio no indivíduo, ampliando seus fatores protetivos.

Em referência ao fator busca de sentido, não houve mudança significativa na comparação com os grupos. Estudos sugerem, em geral, correlações negativas entre busca e presença de sentido (Damásio, 2103) e entre busca de sentido e bem-estar subjetivo (Bonebright et al., 2000). Deste modo, a ausência de mudança nesta variável deve ser interpretada como esperada.

Quanto aos escores de afetos positivos, os dados revelaram alterações significativas, representadas pela diminuição de afetos negativos no GE e diminuição dos afetos positivos no GC. Além disso, constatou-se que a média de afetos positivos foi superior à de afetos negativos. Este resultado encontra respaldo em estudos anteriores (Arteche \& Bandeira, 2003, Huebner \& Dew, 1996), que sugerem que, no geral, os adolescentes reportam bons níveis de 
bem-estar. O contexto político e econômico quando da coleta de dados pode ser uma possível explicação para a alteração observada no GC, uma vez que aos participantes dessa condição não foi oferecido um espaço de escuta e partilha de sentimentos. O fato de serem adolescentes que estão se inserindo no mercado de trabalho e de sentirem diretamente o impacto negativo do momento econômico, colabora para essa compreensão. Considerando esse contexto, também vivenciado pelos participantes do grupo experimental, a mudança observada pode ser também respaldada por Frankl quando diz que, a dimensão espiritual no ser humano preserva fatores protetivos no indivíduo, independente da situação que ele vivencie.

No que diz respeito à construção de um projeto de vida, foram observados nos relatos dos adolescentes, planos e projetos ligados à família, estudos, crescimento pessoal, lazer, patrimônio e trabalho/carreira. Os planos profissionais e de carreira foram os mais frequentes. Essa maior frequência de planos profissionais pode ser explicado pelo fato da amostra ser de conveniência, composta por adolescentes inseridos em um programa de formação socioprofissional. A percepção de significado na vida a partir do estabelecimento de metas profissionais e de carreira encontra respaldo em Frankl (2005, 1990) que afirma que a vivência dos valores de criação (valores ligados à ação, tarefa ou trabalho) é uma das vias para se encontrar o sentido na vida. Ademais, estudos apontam que a percepção de meta futura é um fator de motivação na busca de estratégias para alcançá-las (Río-González \& Herrera, 2006) e um fator de proteção que promove resiliência (McCabe \& Barnett, 2000).

No referente às variáveis de processo, os resultados apontam para uma boa compreensão, por parte dos adolescentes, das atividades propostas e uma participação ativa nas mesmas. Esse entendimento se deu a partir de observações do pesquisador na execução das tarefas e na interação entre os adolescentes no decorrer da intervenção. Relatos que indicam exposição pessoal do adolescente ajudam a sustentar esse entendimento em relação 
ao engajamento nas tarefas. Quando solicitados a imaginar o que fariam no último dia de vida de cada um, por exemplo, muitos adolescentes relataram que pediriam perdão a pais, amigos, familiares por possíveis sofrimentos que tivessem causado ou por não terem se comportado conforme desejo dos pais. Berkel et al. (2011) apontam a participação ativa como elemento importante no processo de implementação, sendo frequentemente associados a resultados positivos de uma intervenção. Outro indicador do envolvimento dos adolescentes na proposta são os resultados a partir da técnica Carta a um Amigo, como descrito anteriormente.

Quanto à validade social, é importante saber como os participantes avaliam os procedimentos de uma intervenção. Quando essa avaliação se apresenta como socialmente relevante aumenta a possibilidade de efeitos positivos da ação (Lane \& Beebe-Frankenberger, 2004). Os relatos dos participantes apontam para um reconhecimento de que os temas trabalhados foram importantes e os ajudariam a construir um projeto de vida a partir da reflexão e vivência de valores pessoais. Quanto à avaliação de satisfação em relação à intervenção, a partir do Diário de Emoções, foi observada uma maior frequência de emoções positivas, em comparação às negativas. Os resultados mostram ainda que à medida que a intervenção ia acontecendo, a frequência de emoções positivas aumentava, sugerindo que os adolescentes, em sua maioria, estavam satisfeitos com o que estava sendo oferecido nas sessões. Mesmo quando o relato de algum participante indicava a presença de angústia, a fala era acompanhada de justificativa que aliviava o sentimento: "esses textos mexem com nosso psicológico, mas ajuda às vezes”; “a gente não para pra pensar nessas coisas no dia a dia. Parece que não é importante. Agora eu consigo pensar melhor no que eu quero ser”. A satisfação do participante é também um indicador de uma intervenção exitosa (Berkel et al., 2011; Steckler \& Linnan, 2002). 


\section{Considerações Finais}

Em síntese, os resultados deste estudo indicam evidências favoráveis à eficácia da intervenção. Quando comparado ao GC, o GE apresentou mudanças positivas nos escores de percepção de significado na vida, bem como diminuição dos afetos negativos. Estes dados quantitativos são coerentes com os qualitativos, acerca da elaboração de projetos de vida ao término da intervenção, o que parece indicar a presença de recursos e fontes de motivação para o alcance das metas estabelecidas. Ademais, estes resultados estão alinhados à implementação bem sucedida da intervenção, considerando-se o engajamento dos adolescentes na intervenção, sua compreensão dos procedimentos, sua satisfação e percepção de relevância da intervenção (Berkel et al., 2011; Lane \& Beebe-Frankenberger, 2004; Steckler \& Linnan, 2002).

As evidências deste estudo somam-se às obtidas por Aquino et al. (2011), sugerindo consistentemente benefícios da intervenção para promoção de sentido da vida em adolescentes. Esses achados sugerem a aplicabilidade da Logoterapia em ações de promoção e prevenção na adolescência, em contextos de grupo, conforme trabalhos semelhantes descritos por Bretones (1998) e Leonardi (2011) e Reinhold (2004). Ademais, este estudo apresenta algumas contribuições adicionais ao estudo inicial de Aquino et al. (2011), dentre as quais podem ser citadas a replicação em novo contexto, o uso de múltiplas medidas e a associação entre avaliação de resultados e de processo de implementação da intervenção. Este estudo também contribui para ampliação das pesquisas nacionais em prevenção e promoção de saúde mental do adolescente, necessidade apontada por Abreu (2012), e para o desenvolvimento de estudos em promoção do sentido da vida, ainda escassos no Brasil.

O presente estudo caracteriza-se por ser um estudo de replicação de intervenção. A replicação de um estudo objetiva encontrar resultados semelhantes aos achados anteriormente, sendo considerada um critério de efetividade de uma intervenção (Flay et. al, 
2005). Desta forma, traz ao pesquisador alguns desafios, dentre os quais podemos destacar a adaptação - modificações necessárias para o bom funcionamento da intervenção no novo contexto - sem, contudo, descuidar da fidelidade da implementação, isto é, sem esvaziar a intervenção de seus componentes críticos (Berkel et al., 2011). Neste estudo, adotou-se uma versão mais compacta da intervenção, ao mesmo tempo em que seus objetivos, procedimentos e conteúdos centrais foram preservados. O formato usado neste estudo, com seis sessões, demonstrou ser de implementação mais viável, em comparação à intervenção original, de 15 sessões (Aquino et al., 2011). Desta feita, os achados do presente estudo, como replicação de uma intervenção preventiva e sua avaliação sistemática, indicam ser relevante a adaptação sensível ao contexto sem ameaças à fidelidade e ampliam as evidências de efetividade de intervenções nacionais em prevenção e promoção de saúde mental do adolescente, necessidade apontada por Abreu (2012), ainda escassas no Brasil.

Apesar dos avanços em relação à proposta inicial de Aquino et al. (2011), esse estudo apresenta algumas limitações. A principal delas é a ausência de alocação randômica dos participantes entre as condições experimental e controle. Embora os GC e GE não difiram significativamente entre si nos aspectos sociodemográficos e nos escores iniciais das variáveis estudadas, não é possível assegurar a equivalência entre eles no pré-teste. Outras limitações importantes são a amostragem por conveniência e a ausência de follow $u p^{3}$.

Isto considerado, sugere-se que estudos futuros ampliem a amostra, utilizem novas medidas para variáveis de processo, façam uso de grupos de comparação randomizados e incluam avaliações longitudinais. Adicionalmente, são recomendados cuidados para reduzir a complexidade da intervenção com vistas a facilitar o recrutamento de novos participantes. Neste sentido, o formato usado neste estudo, com seis sessões, demonstrou ser de implementação mais viável, em comparação à intervenção original, de 15 sessões (Aquino et

\footnotetext{
${ }^{3}$ A avaliação de follow up foi realizada, no entanto seus resultados não foram apresentados na dissertação porque não houve tempo hábil para o tratamento dos dados.
} 
al., 2011). Portanto, estudos futuros devem levar em conta formatos mais breves, de modo a facilitar a adoção por serviços especializados para adolescentes e promover a adesão e retenção dos participantes. 


\section{Referências}

Abreu, S. O. (2012). Prevenção primária em saúde mental no Brasil na perspectiva da literatura e de especialistas da área. Dissertação de mestrado, Universidade de Brasília, Brasília, DF, Brasil. $\quad$ Recuperado em http://repositorio.unb.br/bitstream/10482/11952/1/2012_SamiaAbreuOliveira.pdf.

Aquino, T. A .A. (2013) Logoterapia e análise existencial. São Paulo: Paulus.

Aquino, T. A. A (2015). Sentido da vida e valores no contexto da educação: Uma proposta de intervenção à luz do pensamento de Viktor Frankl. São Paulo: Paulinas.

Aquino, T. A. A., Correia, A. P. M., Marques, A. L., C., Souza., C. G., Freitas, H. C. A., \& Dias, P. S., Araújo, W. F. (2009). Atitude religiosa e sentido da vida: Um estudo correlacional. Psicologia: Ciência e Profissão, 29(2), 228-243.

Aquino, T. A. A., Silva, J. P., Figueiredo, A. T. B., Dourado, E. T. S., \& Farias, C. S. (2011). Avaliação de uma proposta de prevenção ao vazio existencial com adolescentes. Psicologia: Ciência e Profissão, 31, 146-159.

Aquino, T. A. A., Damásio, B. F., \& Silva, J. P. (Orgs). (2012) Logoterapia e educação: fundamentos e prática. São Paulo: Paulinas.

Aquino, T. A. A., Gouveia, V. V., Aguiar, A. A., Pereira, G. A., Fernandes, A. S., Serafim, T. D. B., \& Pontes, A. M. (2015). Questionário de |Sentido da Vida: evidências de sua validade fatorial e consistência interna. Psicologia: Ciência e Profissão, 35(1), 4-19.

Arteche, A. X. \& Bandeira, D. R. (2003). Bem-estar subjetivo: um estudo com adolescentes trabalhadores. Psico-USF, 8(2), 193-201.

Baptista, M., Baptista, A., \& Dias, R. (2001). Estrutura e suporte familiar como fatores de risco na depressão de adolescentes. Psicologia: Ciência e Profissão, 21, 56-61.

Bardagi, M. (2002). Os estilos parentais e sua relação com a indecisão profissional, ansiedade e depressão dos filhos adolescentes. Dissertação de mestrado, Universidade 
Federal do Rio Grande do Sul. Porto Alegre, RS, Brasil. Recuperado em 05/06/2015 https://www.lume.ufrgs.br/bitstream/handle/10183/2147/000315102.pdf?sequence=1.

Berkel, C., Mauricio, A. M., Schoenfelder, E., \& Sandler, I. N. (2011). Putting the pieces together: an integrated model of program implementation. Prevention Science, 12, 23-33

Bonebright, C. A., Clay, D. L., \& Ankenmann, R. D. (2000). The relationship of workaholism of with work life conflict, life satisfaction and purpose in life. Journal of Counseling Psychology, 47, 469-477.

Braun, V. \& Clarke, V. (2006). Using thematic analysis in psychology. Qualitative Research in Psychology, 3 (2), 77-101.

Bretones, F. (1998). A logoterapia é óbvia: experiências logoterapêuticas com o homem comum. São Paulo: Paulinas.

Chaves, S. S. S. (2003) Valores como preditores do bem-estar subjetivo. Dissertação de mestrado, Universidade Federal da Paraíba, PB, Brasil. Recuperado em 01/04/2014 http://www.vvgouveia.net/images/Dissertações1/Chaves_S._S._S._2003.pdf.pdf.

Damásio, B. F. (2013). Sentido de vida e bem-estar subjetivo: interações com esperança, otimismo, autoeficácia e autoestima em diferentes etapas do ciclo vital. Tese de doutorado, Universidade Federal do Rio Grande do Sul, RS, PB, Brasil. Recuperado em 20/02/2014 http://www.lume.ufrgs.br/handle/10183/80120.

Diener, E., Suh, E., \& Oishi, S. (1997). Recent fi ndings on subjective well being. Indian Journal of Clinical Psychology, 24(1), 25-41.

Debats, D. L., Van der Lubbe, P. M., \& Vezeman, F. R. A. (1993). On psychometric properties of theLife Regard Index (LRI): A measure of meaningful life. Personality and Individual Differences, 14, 337-345.

Doğana, T., Sapmaz, F., Telb, F. D., Sapmazc, S., \& Temizelc, S. (2012). Meaning in Life and Subjective Well-Being among Turkish University Students. Procedia - Social and Behavioral Sciences 55, 612-617. 
Flay, B. R., Biglan, A., Boruch, R., Castro, F. G. \& Gottfredson, D., Kellam, S., Moscicki, e. k., Schinke, S., Vlentine, J. C., \& Ji, P. (2005). Standards of evidence: Criteria for efficacy, effectiveness and dissemination. Prevention Science, 6, 151-175.

Frankl, V. E. (1990) A questão do sentido em psicoterapia. Campinas: Papirus.

Frankl, V. E. (2003). Psicoterapia e sentido da vida: Fundamentos da logoterapia e análise existencial. São Paulo: Quadrante.

Frankl, V. E. (2005) Um sentido para a vida. Petrópolis: Vozes.

Frankl, V. E. (2011) Em busca de sentido. Petrópolis: Vozes.

Gomes, E. S. (2009) Evidencias teóricas y empíricas entre la psicologia positiva de Seligman y la psicologia humanista-existencial de Frankl. Tese doutoral não publicada.

Haditabar, H., Far, N. S., \& Amani, Z. (2013). Effectiveness of logotherapy concepts training in increasing the quality of life among students. International Journal of Psychology and Behavioral Research, 2(4), 223-230.

Huebner, E. \& Dew, T. (1996). The inter-relationships of positive affect, negative affect and life satisfaction in an adolescent sample. Social Indicators Research, 38, 129-137.

Lane, K. L. \& Beebe-Frankenberger, M. (2004). Social validity: goals, procedures, and outcomes. In K. L. Lane \& M. Beebe-Frankenberger (Eds). School-based interventions: the tools you need to succeed (pp. 85-127). Boston: Pearson Education.

Kang, K., Im, J., Kim, H., Kim, S., Song, M., \& Sim, S. (2009) The effect of logotherapy on the suffering, finding meaning, and spiritual well-being of adolescents with terminal cancer. Journal of Korean Academy of Nursing, 15(2), 136-144.

Kazdin, A. E. (2010). Research design in Clinical Psychology. Boston: Allyn e Bacon.

Leonardi, J. (2011). Logomúsica: a criação de um novo approach musicoterápico como veículo na promoção de saúde mental. Tese de doutorado, Universidade de São Paulo, 
São Paulo, SP, Brasil. Recuperado em 04/06/2014 http://www.teses.usp.br/teses/disponiveis/22/22131/tde-31102011-084343/en.php.

Löhr, S. S., Pereira, A. C. S., Andrade, A. L. M., \& Kirchner, L. F. (2007). Avaliação de programas preventivos: Relato de experiência. Psicologia em Estudo, 12, 641-649.

Lukas, E. (1989) Logoterapia: A força desafiadora do espírito. São Paulo: Loyola.

Lukas, E. (1992). Assistência logoterapêutica: Transição para uma psicologia humanizada. Petrópolis: Vozes.

Malta, D. C., Mascarenhas, M. D. M., Porto, D. L., Duarte, E. A., Sardinha, L. M., Barreto, S. M., \& Morais Neto, O. L. (2011). Prevalência do consumo de álcool e drogas entre adolescentes: análise dos dados da Pesquisa Nacional de Saúde Escolar. Revista Brasileira de Epidemiologia, 14 (1), 136-146.

McCabe, K. \& Barnett, D. (2000). First comes work, then comes marriage: Future orientation among African American young adolescents. Family relations, 49, 63-70.

Murta, S. G. (2007). Programa de prevenção a problemas emocionais e comportamentais em crianças e adolescentes: Lições de três décadas de pesquisa. Psicologia: Reflexão $e$ Crítica, 20(1), 1-8.

Nascimento, M. O. \& Avallone, D. M. (2013). Prevalência do uso de drogas entre adolescentes nos diferentes turnos escolares. Adolescência \& Saúde, 10 (4) 41-49.

Reinhold, H. H. (2004). O sentido da vida: Prevenção do stress e burnout do professor. Tese de doutorado, Pontifícia Universidade Católica de Campinas, Campinas, SP, Brasil. $\begin{array}{llll}\text { Recuperado em } & \text { 15/10/2013 www.bibliotecadigital.puc- }\end{array}$ campinas.edu.br/tde_busca/arquivo.php?codArquivo=250.

Reppold, C. T. \& Hutz, C. S. (2003). Prevalência de indicadores de depressão entre adolescentes no Rio Grande do Sul. Avaliação Psicológica, 2 (2), 175-184. 
Río-González, A. M. \& Herrera, A. N. (2006). Desarrollo de un instrumento para evaluar perspectiva de tempo futuro em adolescentes. Avances en Medición, 4, 47-60.

Ryff, C. \& Keyes, C. (1995). The structure of psychological well-being revisited. Journal of Personality and Social Psychology, 69(4), 719-727.

Salle, E., Segal, J., \& Sukiennik, P. (1996). Transtornos depressivos. Em P. B. Sukiennik (Ed.), O aluno problema: Transtornos emocionais de crianças e adolescentes. Porto Alegre: Mercado Aberto.

Secretaria Nacional de Juventude (2014a). Agenda juventude Brasil. Brasília, Brasil.

Secretaria Nacional de Juventude (2014b). Estação juventude: conceitos fundamentais. Brasília, Brasil.

Seligman, M. E. P. (2011). Florescer. Rio de Janeiro: Objetiva.

Seligman, M. E. P. \& Csikszentmihalyi, M. (2000). Positive psychology: an introduction. American Psychologist. 55, 5-14.

Steckler, A. \& Linnan, L. (2002). Process evaluation for public health interventions and research. An overview. In A. Steckler \& L. Linnan (Eds.). Process evaluation for public health interventions and research (pp. 1-21). San Francisco, CA: Jossey-Bass Publishers.

Steger, M. F. (2009). Meaning in life. In S. J. Lopez (Ed.), Oxford handbook of positive psychology (2nd ed., pp. 679-687). Oxford: Oxford University Press.

Waiselfsz, J. J. (2014). Mapa da violência 2014: os jovens do Brasil. Brasília: Flacso Brasil. World Health Organization. (2011). Impact of economic crises on mental health. Copenhagen, Dinamarca. Retirado de: http://www.euro.who.int/_data/assets/pdf_file/0008/134999/e94837.pdf.

Xausa, I. A. M. (1986) A psicologia do sentido da vida. Petrópolis: Vozes. 


\section{CONCLUSÃO}

O objetivo principal desta pesquisa foi replicar em novo contexto uma intervenção para prevenção do vazio existencial entre adolescentes, proposta por Aquino et al. (2011), ampliando sua avaliação, com foco em seu processo de implementação e nos resultados por ela alcançados. Esses resultados sugerem evidências favoráveis à eficácia da intervenção.

Além do estudo empírico, foram elaborados outros dois manuscritos teóricos. O primeiro discutiu os conceitos de saúde mental, prevenção e promoção. Discorreu sobre programas de promoção de saúde mental, seu processo de implementação e sobre as dimensões relevantes para sua eficácia e efetividade. Ele contribuiu para mostrar lacunas na área da prevenção e promoção em saúde mental para adolescentes e descrever intervenções para promoção de empatia, otimismo, habilidades de vida e sentido da vida, avaliadas sistematicamente e com evidências de eficácia, indicando uma alternativa adequada nos cuidados em saúde mental. Outra contribuição é a descrição de sobre os cuidados que

precisam ser observados na implementação de programas, que facilite a adesão e o engajamento dos participantes.

O segundo manuscrito descreveu a evolução conceitual do construto sentido da vida, apontando suas implicações com a saúde mental. Apresentou a logoterapia, escola terapêutica criada por Viktor Frankl, pioneiro nos questionamentos pelo sentido da vida. Discorre sobre a compreensão de homem proposta pela logoterapia, bem como a utilização de seu arcabouço teórico na fundamentação de intervenções preventivas para públicos e condições diversas. Descreve ações que se utilizaram desta abordagem, com resultados exitosos, sugerindo desta forma, a adequabilidade teórica da escola de Frankl. Uma das contribuições do estudo é a apresentação de um modelo de prevenção, consonante com as concepções atuais, baseada na antropologia proposta pela logoterapia. 
O estudo empírico, descrito no terceiro manuscrito, avaliou o processo de implementação e os resultados alcançados em uma intervenção para prevenção do vazio existencial entre adolescentes. A avaliação de processo incluiu medidas de satisfação, validade social, engajamento e compreensão das atividades por parte dos adolescentes. Ademais, foram realizadas também avaliações antes e após a intervenção, para as variáveis presença de sentido, busca de sentido, afetos positivos, afetos negativos e elaboração de planos e metas significativas. Os resultados exitosos alcançados indicam evidências de eficácia dessa estratégia preventiva, revelando um aumento na percepção de sentido de vida, diminuição de afetos negativos e a existência de planos futuros específico, no grupo experimental. Outros resultados exitosos encontrados foram a compreensão e engajamento dos adolescentes nas atividades propostas; a satisfação em relação à intervenção e a percepção de relevância dos conteúdos da intervenção.

Dentre as contribuições desse estudo, podem ser observadas a replicação da proposta inicial em novo contexto, o uso de múltiplas medidas e a associação entre avaliação de resultados e de processo de implementação da intervenção. Contribui ainda para o desenvolvimento das pesquisas nacionais em prevenção e promoção de saúde mental do adolescente e estudos em promoção do sentido da vida, ainda escassos na literatura nacional.

Embora esses avanços percebidos, o estudo apresenta algumas limitações como a distribuição randomizada dos participantes nos grupos, a mostra de conveniência e ausência de avaliação de follow up. Cuidados que superem tais limitações devem ser adotados em estudos futuros, considerando também as dificuldades relatadas nesse estudo, do processo de implementação da intervenção, com vistas a facilitar a adesão dos participantes e a inclusão em políticas públicas voltadas para adolescentes. 
Anexo A

Questionário de Avaliação Sociodemográfica 


\section{Questionário de Avaliação Sociodemográfica}

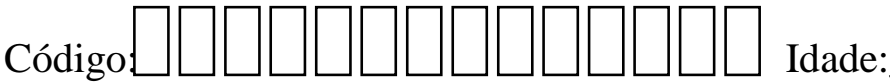

Sexo:

Turma:

(O código é composto pelas iniciais do nome de seus pais, seguido de sua data de nascimento. Por exemplo: se o nome de seus pais são Antonio Araujo de Almeida e Beatriz Braga Almeida e se você nasceu no dia 10 de outubro de 2000, o seu código de identificação ficará da seguinte forma AAABBA10102000. Este código servirá apenas para controle do pesquisador).

Por favor, responda às perguntas abaixo:

1. Com quem você mora?
( ) Com meus pais
( ) Somente com minha mãe
( ) Somente com meu pai,
( ) Com meus avós
( ) Outros:

2. Quantos irmãos você têm?
( ) 1
( ) 2
( ) 3
( ) $4+$

3. Você participa de...

a. Grupo de escoteiros?

( ) Sim ( ) Não

b. Grêmio estudantil?

( ) Sim ( ) Não

c. Grupo religioso?

( ) Sim ( ) Não

d. Grupo para prática de esporte?
( ) $\operatorname{Sim}$ ( ) Não
e. Outro grupo? Qual

4. Quantos amigos íntimos você possui?
( ) 1
( ) 2
( ) 3
( ) $4+$

5. Quando você tem necessidade de desabafar, a quem você recorre? (Obs: Você pode marcar mais de uma opção).
( ) Um amigo ( ) Minha mãe ( ) Meu pai
( ) Outra pessoa da família
( ) Namorado/a ( ) Outros.

6. Como você avalia seu rendimento escola?
( ) Ótimo
( ) Muito bom
( ) Bom
( ) Regular
( ) Insatisfatório

7. Qual é o grau de instrução do chefe da família? Considere como chefe da família a pessoa que contribui com a maior parte da renda do domicílio.
( ) Analfabeto / Fundamental I incompleto
( ) Fundamental I completo / Fundamental II incompleto
( ) Fundamental completo / Médio incompleto
( ) Médio completo / Superior incompleto
( ) Superior completo 
Por favor, responda às perguntas abaixo sobre itens do domicilio para efeito de classificação econômica.

Quantidade que possui

\begin{tabular}{|c|c|c|c|c|c|}
\hline ITEM & $\begin{array}{l}\text { NÃO } \\
\text { POSSUI }\end{array}$ & 1 & 2 & 3 & $4+$ \\
\hline \multicolumn{6}{|c|}{$\begin{array}{l}\text { Quantidade de automóveis de passeio exclusivamente para uso } \\
\text { particular. }\end{array}$} \\
\hline \multicolumn{6}{|l|}{$\begin{array}{l}\text { Quantidade de empregados mensalistas, considerando apenas } \\
\text { os que trabalham pelo menos cinco dias por semana. }\end{array}$} \\
\hline \multicolumn{6}{|l|}{ Quantidade de máquinas de lavar roupa, excluindo tanquinho. } \\
\hline \multicolumn{6}{|l|}{ Quantidade de banheiros. } \\
\hline \multicolumn{6}{|l|}{$\begin{array}{l}\text { DVD, incluindo qualquer dispositivo que leia DVD e } \\
\text { desconsiderando DVD de automóvel. }\end{array}$} \\
\hline \multicolumn{6}{|l|}{ Quantidade de geladeiras. } \\
\hline \multicolumn{6}{|l|}{$\begin{array}{l}\text { Quantidade de freezers independentes ou parte da geladeira } \\
\text { duplex. }\end{array}$} \\
\hline \multicolumn{6}{|l|}{$\begin{array}{l}\text { Quantidade de microcomputadores, considerando } \\
\text { computadores de mesa, laptops, notebooks e netbooks e } \\
\text { desconsiderando tablets, palms ou smartphones. }\end{array}$} \\
\hline \multicolumn{6}{|l|}{ Quantidade de lavadora de louças } \\
\hline \multicolumn{6}{|l|}{ Quantidade de fornos de micro-ondas } \\
\hline \multicolumn{6}{|l|}{$\begin{array}{l}\text { Quantidade de motocicletas, desconsiderando as usadas } \\
\text { exclusivamente para uso profissional. }\end{array}$} \\
\hline $\begin{array}{l}\text { Quantidade de máquinas secadoras de roupas, considerando } \\
\text { lava e seca. }\end{array}$ & & & & & \\
\hline
\end{tabular}

A água utilizada neste domicílio é proveniente de?

$1-($ ) Rede geral de distribuição

$2-$ ( ) Poço ou nascente

$3-($ ) Outro meio

Considerando o trecho da rua do seu domicílio, você diria que a rua é:

$1-$ ( ) Asfaltada/Pavimentada

$2-()$ Terra/Cascalho 
Anexo B

Questionário de Sentido de Vida 


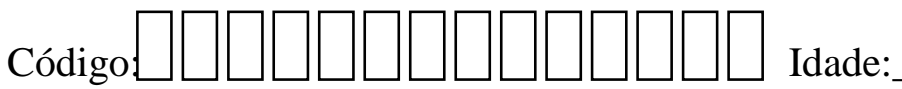

Sexo:

Turma:

(O código é composto pelas iniciais do nome de seus pais, seguido de sua data de nascimento. Por exemplo: se o nome de seus pais são Antonio Araujo de Almeida e Beatriz Braga Almeida e se você nasceu no dia 10 de outubro de 2000, o seu código de identificação ficará da seguinte forma AAABBA10102000. Este código servirá apenas para controle do pesquisador).

Tire um momento para pensar sobre os elementos que fazem sua vida parecer importante para você. Responda às afirmações abaixo da forma mais sincera e precisa que puder. Lembre-se que são questões muito pessoais e que não existem respostas certas ou erradas. Responda de acordo com a escala abaixo:

\begin{tabular}{|c|c|c|c|c|c|c|}
\hline $\begin{array}{l}\text { Totalmente } \\
\text { falsa }\end{array}$ & $\begin{array}{l}\text { Geralmente } \\
\text { falsa }\end{array}$ & $\begin{array}{c}\text { Um pouco } \\
\text { falsa }\end{array}$ & $\begin{array}{l}\text { Nem falsa, } \\
\text { nem } \\
\text { verdadeira }\end{array}$ & $\begin{array}{l}\text { Um pouco } \\
\text { verdadeira }\end{array}$ & $\begin{array}{l}\text { Geralmente } \\
\text { verdadeira }\end{array}$ & $\begin{array}{l}\text { Totalmente } \\
\text { verdadeira }\end{array}$ \\
\hline 1 & 2 & 3 & 4 & 5 & 6 & 7 \\
\hline
\end{tabular}

1. ___ Eu entendo o sentido da minha vida.

2. ___ Estou procurando por algo que faça a minha vida ser significativa.

3. ___ Eu estou sempre procurando encontrar o propósito da minha vida.

4. ___ Minha vida tem um propósito claro.

5. ___ Eu tenho uma clara noção do faz a minha vida ser significativa.

6. ___ Eu encontrei um propósito de vida satisfatório.

7. ___ Eu estou sempre procurando por algo que faça com que minha vida seja significativa.

8. ___ Eu estou buscando um propósito ou missão para minha vida.

9. Minha vida não tem um propósito claro.

10. ___ Estou buscando sentido na minha vida. 
Anexo C

Escala de Afetos Positivos e Negativos 
Código $\square \bigsqcup \bigsqcup \bigsqcup \bigsqcup \bigsqcup \square \bigsqcup \bigsqcup \square \square \square \square$ Idade:__ Sexo:__ Turma:

(O código é composto pelas iniciais do nome de seus pais, seguido de sua data de nascimento. Por exemplo: se o nome de seus pais são Antonio Araujo de Almeida e Beatriz Braga Almeida e se você nasceu no dia 10 de outubro de 2000, o seu código de identificação ficará da seguinte forma AAABBA10102000. Este código servirá apenas para controle do pesquisador).

Instruções: A seguir você encontrará uma lista com dez estados emocionais. Para cada um deles, pedimos-lhe que indique o quanto você o tem experimentado ultimamente. Faça isso escrevendo um número no espaço ao lado de cada emoção / adjetivo, segundo a escala de respostas abaixo, de acordo com a sua opinião. Por favor, seja o mais sincero e honesto possível nas suas respostas.

\begin{tabular}{|c|c|c|c|c|c|c|}
\hline $\begin{array}{l}1 \\
\text { Nada }\end{array}$ & $\begin{array}{l}2 \\
\text { Muito } \\
\text { Pouco }\end{array}$ & $\begin{array}{l}3 \\
\text { Pouco }\end{array}$ & $\begin{array}{l}4 \\
\text { Mais ou } \\
\text { menos }\end{array}$ & $\begin{array}{l}5 \\
\text { Bastante }\end{array}$ & $\begin{array}{l}6 \\
\text { Muito }\end{array}$ & $\begin{array}{l}7 \\
\text { Extremamente }\end{array}$ \\
\hline
\end{tabular}

01.

Feliz

02 .

Deprimido

03.

Satisfeito

04.

Frustrado

05.

Raivoso

06.

Divertido

07.

Preocupado

08.

Otimista

09.

Infeliz

10.

Alegre 
Anexo D

Diário de Emoções 


\section{Diário de Emoções}

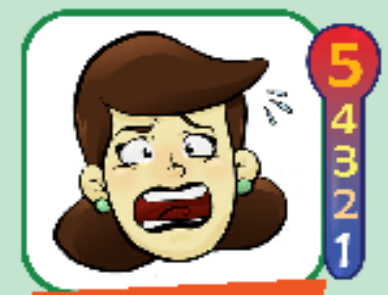

AMEDRONTADO

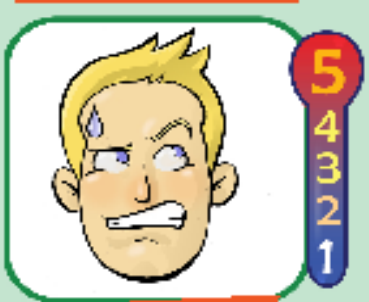

ANSIOSO

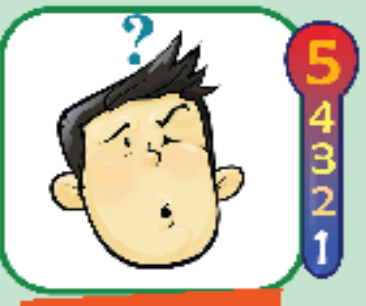

CONFUSO

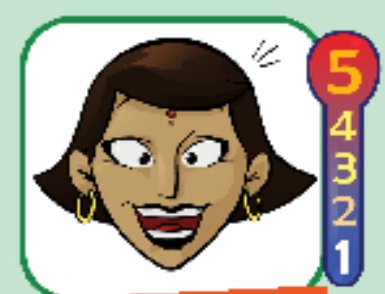

ANIMADO

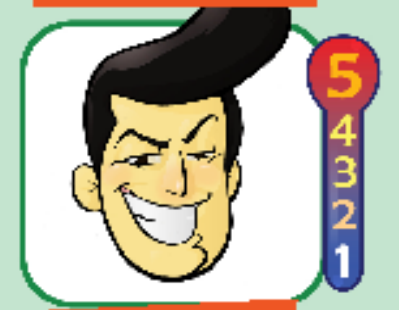

CONFIANTE

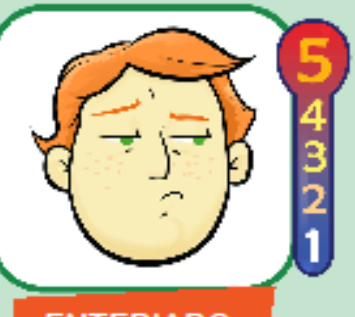

ENTEDIADO

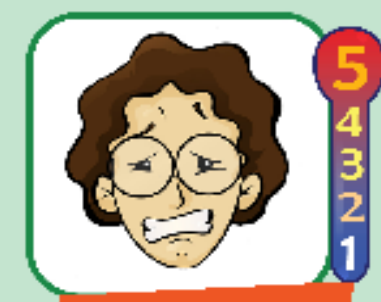

PREOCUPADO

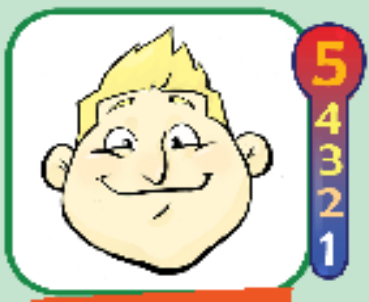

SATISFEITO

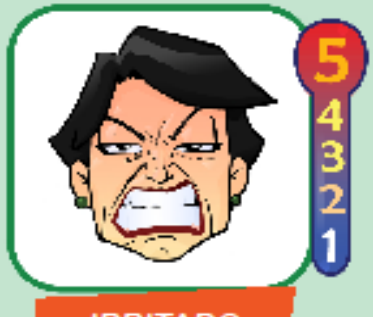

IRRITADO

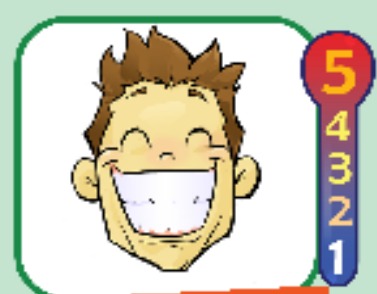

FELIZ

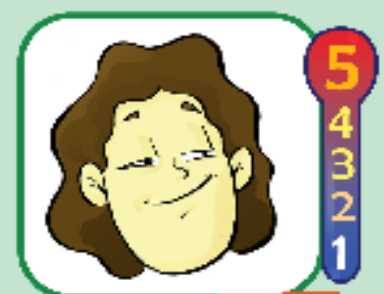

TRANQUILO

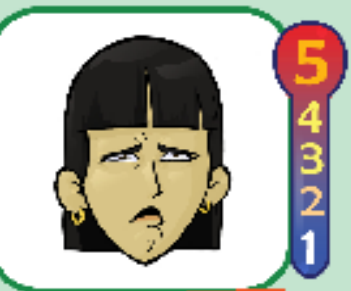

TRISTE a)

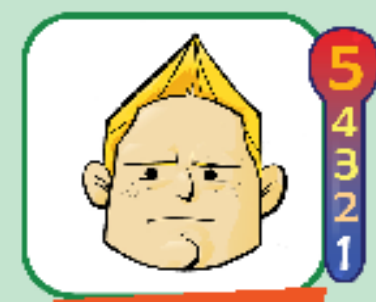

AINDA NĀO SEI

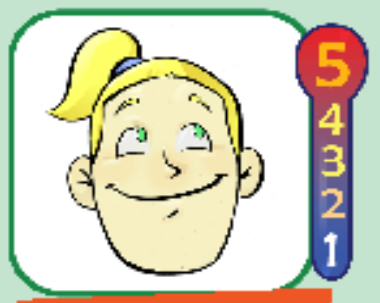

ESPERANÇOSO

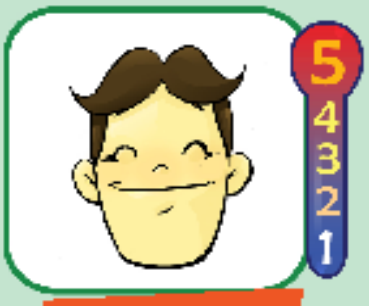

AGRADECIDO 
Anexo E

Árvore da Minha Vida 
Árvore da Minha Vida

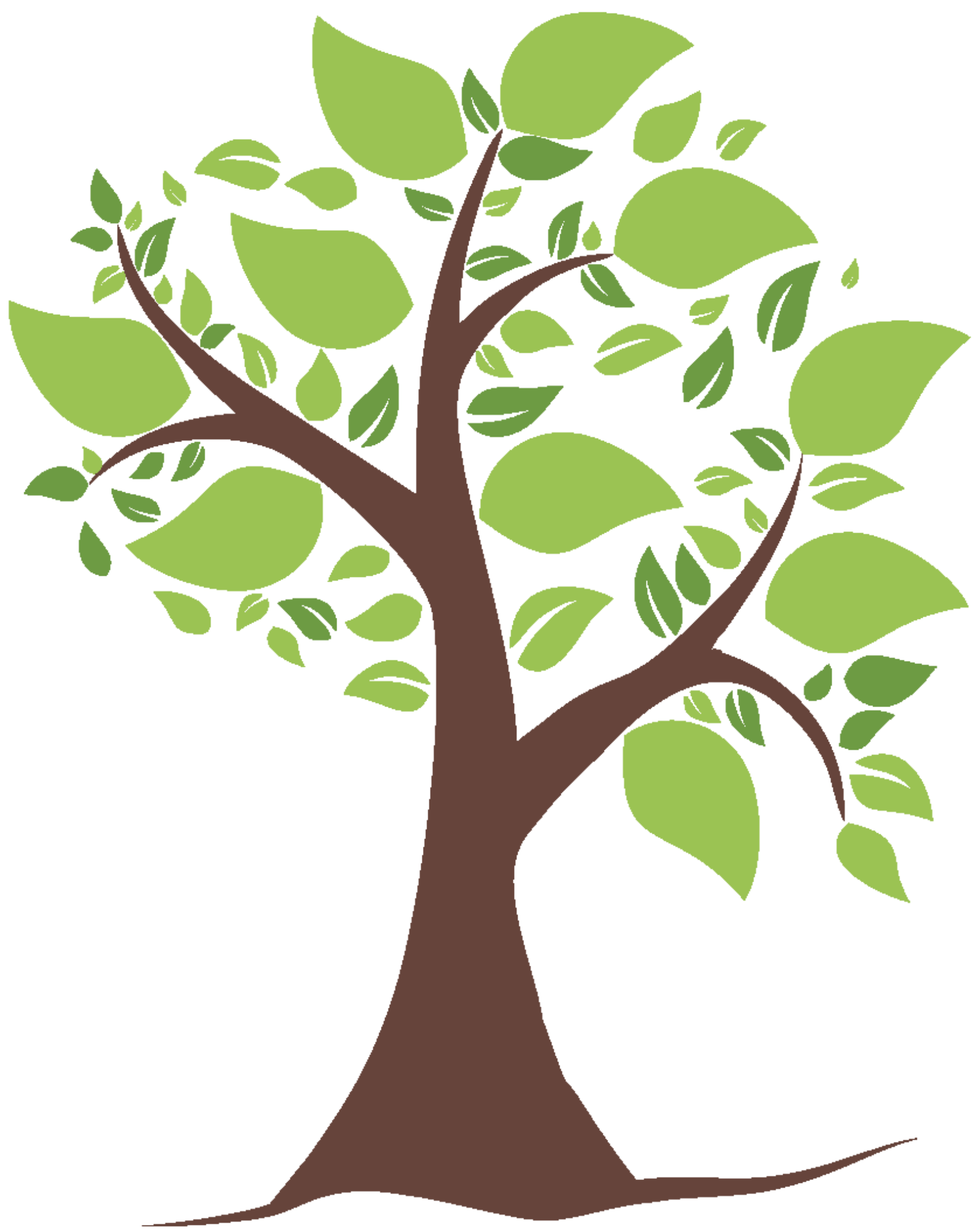


Anexo F

Parecer Consubstanciado do Comitê de Ética em Pesquisa 


\section{INSTITUTO DE CIENCIAS HUMANAS / UNIVERSIDADE DE BRASÍLIA / CAMPUS}

\section{PARECER CONSUBSTANCIADO DO CEP}

\section{DADOS DO PROJETO DE PESQUISA}

Título da Pesquisa: Avaliação da Eficácia de uma Intervenção para Prevenção do Vazio Existencial entre Adolescentes

Pesquisador: José Marcelo Oliveira da Luz

Área Temática:

Versäo: 2

CAAE: 37157214.5 .0000 .5540

Instituição Proponente: Instituto de Psicologia -UNB

Patrocinador Principal: Instituto de Psicologia -UNB

\section{DADOS DO PARECER}

Número do Parecer: 1.090.677

Data da Relatoria: 26/06/2015

Apresentação do Projeto:

O projeto de pesquisa considera que a prevenção de desfechos negativos em saúde mental é uma demanda atual e necessária para o avanço da atenção à saúde mental no Brasil, especialmente entre adolescentes entre de 10 e 19 anos usuários de álcool e drogas, bem como aqueles que sofrem de transtorno mental menor (TMM). Nesse contexto, a logoterapia propõe que a sensação de falta de sentido para a vida seja um dos mais importantes fatores de risco para adoçäo deste tipo de comportamento e apresentação de sintomas de sofrimento psíquico. Dessa forma, é necessário investir em ações de promoção e prevençäo em saúde para este público, sendo a escola um ambiente propício a este tipo de intervenção. Uma proposta de intervenção proposta por Aquino (2009) mostrou-se adequada a esta demanda e público, apontando critérios parciais de eficácia. Assim sendo, a proposta deste estudo é avaliar sistematicamente a eficácia desta proposta de Aquino (2009), ampliando os critérios de eficácia.

Objetivo da Pesquisa:

O presente estudo intenciona avaliar sistematicamente a eficácia e o processo de implementação de uma intervenção para prevençäo do vazio existencial entre adolescentes.

Avaliação dos Riscos e Beneficios:

A pesquisa não apresenta riscos substanciais. Como beneficio indireto, a pesquisa oferece a

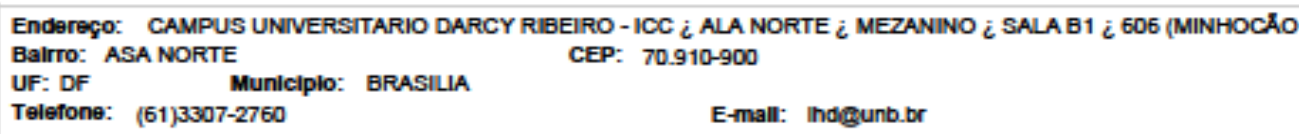




\section{INSTITUTO DE CIENCIAS HUMANAS / UNIVERSIDADE DE BRASÍLIA / CAMPUS}

Contlnuaşbo do Parecer: 1.090 .677

possibilidade de gerar conhecimento para a área de prevençäo a desfechos negativos em saúde mental e. como beneficio direto, espera-se a sensibilizaçäo dos participantes para o autocuidado e para a responsabilizaçäo.

Comentários e Consideraçőes sobre a Pesquisa:

Trata-se de uma pesquisa qualitativa em psicologia que abordará a perspectiva da logoterapia. Seräo realizadas entrevistas em duas escolas de ensino médio de Brasília, uma publica e outra privada.

Consideraçöes sobre os Termos de apresentação obrigatória:

Inalterado em relaçäo ao parecer do dia 19 de dezembro de 2014 emitido pelo CEP/IH.

Recomendaçöes:

Inalterado em relaçäo ao parecer do dia 19 de dezembro de 2014 emitido pelo CEP/IH.

Conclusões ou Pendências e Lista de Inadequaçöes:

Inalterado em relaçäo ao parecer do dia 19 de dezembro de 2014 emitido pelo CEP/IH.

Situação do Parecer:

Aprovado

Necessita Apreciaçäo da CONEP:

Näo

Consideraçöes Finais a critério do CEP.

BRASILIA, 02 de Junho de 2015

Assinado por:

Livia Barbosa

(Coordenador)

Endereģ: CAMPUS UNIVERSITARIO DARCY RIBEIRO - ICC i ALA NORTE \& MEZANINO ¿ SALA B1 ¿ 606 (MINHOCÅO

BalrTo: ASA NORTE

CEP: $70.910-900$

UF: DF Municiplo: BRASILIA

Telefone: (61)3307-2760

E-mall: Indgunb.br 
Anexo G

Termo de Assentimento 


\section{Termo de Assentimento}

Caro aluno,

Você está sendo convidado(a) a participar de um estudo sobre uma proposta de prevenção ao vazio existencial para adolescentes, de responsabilidade de José Marcelo Oliveira da Luz, aluno de mestrado da Universidade de Brasília, sob a orientação da Profa. Dra. Sheila Giardini Murta do Programa de Pós-Graduação em Psicologia Clínica e Cultura da UnB. O objetivo desta pesquisa é avaliar os efeitos de um programa de prevenção a desfechos negativos em negativos em saúde mental entre adolescentes. Assim, gostaria de consultá-lo(a) sobre sua anuência em participar do estudo.

Você receberá todos os esclarecimentos necessários antes, durante e após a finalização da pesquisa, e lhe asseguro que o seu nome não será divulgado, sendo mantido o mais rigoroso sigilo mediante a omissão total de informações que permitam identificá-lo(a). Os dados provenientes de sua participação na pesquisa ficarão sob a guarda do pesquisador responsável pela pesquisa. Na coleta de dados, a sua colaboração consistirá na participação de uma intervenção em grupo de adolescentes (6 encontros, uma vez por semana, com 105 minutos de duração cada encontro).

Por necessidades metodológicas, o estudo precisará de avaliações que serão realizadas em 3 momentos diferentes: (1) antes do programa; (2) logo após o término do programa; (3) dois meses após o término do programa. Espera-se com esta pesquisa conhecer os efeitos de um programa de prevenção ao vazio existencial, de modo a minimizar desfechos negativos na saúde mental dos participantes.

Sua participação é livre de qualquer remuneração ou benefício, não implicando a você nenhum risco.

Se você tiver qualquer dúvida em relação à pesquisa, pode procurar o serviço de orientação da escola que, caso não consiga esclarecer a sua dúvida, entrará em contato com o pesquisador responsável através do telefone 6196218774 ou pelo e-mail mluzpsi@gmail.com. Asseguramos que os resultados do estudo serão devolvidos a você por meio de um encontro a ser previamente agendado com o serviço de orientação da escola. Os dados serão publicados posteriormente na comunidade científica.

As informações com relação à assinatura do TCLE ou os seus direitos enquanto sujeito da pesquisa podem ser obtidos através do e-mail do CEP/IH cep_ih@unb.br.

Agradecemos, sinceramente, sua colaboração. Para confirmar sua participação, assine abaixo, nas duas vias. Uma delas ficará com o pesquisador responsável pela pesquisa e a outra com você.

Brasília, 2015 
Anexo G

Termo de Consentimento Livre e Esclarecido 


\section{Termo de Consentimento Livre e Esclarecido}

Senhor (a) Pai/Mãe,

Seu (sua) filho (a) está sendo convidado (a) a participar de um estudo sobre uma proposta de prevenção ao vazio existencial para adolescentes, de responsabilidade de José Marcelo Oliveira da Luz, aluno de mestrado da Universidade de Brasília, sob a orientação da Profa. Dra. Sheila Giardini Murta do Programa de Pós-Graduação em Psicologia Clínica e Cultura da UnB. O objetivo desta pesquisa é avaliar os efeitos de um programa de prevenção a desfechos negativos em saúde mental entre adolescentes. Assim, gostaria de consultá-lo (a) sobre sua autorização para que seu (sua) filho (a) participe do estudo.

Seu (sua) filho (a) receberá todos os esclarecimentos necessários antes, durante e após a finalização da pesquisa, e lhe asseguro que o seu nome não será divulgado, sendo mantido o mais rigoroso sigilo mediante a omissão total de informações que permitam identificá-lo (a). Os dados provenientes de sua participação na pesquisa ficarão sob a guarda do pesquisador responsável pela pesquisa.

Na coleta de dados, a colaboração de seu (sua) filho (a) no estudo consistirá na participação de uma intervenção em grupo de adolescentes (6 encontros, uma vez por semana, com 105 minutos de duração cada encontro). Por necessidades metodológicas, o estudo precisará de avaliações que serão realizadas em 3 momentos diferentes: (1) antes do programa; (2) logo após o término do programa; (3) dois meses após o término do programa. Espera-se com esta pesquisa conhecer os efeitos de um programa de prevenção ao vazio existencial, de modo a minimizar desfechos negativos na saúde mental dos participantes.

Se você ou seu (sua) filho (a) tiver qualquer dúvida em relação à pesquisa, podem contatar o serviço de orientação da escola, que caso não consiga esclarecer sua dúvida, entrará em contato com o pesquisador responsável através do telefone 6196218774 ou pelo e-mail mluzpsi@gmail.com. Asseguramos que os resultados do estudo serão devolvidos aos participantes por meio de um encontro a ser previamente agendado com o serviço de orientação da escola. Os dados serão publicados posteriormente na comunidade científica.

As informações com relação à assinatura do TCLE ou os direitos do sujeito da pesquisa podem ser obtidos através do e-mail do CEP/IH cep_ih@unb.br.

Agradecemos, sinceramente, sua colaboração.

Brasília, 2015 